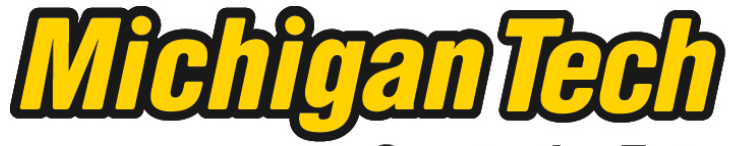 \\ Michigan Technological University Create the Future Digital Commons @ Michigan Tech
}

Dissertations, Master's Theses and Master's Reports - Open

Dissertations, Master's Theses and Master's

Reports

2013

Sound As Artifact

Jeff Benjamin

Michigan Technological University

Follow this and additional works at: https://digitalcommons.mtu.edu/etds

Part of the Music Commons, Other History of Art, Architecture, and Archaeology Commons, and the United States History Commons

Copyright 2013 Jeff Benjamin

\section{Recommended Citation}

Benjamin, Jeff, "Sound As Artifact", Master's Thesis, Michigan Technological University, 2013.

https://doi.org/10.37099/mtu.dc.etds/591

Follow this and additional works at: https://digitalcommons.mtu.edu/etds

Part of the Music Commons, Other History of Art, Architecture, and Archaeology Commons, and the United States History Commons 


\title{
SOUND AS ARTIFACT
}

By

Jeffrey L. Benjamin

\begin{abstract}
A THESIS
Submitted in partial fulfillment of the requirements for the degree of MASTER OF SCIENCE

In Industrial Archaeology
\end{abstract}

MICHIGAN TECHNOLOGICAL UNIVERSITY

2013

Copyright 2013 Jeffrey L. Benjamin 
This thesis has been approved in partial fulfillment of the requirements for the Degree of MASTER OF SCIENCE in Industrial Archaeology.

Department of Social Sciences

Thesis Advisor: Dr. Susan Martin

Committee Member: $\quad$ Dr. Samuel Sweitz

Committee Member: Erik Nordberg

Department Chair: Dr. Patrick Martin 


\section{Table of Contents}

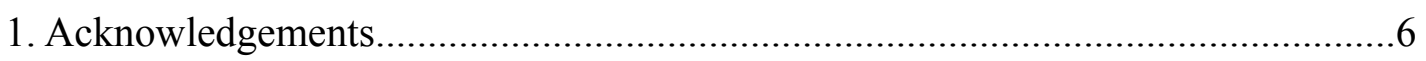

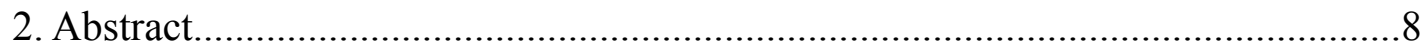

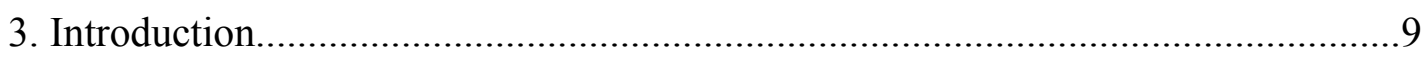

3.1 The Acoustics of Abandonment............................................................ 18

3.2 Sonifact: Witness of the Kinetic Past.......................................................23

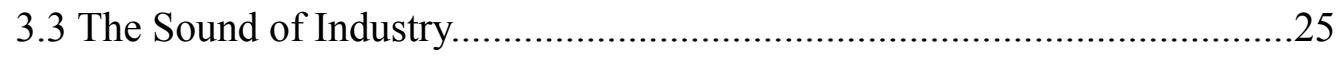

3.4 The Blacksmith Shop as Symbol and Musical Archetype........................27

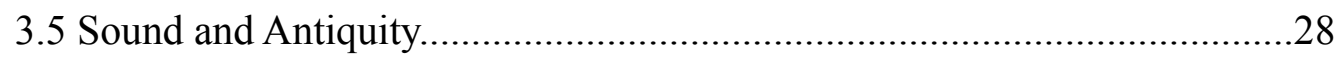

4. The Repeated Tone of Industrialization: Musical Associations............................32

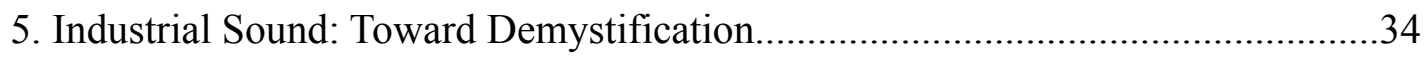

6. Research Question: Sound as Artifact........................................................... 37

7. Methodology: An Historic Soundwalk........................................................ 41

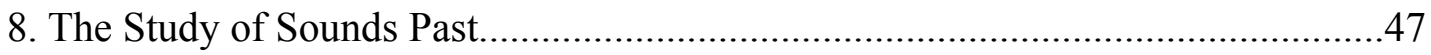

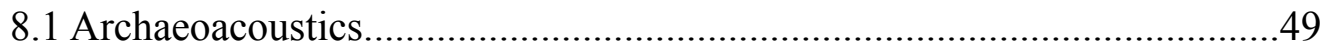

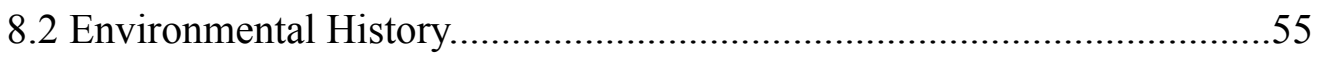

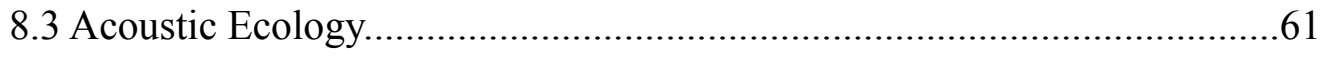

8.4 Sonic Heritage Studies............................................................ 70

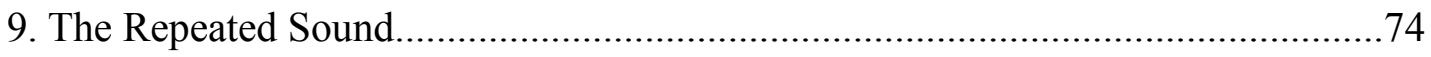

10. Narrative: A Plausible Subjective Experience of Historic Sound........................81

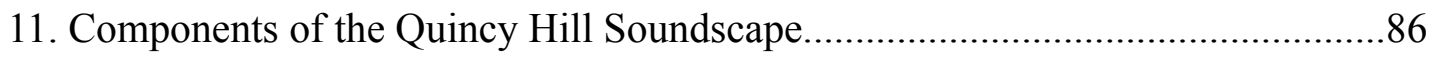

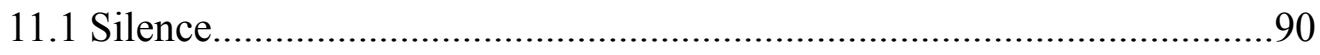




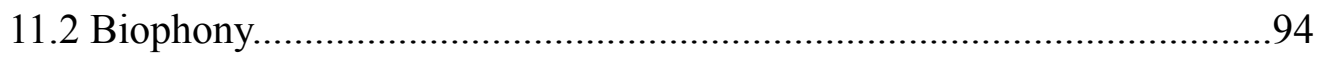

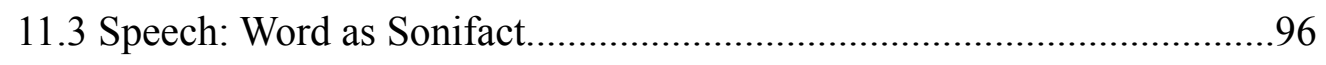

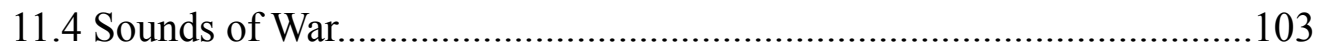

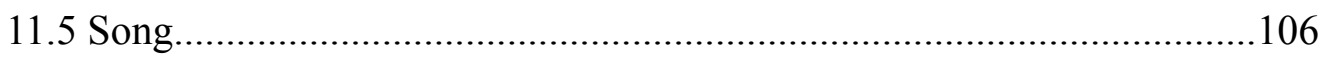

11.6 "Just Like the Fourth of July Every Day"........................................108

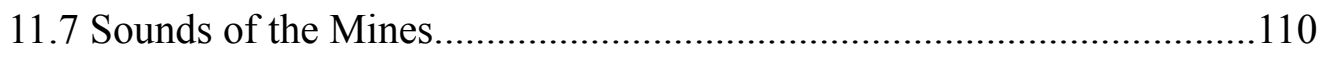

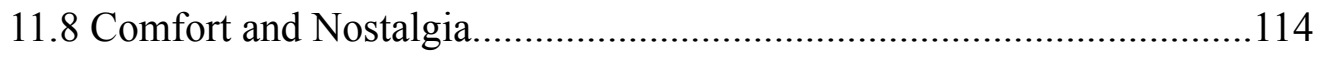

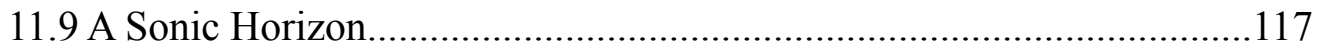

12. The Quincy Mine Blacksmith Shop: A Sonic Midden.......................................122

12.1 The Structure................................................................................ 138

12.2 Tools and Operations: A Sonifactual Assemblage...............................146

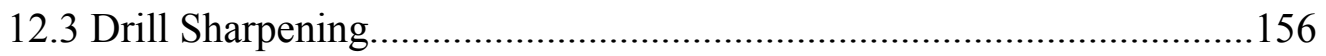

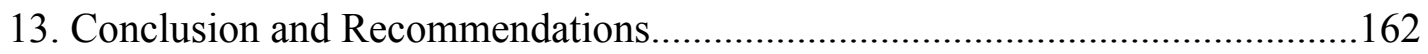

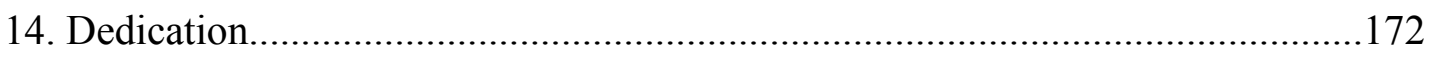

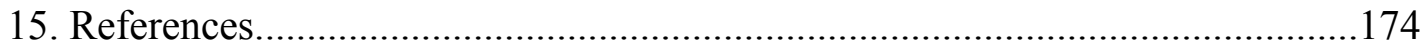

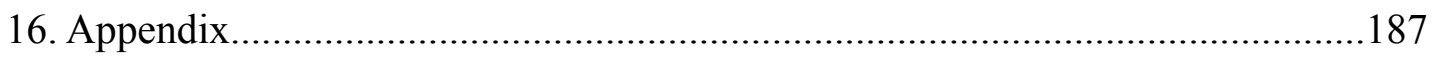




\section{List of Figures}

1. This map depicts the operations of the Quincy Mining Company, Hancock, Michigan, in 1902.....11

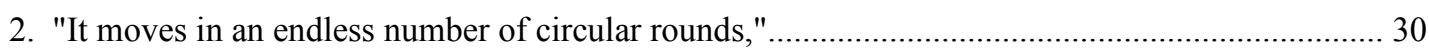

3. The Quincy Mining Company blacksmith shop in the fall of 2012, north face.............................. 31

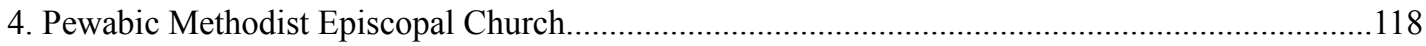

5. Close-up of Pewabic Methodist Church steeple with bell silhouette...............................................121

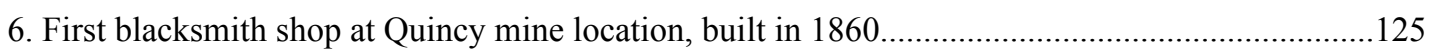

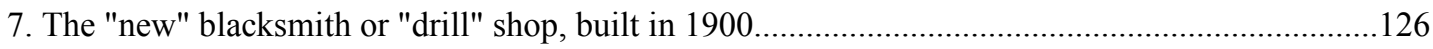

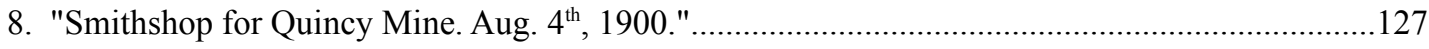

9. "Drill Shop for Quincy Mine. March 10, 1908"...........................................................................129

10. "Plan Showing Arrangement of Forges and Drill Sharpeners, March 26 1912"............................130

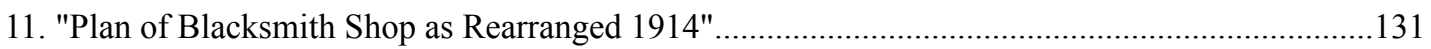

12. Quincy Mine Blacksmith Shop in its present condition (October, 2011).....................................140

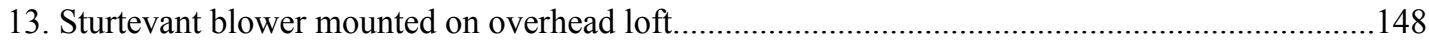

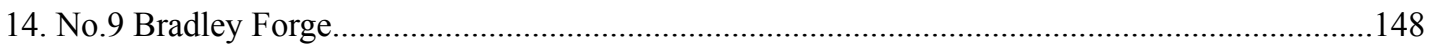

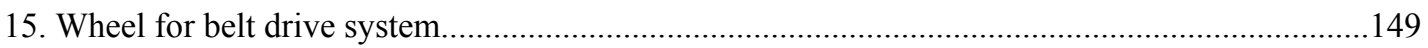

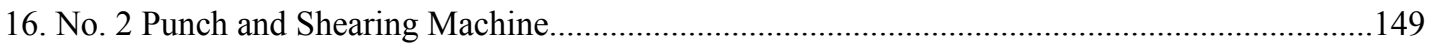

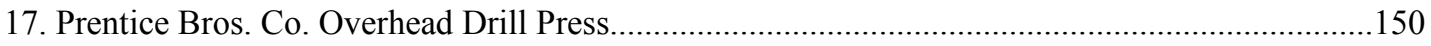

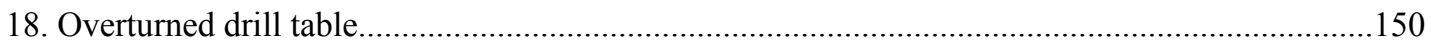

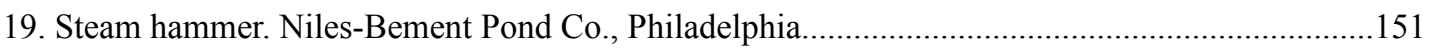

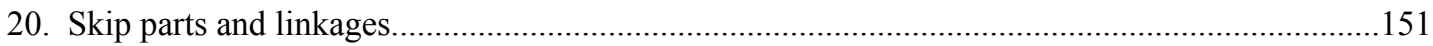

21. Cement base and mounting arm for hammers for Word Drill Sharpener.......................................152

\section{List of Tables}

1. Man-days per operation for Blacksmith shop at Quincy Mine...................................................133

2. Man-days per operation for Blacksmith Shop at Quincy Mine, June 1904.....................................135

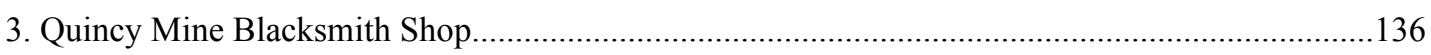

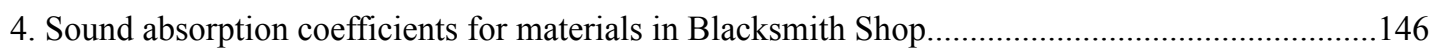

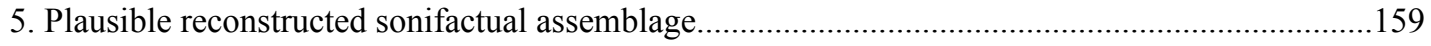

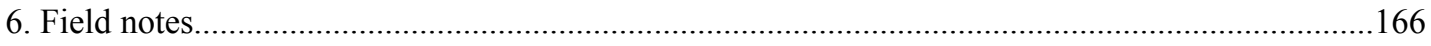




\section{Acknowledgements}

I would like to express my gratitude to my thesis advisor, Dr. Susan Martin. Without her support, encouragement, and real interest in the subject matter, this thesis never would have taken flight. In our weekly meetings, Dr. Martin encouraged and supported my research and directed my attention to many articles and books regarding sound which influenced the direction and scope of this thesis. After each of our weekly conversations I was able to turn back to the task at hand with renewed energy and commitment. I am also thankful for her patience in staying with me as an advisor since I have taken an extra year to complete this project.

I would also like to thank Alan Neumann of Rhinecliff, New York, for directing my attention to the Industrial Archaeology program at Michigan Technological University. We both shared work spaces in a repurposed industrial building in Kingston, New York around 2006. It was his enthusiasm and our many conversations about industrial history in the Shirt Factory that led me to this program. In the subsequent three years of coursework and writing, periodic discussions with Alan have been inspiring and have helped me to stay the course.

Many thanks to my committee member, Dr. Samuel Sweitz, for exposing me to a vast variety of archaeological thinkers and writers, both in his Historical Archaeology course and while working as a teaching assistant in his Pre-history and Archaeology course. I came to this program with little experience in archaeology, and it was because of the knowledge I attained in attending these courses that I was able to come to appreciate the unique contribution of the discipline of archaeology in intellectual discourse, as well as finding ways to situate my own thoughts within that discourse.

My sincere thanks to Dr. Fred Quivik for a very instructive and enlightening directed reading course, which exposed me to a variety of writers that have been very influential in forming my thoughts about industrial history and the 'industrial sublime.' Dr. Quivik's concern and engagement with environmental history has also opened my eyes to many new perspectives.

My gratitude goes to my fellow students in both the Industrial Archaeology and Environmental Policy departments, especially to John Baeten, Natiffany Mathews, Mark Dice and Carol Griskavich. I am especially indebted to Mariah and Jarod Maggio, who took me into their warm home many cold evenings and fed me, and also for teaching me how to curl. It was a lonely two years in the snowy north, and without their kindness I may not have survived.

Many thanks to Dr. Tim Scarlett for helping me to see the 'big picture'. In the first semester, it was Dr. Scarlett's Industrial Archaeology seminar that confirmed for me that I had chosen the right program. Having come from an arts background, at times I felt a bit out of place at a science and technology school. Always willing to talk, Dr. Scarlett helped me understand that I was not imagining things, but that the scientific/technological and artistic mindsets are different but can be compatible. It 
was his understanding of the creative/artistic temperament that helped me feel more at home.

Thank you to Erik Nordberg, for his cheerfulness and competence as the director of the Michigan Tech archives. While our society has sadly come to define "professionalism" by participation in prescribed consumption and behavioral patterns, Erik reminds us that a true professional is someone who is good at what he does. Both Erik and Elizabeth Russell helped me locate some very important documents pertaining to my research. Also, I am very thankful for the assistance of Jo Urion, historian, and Jeremiah Mason, archivist at Keweenaw National Historical Park in Calumet, MI. I am also very grateful to Rick and Lorri Oikarinen for giving me a nice, safe, warm place to live during my studies.

I feel that I should momentarily cross the ocean to express my thanks to Dr. Hilary Orange, fellow Industrial Archaeologist, UCL London, for an enduring and encouraging correspondence that has helped me to feel part of an intellectual dialogue that has great relevance to the challenges facing our world. Also, many thanks to Dr. Riitta Rainio, University of Helsinki, for organizing a most amazing session in Oulu Finland, "Archaeology of the Auditory Past," last year. I am very grateful to her for the inclusion of my paper in this session, because it exposed me to a very serious group of archaeoacousticians.

This leads me to my next to final expression of gratitude, to Dr. Patrick Martin and to the Industrial Archaeology department as a whole, for their willingness to endorse and support a project that might seem a bit out of the mainstream. Dr. Martin's generous support towards my attendance of two international conferences during my studies (Innsbruck, Austria and Oulu, Finland) helped me gain confidence in this archaeological approach to sound, and because of this exposure to other thinkers I was able to frame my thoughts in the context of the work that is currently being done in Industrial Archaeology as well as the newly emerging field of sound studies.

Finally, I am thankful for the sounds themselves: for the howling great lakes wind whistling my windows, for the loose piece of flashing that buzzed like a kazoo for two years in my bedroom window; for the howling and yelling of drinkers as they left the bars of Calumet every morning at 2 a.m.; For the gentle squeaking of the twenty-one steps up to my wonderful apartment above the bike shop; for WTIP in Grand Marais, Minnesota; for the barking of the beagle across the alley; for the melodies of Lucas Westcott playing guitar and singing down the hall; for the gentle and sing-song yooper way of talking; for the daily 12:30 siren in Calumet; the mailboxes being opened and shut at the base of the stairs by the mailman; stones gliding across ice on curling lanes. These sounds formed a kind of informal sonic laboratory that I inhabited as I studied and read, and it was the repetition and daily reemergence of them in my every day life that formed the most powerful body of evidence convincing me of the artifactual nature of sound. 


\section{Abstract}

A distinguishing feature of the discipline of archaeology is its reliance upon sensory dependant investigation. As perceived by all of the senses, the felt environment is a unique area of archaeological knowledge.

It is generally accepted that the emergence of industrial processes in the recent past has been accompanied by unprecedented sonic extremes. The work of environmental historians has provided ample evidence that the introduction of much of this unwanted sound, or "noise" was an area of contestation. More recent research in the history of sound has called for more nuanced distinctions than the noisy/quiet dichotomy. Acoustic archaeology tends to focus upon a reconstruction of sound producing instruments and spaces with a primary goal of ascertaining intentionality. Most archaeoacoustic research is focused on learning more about the sonic world of people within prehistoric timeframes while some research has been done on historic sites.

In this thesis, by way of a meditation on industrial sound and the physical remains of the Quincy Mining Company blacksmith shop (Hancock, MI) in particular, I argue for an acceptance and inclusion of sound as artifact in and of itself. I am introducing the concept of an individual sound-form, or sonifact, as a reproducible, repeatable, representable physical entity, created by tangible, perhaps even visible, host-artifacts. A sonifact is a sound that endures through time, with negligible variability.

Through the piecing together of historical and archaeological evidence, in this thesis I present a plausible sonifactual assemblage at the blacksmith shop in April 1916 as it may have been experienced by an individual traversing the vicinity on foot: an 'historic soundwalk.'

The sensory apprehension of abandoned industrial sites is multi-faceted. In this thesis I hope to make the case for an acceptance of sound as a primary heritage value when thinking about the industrial past, and also for an increased awareness and acceptance of sound and listening as a primary mode of perception. 


\section{Introduction}

The inherent

the social meaning of Industrialization

is not well understood

not because it is difficult -

only because it is so comprehensive. ${ }^{1}$

The vulnerable act of listening- of being prepared and open to hear the unexpected, a turn of a phrase, a note, an inflection, a new word or even language - has its blessings as well as its hazards. A sensitivity to sound, a willingness to listen, is a predisposition that archaeologists, historians and all researchers of the human past either carry into their work or dismiss, tied as it is to introspection, meditation, solitude, uncertainty, surprise, the unknown and unseen.

The genesis of this project springs from a lifelong interest and appreciation of the aesthetic and social power inherent in abandoned industrial sites across the country. The underlying assumption of this study is that an understanding and valuation of the past determines the direction for the future, and it is the future use of this country's industrial heritage that concerns me the greatest. Therefore my exploration of past human experience within industrial sites is directed towards a practical application of historical and archaeological knowledge upon the vibrant potential of industrial spaces as active, living centers of human life.

Broadly considered, the following thesis is an argument for an inclusion of sound

1 R. Buckminster Fuller, Untitled Epic Poem on the History of Industrialization (New York: Simon and Schuster, 1962), 55. 
(and listening) as a primary heritage value when approaching abandoned industrial sites and structures. This is not simply to add more "noise" to an already rowdy debate, but simply to enrich and increase the diversity within the study of cultural heritage management, one which is certainly not alien to negotiating tensions between various stakeholder groups. The field of heritage studies also finds itself frequently in a mediating role between science and technology and the "traditional" or literary and artistic disciplines, and more than fifty years since C.P. Snow delivered his lecture "The Two Cultures," the intellectual landscape has not changed dramatically. Dispensing with generalizations and cliches, it is hard to disagree that "the degree of incomprehension on both sides is a kind of joke which has gone sour."

For this reason, I will make no apologies for regarding abandoned industrial structures as inclusive structures, which can simultaneously be investigated as ecological laboratories, places for solitude and meditation of the past, records of technological processes, and musical instruments unto themselves. One particular landscape feature forms the central subject of this thesis, around which different themes and ways of thinking about industrial sound will revolve: the Quincy Mining Company blacksmith shop, Hancock, Michigan (see map, Fig. 1). Built in 1900 as the operations of the Quincy Mine expanded and new processes and techniques were developed, the blacksmith shop now lies in a state of ruin, but the walls and many of the larger pieces of processing equipment remain in place, posing a challenge for

2 C.P. Snow, The Two Cultures and the Scientific Revolution (New York: Cambridge University Press, 1961), 12. 
anyone interested in the sonic past.

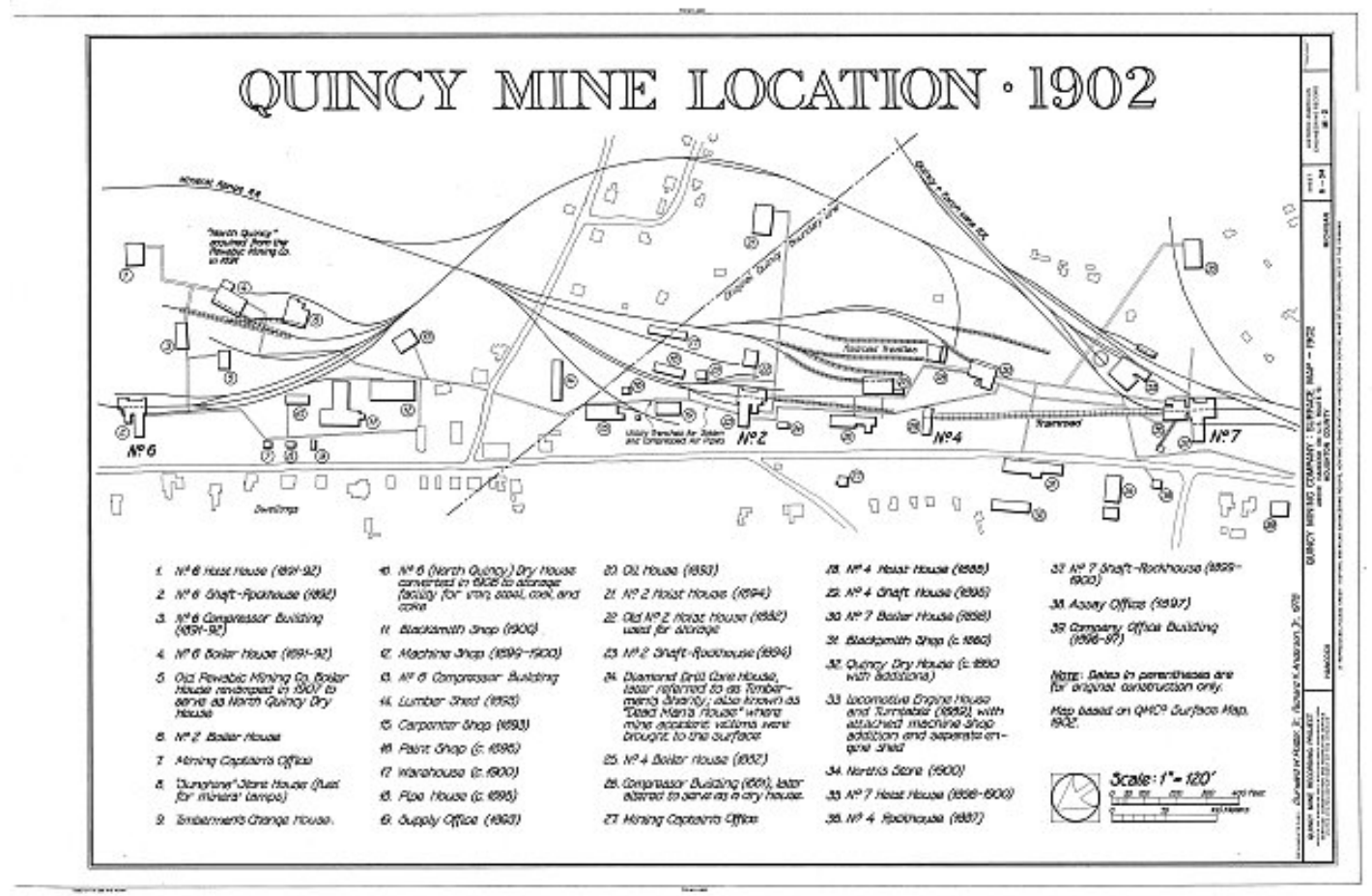

Figure 1. This map depicts the Quincy Mining Company operations in Hancock, Michigan, in 1902. This map was created in 1978 by the Historic American Engineering Record. The "new" blacksmith shop, built in 1900, is the large "T" shaped building in lower left.

This project is borne from the combination of internal contemplation and external, physical experience. Beginning my studies in the fall of 2010, I found that my internal life of reading and thinking about sound was supported and complemented and in many ways inspired by external events and phenomena. These events and aural phenomena constitued the initial setting for a more focused research on environmental sound, and organically coalesced to form a foundation from which future questions emerged (and are still emerging).

In the fall of 2010, construction work on The Great Lakes Research Center at 
Michigan Technological University had just begun, situated on the shore of Portage Lake on the northern end of campus. Pilings were being driven into the shoreline to support the weight of the structure, and a steady, insistent repeated ringing "ping....ping...ping" - could be heard across campus all day, every day, eliciting different responses from different parties. Perhaps the most notable feature of this sound was its ability to penetrate into every space on campus and beyond; over the steep hill at the base of campus, through walls, windows, it seemed to be audible everywhere. It would have been difficult to place if one did not know its originating source, for it was a ubiquitous presence on the landscape, undeniable and omnipresent. As much one may have wanted it to stop, it was a strong sound, a persistent presence, not unlike a strong color in an artist's palette, like thalo blue or alizarin crimson: colors which painters like to joke will show up everywhere-- on one's pillowcase or in one's sandwich. But unlike a patch of color on a canvas, an environmental sound disappears quickly, almost as quickly as it emerges, and without an effort to reconstruct (or resurrect) its existence, it may never be heard again.

From a comfortable vantage point, sitting in a chair at the Portage Lake Public Library, also situated on the shore of Portage Lake, one can still see the tops of many wooden pilings, a small group of countless other similar artifacts spread along both shores of the channel: inverted trees driven into the ground beneath the water's surface $^{3}$ (in a very similar manner to the pilings at the Great Lakes Research Center)

3 A.M. Wellington, ed., Piles and Pile Driving: being a reprint of some of the articles which have appeared in Engineering News on pile driving and the safe load of piles and of the pamphlet on "Bearing piles" by Rudolph Hering (New York: Engineering News Publishing Co., 1893). 
with the shallow waves dancing around them. The small patch of pilings at the library is just one small remainder of a very busy waterfront; there are hundreds of others scattered around the shoreline of Portage Lake. Extrapolating from a personal experience of the acoustic by-products of the pile-driving activity at the Great Lakes Research Center, one can safely surmise that the construction of docks along the waterfront when commerce was burgeoning was accompanied by a significant acoustic counterpart. These silent remainders of a once very active industrial waterfront beg the question: What did the waterfront sound like when the cities of Houghton and Hancock were busy with copper mining and refinement activities? This a very simple and acceptable question to pose, but as one begins to research and contemplate the nature of sound, it becomes a far more complicated one to answer. However, one thing can be said for certain, the soundscape ${ }^{4}$ of the Portage Lake waterfront during the flourishing period of mining activity was significantly different than it was during the fall of 2010, when the "earcon"5 of the Michigan Tech campus was the steady ringing of the pilings being driven into the earth, accompanied by another universal sound of modernity, the drone of automotive traffic.

To step back a moment, perhaps it is instructive to contemplate what might be known about the soundscape of this small part of the world at the dawn of American

4 R. Murray Schafer, The Tuning of the World (Toronto: McClelland and Stewart, 1977), 274. Schafer defines "soundscape" as: "The sonic environment. Technically, any portion of the sonic environment regarded as a field for study. The term may refer to actual environments, or to abstract constructions such as musical compositions and tape montages, particularly when considered as an environment."

5 Barry Blesser and Linda-Ruth Salter. Spaces Speak, Are You Listening? Experiencing Aural Architecture (Cambridge: MIT Press, 2007), 82. "Earcon" is defined as "a sonic event that contains special symbolic meaning not present in the sound wave." 
industrial expansion, as an exercise in contrast. The following account (first delivered as a speech) of Portage Lake in 1846 by John Harris Forster - during its early days of European discovery and mining exploitation - is evocative of a far different aural (as well as visual) reality:

Many of my hearers have doubtless visited Portage lake, the seat of the largest copper industry in the world, whereon lie the flourishing towns of Houghton and Hancock....In 1846 these waters reposed in sylvan solitudes; only occasionally were they disturbed by the Indian canoe or the boat of the enterprising explorer....I quote from my journal.

Next morning we breakfast at daylight, and continue our voyage along the winding shores. Our gay Canadian voyageurs sing as they row....We are charmed with the beautiful scenery; often we rest on our oars to enjoy the charming effects. The native forests almost unbroken, starting from the waters edge, slope up toward the sky precipitately, presenting many pleasing shades and colors, from the soft neutral- tinted maple, the lemon colored birch and poplar, to the dark green of the hemlock and fir. Here and there a bit, a patch, has been touched by the early frosts of autumn; upon it there is a brave display of scarlet, orange, and gold....The surface of the lake is perfectly smooth and reflects, like a mirror, each over-hanging promontory. As we row silently along we hear no sounds except those made by dipping oars; we see no life save an occasional loon darting his anxious head above the water, uttering a shrill quavering scream and diving again; the air is balmy; the repose of nature profound. Man with his restless spirit has as yet scarcely disturbed the scene. A little clearing (where now stands the great copper smelting works) has been made at one place, and a trail winds up the hill to a point where exploring for copper has been attempted. ${ }^{6}$

An interesting aspect of this account is that Forster was portraying an environment as foreign to his readers (or listeners) in 1886 as it is today. By 1886 this small body

6 Hon. John Harris Forster. "Early Settlement of the Copper Regions of Lake Superior," in Pioneer Collections. Report of the Pioneer Society of the State of Michigan. Together with Reports of County, Town, and District Pioneer Societies.Vol. VII. (Lansing: Thorp and Godfrey, State Printers and Binders, 1886), 189-190, accessed October 1, 2012, http://books.google.com. Part of this passage was originally found in: Eleanor A. Alexander, East Hancock Revisited. History of a Neighborhood, Circa 1880-1920. (Hancock, MI: Self Published, 1984), 1. 
of water and its shorelines were in the process of an active industrial development. This sense of foreignness is even more true with sound, for the sounds of Portage Lake in 1846 as he describes them in this spellbinding account were long since vanished by the time his observations were presented publicly (all physical artifacts are time-bound, but the 'decay time ${ }^{17}$ for the sound of an oar in the water is far quicker than the time it takes for the oar itself to decay). It is only during moments of chance that a contemporary individual can experience the silence that Forster describes $^{8}$, but this was already a disappearing phenomenon inland, for earlier in the same article he writes that "everywhere on the Trap Range, for one hundred and fifty miles, one could hear the click of the hammer and drill, and the explosion of powder in the primeval forests, during the busy season of $1846 . " 9$

Support for Forster's account of the idyllic quiet in the area may also be found in Native American stories from the area before European expansion. In one Anishinaabe tale, a child is exhorted by his grandmother: "Listen.... Can you hear the words of the trees?...The voices of the trees have much knowledge for us. This is for you to remember, little one." The boy spends some time carefully listening: "The slight breeze wedged its way around and through each needle on the tree above the child's head and whistled as its caress was replaced by the loving touch of more wind from behind." Then he says: "The voice that I hear from the trees is singing a song

7 Barry Truax, ed., The World Soundscape Project's Handbook for Acoustic Ecology (Vancouver: ARC Publications, 1978), 32.

8 Leslee Goodman, "Quiet, Please: Gordon Hempton On the Search for Silence in a Noisy World," The Sun, September 2010, Issue 417. In this article, Goodman describes the fascinating efforts of Gordon Hempton to remove chance from this experience through his "One Square Inch of Silence" project, a "campaign for the creation of a place totally free of human noise" in the Olympic National Park, Washington State.

9 Forster, "Early Settlement of the Copper Regions of Lake Superior," 190. 
to me. The song is winding its way into my nose because I can smell this song through the pine cone. I can see the voice of the pine tree, it was singing to the hawk and lifted him away on a song...." ${ }^{10}$ While conjuring a bucolic environment similar to Forster's account, this passage also demonstrates a moment of 'sensitivity-training' to the felt environment, as well as exhibiting an accepted expression of synaesthetic perception common to many cultures. ${ }^{11}$

Another very interesting account of the early moments of European exploration in North America is John Bakeless' The Eyes of Discovery. First printed in 1950, this book could also be called "The Ears of Discovery," due to the importance of listening for the survival of the first explorers. Describing an experience of the explorer LaSalle in the woods of what are now Michigan in the late 1600s, Bakeless narrates an encounter with an unknown visitor: "LaSalle shouted friendly messages in various native languages. Then, when the silent, snow-muffled woods gave back no answer, he built a barricade of bushes so that he would hear anyone approaching, lay down on the warm grass bed himself and went to sleep- so tired that he was willing to risk his scalp."12

During the fall of 2010, the aural environment of Portage Lake was composed of a far different sonic material than Forster's account. Bordered on the south by U.S. Highway 41 and on the north by Michigan Route 26, Portage Lake now buzzes with a constant automotive drone. The metronomic, almost hypnotic ringing of the pile

10 Bill Church, "Stories of the Northwoods (Win Awenen Nisitotung)" The Daily Mining Gazette, 19. 11 Blesser and Ruth-Salter, Spaces Speak, Are You Listening? Experiencing Aural Architecture, 5. 12 John Bakeless, The Eyes of Discovery: The Pageant of North America as Seen by the First Explorers (New York: Dover, 1961), 292. 
driving activity at the Great Lakes Research Center became the soundtrack during the early days of my studies, and it informed and reinforced my interest in sound as an important research topic. Coming out of twenty years work in carpentry and construction, the sound of things being built has always carried with it a familiar and somewhat reassuring quality (though I would probably not consistently choose it over the placid sound of oars dipping in water). This sentiment is common for industrial workers and those tied to industrial practices or communities, and it will be echoed in many subsequent historical accounts in a later section of this thesis. It is perhaps worth mentioning one notable example, coming from the crucible of American industrialization itself. When contrasting the sounds of the textile mills of Lowell, Massachusetts with the countryside, Lucy Larcom writes: "I found that I enjoyed even the familiar, unremitting clatter of the mill, because it indicated that something was going on."13 Indeed, while much of the scholarship of industrial sound tends to focus on unwanted sound, or "noise," it would be amiss to neglect the many affective responses to the clatter of industry: its power to project hope, reassurance, community. In October of 2010, as the entire world watched, thirtythree Chilean miners were rescued after being trapped in an underground mine for two months ${ }^{14}$. In a subsequent discussion connecting this incident with the wider topic of industrial sound, a friend observed: "(C)an you imagine the joy the Chilean

13 Mark M. Smith, "The Garden in the Machine: Listening to Early American Industrialization," in The Oxford Handbook of Sound Studies, ed. Trevor Pinch and Karin Bijsterveld. (New York: Oxford University Press, 2012), 54.

14 The New York Times, (no author), "Chile Mining Accident (2010)," October 12, 2012, accessed January 4, 2012, http://topics.nytimes.com/top/reference/timestopics/subjects/c/chile_mining_accident_2010/index. html?s=oldest \& 
miners felt when they heard industrial machines making their way to them? How much they must have longed for the sound and asked themselves whether or not they really heard it?"15

For anyone living in the post-industrial mining town of Calumet, Michigan, the 12:30 p.m. siren - an extended, loud, howling call - is an inevitable part of daily life, but it's perpetuation upon the local soundscape is not mandated by any particular contemporary community event or gathering (other than its' own existence). It stands alone as an acoustic relic, an aural artifact indicating activities of a bygone era. An online discussion regarding the siren was described to me during the spring of 2012 by my thesis advisor, Dr. Susan Martin, and it is generally held (appropriately through 'hear-say') that the siren's call indicates lunch break for the long-sincedeparted miners. This is one particularly blatant example of a sonic artifact, or sonifact, but smaller, less obtrusive sounds scattered through daily life also qualify as such: the opening or closing of a door, a dinner bell, a song played on a musical instrument, footsteps moving up a staircase in an historic building. As a listener, one's physical being is wrapped in a complexly layered sonic bricolage, and many pieces of this are heirlooms, artifacts, sounds of the past, reanimated and brought to life by physical interventions with tangible forms: the clinking of a teaspoon on a teacup, the sliding of a book across the table, a rattling pane of glass in a window.

15 Dr. Madeleine Muntersbjorn, e-mail message to author, February 20, 2011. 


\subsection{The Acoustics of Abandonment}

The squeaking, groaning, clicking and thumping of stressed structural components of buildings; the breathing, whistling, hissing of air moving through cracks in doors and windows, moving through passageways, the deep, powerful echoing reverberation within the empty chasms of industrial shells; all of these sounds bear witness to the possible aural experience of past peoples:

Once constructed, the aural architecture of a space memorializes the values of those who built it. Later generations, in turn, develop their own cognitive frameworks from experiences within those inherited spaces; newly constructed spaces are then created from those cognitive frameworks. ${ }^{16}$

The sonority of the built environment is particularly unique in an abandoned structure, where one is immersed into a rich sonic world, where historic sounds of structural stress and motion are allowed to reverberate through an empty space, often composed of reflective materials such as concrete and sheet metal. The sound of such a structure is anomalous in the wider acoustic realm; it is simultaneously old and new, for it incorporates the immediate sounds of wind, automotive traffic, human voices, and distributes them through a prefigured physical arena. Heard within such a space, even the contemporary sound of a car horn or a person singing becomes a hybrid sonifact because it is isolated and augmented by the particular structural and spatial eccentricities of the site:

Sound, like light, reveals information about a space via echo and reverberation.... With every reflection the geometric space transfers to the incident wave part of its geometric features, modifying the internal

16 Blesser and Ruth-Salter, Spaces Speak, Are You Listening? Experiencing Aural Architecture, 67. 
composition of its frequencies. The modified sound wave will transfer to the listener the specific sound of that space. ${ }^{17}$

In its decades of productive activity, one may safely conclude that the 'casting shed' structure located at the smelter of the Quincy Mining Company rarely heard a moment's silence, so as an individual wandering through it's vast openness, the opportunity to listen to the space itself constituted a privilege. While working on a separate class project locating, documenting and recording artifacts from the nearby carpenter's shop at the Quincy Mining Company smelter site (recently burned down), I spent time listening to and recording the sounds of the cavernous production shed structure at the smelter. During an earlier tour of the site, I had found the acoustic experience to be viscerally enchanting, and perhaps the most fascinating aspect of the structure's acoustics was how it incorporated exterior sounds of the wider environment and gave them a new 'flavor.' This was one dramatically resonant example of an historic structure giving contemporary sounds an historic character. Spaces that have fallen out of use retain within their confines a very particular sonic quality; for just as the materials and forms and scattered objects are unwanted and unnoticed, so are the sounds. For an attentive listener such a space constitutes a sonic midden, a rich grouping of past sounds, sometimes isolated and identifiable, and sometimes hybridized by their mixing with present day sound-forms.

The experiential and sensory approach to the study of abandoned structures was provided validation by an earlier reading of Industrial Ruins: Space, Aesthetics and

17 Matteo Melioli, "Inhabiting Soundscape: Architecture of the Unseen World," in In the Place of sound: Architecture/Music/Acoustics, ed. Colin Ripley et al. (Newcastle, UK: Cambridge Scholars Publishing, 2007), 50. 
Materiality by Tim Edensor. In this work, the author thoroughly analyzes the sirenic call of abandoned industrial sites, their seductive allure, and as he argues, their essential quality, with one particular theme recurring throughout: such places provide a respite from a wider physical environment permeated by directives of behavioral control:

...ruins also provide spaces where forms of alternative public life may occur, activities characterised by an active and improvisational creativity, a casting off of self-consciousness conditioned by the prying gaze of CCTV cameras and fellow citizens, and by the pursuit of illicit and frowned-upon practices. These uses contrast with the preferred forms of urban activity in over-designed and themed space: the consumption of commodities and staged events, a toned down, self-contained ambling, and a distracted gazing upon urban spectacle. $^{18}$

While providing ample inspiration and theoretical justification for the investigation and exploration of industrial ruins, Edensor's work is also characterized by a marked ahistoricity, a willingness to let the past uses and past events contained within industrial structures remain a conjectural matter, a mystery. Addressing the 'sounds' of ruins in particular, he writes:

In a large, abandoned factory, the initial peculiarity of finding oneself alone in a vast space, devoid of other people and often stripped of fixtures, is compounded by the shroud of quiet which covers space and heightens awareness of sound....The removal of machinery and furniture means that noises echo: the drips of water, birdsong, eddies of winds, creaking machinery and doors, rustling of rodents, the cooing of pigeons and their flurries of urgent flight. The sound becomes fuller with the intrusions of weather from outside: an upsurge in clattering and squeaking during a gale, and throughout a shower of rain, a succession of drips of varying intensity produce a symphony of spatters and splashes which evoke the material upon which raindrops land-- tin, foliage and stone. The stillness and the gentle noises that float through the ruin can evoke an absent

18 Tim Edensor, Industrial Ruins: Spaces, Aesthetics and Materiality (Oxford: Berg, 2005), 31. 
soundscape-- the whistling, shouts, talk and laughter, whirring machinery, singing and the radio which would have filled the air during its occupation-- an evocation that provokes a tendency to stop and listen.... Things sound different in the ruin. ${ }^{19}$

While it seems indisputable that a vacant industrial site does indeed seem to inspire a host of alternative, creative and transgressive activities, the same could be said of a canyon, a corner of the desert or a secluded cave - due to their remote nature, away from the suppressive and normalizing gaze of society. However, it is the materiality of human history imbedded within an industrial structure, the pathos of human effort, passion, pain, which gives it this unique power, and this includes the materiality of sound. When listening to an empty structure, we are not hearing an abstract replication or haunted aural distortion, we are hearing the past in present time, just as when we look up at the night sky, the light we are seeing is old light, just reaching the earth. Once one is willing to accept the artifactual nature of sound, the extension of the language and concepts of archaeology into the sonic realm proves to be dynamic and illuminating. The aural material of an industrial ruin is composed of unwanted, discarded sonifacts, therefore an abandoned industrial space can therefore be considered, as mentioned earlier, a sonic midden.

The magical immediacy of vacated industrial sonic space still cannot be denied, however, and my aural apprehension of the Quincy Smelter is echoed in an account of Anna Friz, a sound artist working in Montreal. Working as an assistant to Dr. Andra McCartney, Friz recorded the changing soundscape of abandoned industrial sites along the Lachine Canal in south-west Montreal during 2001 and 2002. Taking

19 Edensor, Industrial Ruins: Spaces, Aesthetics and Materiality, 91. 
monthly soundwalks, she would explore many of the structures she encountered.

Entering a massive grain silo, she writes:

Black nothingness: a dark so dark and so vast that I couldn't imagine where the walls could be, but I could hear them as soon as I uttered a sound. Many-second reverberations rang in my ears as my startled remarks echoed inside eight undivided storeys in the cylinder. Suddenly I had no sense of space, of gravity. Was I looking up or down? I called into the darkness, half expecting whales to answer. The sound was tremendous, sweet, excruciating, huge. I called again and again.... Why should resonance feel so sublime? ${ }^{20}$

As with all disciplines, the study of sound originates from a predisposition (in this case, toward listening), and only certain individuals will be driven to explore it in depth or give it more than cursory notice. To provide a balance, it is also instructive to consider accounts where sound is not even mentioned; or descriptions of empty industrial settings where the intrusive, annoying or non-aesthetic qualities of sound are given emphasis. In an analysis of the allure and merits of urban exploration, Bradley L. Garrett humorously describes his experience of being "aurally tortured by some bit of metal getting smashed over and over again on a part of the roof we can't reach,"21 an experience we can all relate to.

\subsection{Sonifact: Witness of the Kinetic Past}

In the process of developing the ideas that spring from a contemplation of sound as artifact, I have created a few terms that seem to serve the project well (in italics). I am

20 Anna Friz, "Vacant City Radio," in In the Place of Sound: Architecture/Music/Acoustics, ed. Colin Ripley et al. (Newcastle, UK: Cambridge Scholars Publishing, 2007), 17.

21 Bradley L. Garrett, "Assaying history: creating temporal junctions through urban exploration," Environment and Planning D: Society and Space 29 (2011): 1053. 
introducing the term sonifact as an umbrella term that embraces both sonic artifact and sonic ecofact. The term sonifact therefore describes a cultural or ecological sound-form, contextually dependent upon tangible host artifacts (the tactile, perhaps even visible forms that make the sound). A sonifact is a recognizable, reproducible, repeatable sound, made by people, other life forms, or the environment, one that endures through time, with negligible variability. The theoretical basis for the assertion that sound can be treated as artifact in archaeological terms will be discussed in greater length in the section entitled "Research Question: Sound as Artifact."

Of course, sound is different than the tangible objects that we normally associate with artifacts, and perhaps the major difference, the thing that really sets sound apart, is its kinetic nature. In general, as tangible artifacts reach their end of use and fall into a state of repose, their subsequent discovery, retrieval, investigation and preservation tends to maintain a quality of stasis in their later treatment, in order to mitigate any possible further aging or damage. Tangible artifacts move through space when they are handled or transported, but for observation purposes they tend to remain static. Likewise, when we read about them and contemplate them we do so in the silent confines of our own minds. This quality of serenity and repose associated with artifacts tends to lead to certain biases and misunderstandings about the real nature of past experience or historical reality. The distortion incurred upon artifacts by this imposed stasis cannot hold true with sound however: the elegance of the study of sound as artifact is that, by necessity, a past sound has the same dynamic reality in the present as it did in the past, because it can only exist as a kinetic phenomenon. In order to exist, sound must move. 
For this reason, the contemplation and study of sound as a physical artifact provides a powerful impetus toward a greater understanding and study of the kinetic past.

\subsection{The Sound of Industry}

The study of the history of sound and industrial heritage are highly compatible, if only for the simple reason that industrialization has brought with it a sonic intensity hitherto unknown in human history:

It has been left for modern industrial society to create new sound to a point where sound levels in many industrial plants and offices are at the threshold of pain; where most urban areas have an average loudness level which makes protection against it necessary; where jetports and multilane highways have already exceeded tolerable noise limits and where the new supersonic jets, with their sonic booms, threaten the physical integrity of buildings, let alone the human ear. ${ }^{22}$

Other authors support this by portraying the onset of industrialization as an era of brutal sensory bombardment, expressing a kind of lamentation at the subsequent loss of sensory receptivity. In Technics and Civilization, Lewis Mumford writes: "The eye, the ear, the touch, starved and battered by the external environment, took refuge in the filtered medium of print; and the sad constraint of the blind applied to all the avenues of existence....The starvation and dimunition of life was universal: a certain dullness and irresponsiveness, in short, a state of partial anaesthesia, became a condition of survival."23 In general, R. Murray Schafer depicts the advent of

22 James Marston Fitch, American Building 2: The Environmental Forces That Shape It (New York: Schocken Books, 1972) 133.

23 Lewis Mumford. Technics and Civilization. (New York: Harcourt, Brace and Company, 1934), 181. 
industrial sound as a profound loss, with a particularly insightful discussion of the new "flat line" sounds (ventilator, electrical hum, automotive drone) arrival and persistence on the soundscape: "...the generator or the air-conditioner do not die; they receive transplants and live forever." ${ }^{24}$ A comprehensive visual map of the morphology of material culture after the onset of industrialization would be impossible considering its exponential expansion, but it needs to be noted that with every new tangible artifact introduced into the world, a new sound-form is also introduced: a real physical thing produced by the tangible object's use or interaction with existing spaces and forms.

In the interest of moving beyond the "noisy/quiet" dichotomy that characterizes much discussion of industrial sound and its absence, it would be helpful to look carefully at the particular qualities of sound at a specific location and particular time. This research would be assisted by a well developed descriptive language of sound, something which, unfortunately, does not yet exist and would probably require the invention of new words. Efforts have been made to create categorized lists of different kinds of sounds based on their source of origin ${ }^{25}$ as well as useful glossaries of terminology associated with sound and all of its related phenomena ${ }^{26}{ }^{27}$, but nuanced descriptive language that communicates the qualitatively subtle differences in individual sounds and which does not immediately resort to mimetic or

24 Schafer, The Tuning of the World, 78.

25 Ibid, 135.

26 Barry Truax, ed., The World Soundscape Project's Handbook for Acoustic Ecology, (Vancouver, B.C.: Arc Publications, 1978).

27 Jean-Francois Augoyard and Henry Torgue, eds. Sonic Experience: A Guide to Everyday Sounds (Montreal: McGill-Queen's University Press, 2005). 
onomatopoeic techniques simply does not yet exist in the English language. It is possible that the creation of a new descriptive language of sound could be assisted by borrowing words and concepts from the other senses (for instance, could a sound be "bitter" or "salty"?). The adoption of synaesthetic techniques (such as mentioned earlier in the Anishnaabe tale) may indeed help encourage the genesis of vernacular expressions of particular sounds which are readily communicable and understood.

This is mentioned because the superlative nature of the new sonic intensity of industrialization was both quantitative and qualitative. The everyday acoustic reality of industrial society saw new extremes in volume and intensity but also an exponential expansion in the kinds of sounds produced, but in terms of describing them we are still stuck with bing, bang, boom, tick, tock. Even more unfortunately, there is still a common tendency to reinforce a narrative description of the intensity of a sound by duplicating that intensity in presentation, something we don't ordinarily do with the other senses (i.e. one generally does not shine a flashlight into someone's eyes in order impress upon them the brightness of the sun).

\subsection{The Blacksmith Shop as Symbol and Musical Archetype}

The isolation of a particular industrial structure for an archaeoacoustic analysis has its own merits and challenges. A structure has easily definable boundaries, while sound does not. Only a brief assessment of one's own sound environment will 
demonstrate that only rarely will one hear an isolated sound, out of context with other sounds. Therefore, if one is interested in the sound environment of the blacksmith shop in 1916 as experienced by a listener, one cannot exclude the church across the street, the road separating them, the machine shop nearby to the south, the streetcar line to the west, etc.. The central focus of this thesis is an argument for the artifactuality of sound, for its inclusion into the realm of material culture studies and archaeology, using the phenomenon of historic industrial sound as a focus. Many structures would qualify for this discussion, and would serve equally well as subjects for study. I initially (and tentatively) chose the blacksmith shop for its symbolic power and close relationship to music, and after research proceeded I found that there was enough historical information available to warrant further study. While a clearer understanding of the life history of The Quincy Mining Company blacksmith shop is a main priority, for the purposes of this study it remains a case study in the service of a discussion regarding the affective responses to industrial sound as well as a meditation upon the idea of the artifactuality of sound in and of itself.

\subsection{Sound in Antiquity}

Recorded attempts to define or understand the nature of environmental sound stretch far back into antiquity and have yielded different models to assist in the apprehension of its complex nature. While one might argue that much has been 
learned about the physical nature of sound and its propagation across the landscape, these accounts still maintain a sympathetic tone to the modern ear. Among other properties, sound still has a remarkable capacity to elicit surprise, and to catch people "off guard." Writing around 55 B.C., ${ }^{28}$ the Epicurean philosopher Lucretius attempts to describe the dynamic and ubiquitous qualities of environmental sound by comparing it to fire: "Again, sounds are disseminated in all directions because each one, after its initial splintering into a great many parts, gives birth to others, just as a spark of fire often propagates itself by starting fires of its own. ${ }^{129}$ Writing around the same time, the Roman architect Vitruvius (Marcus Vitruvius Pollio) chooses a different visual analogy, one still frequently used to model acoustic properties today:

Voice is a flowing breath of air, perceptible to the hearing by contact. It moves in an endless number of circular rounds, like the innumerably increasing circular waves which appear when a stone is thrown into smooth water, and which keep on spreading indefinitely from the centre unless interrupted by narrow limits, or by some obstruction which prevents such waves from reaching their end in due formation. When they are interrupted by obstructions, the first waves, flowing back, break up the formation of those which follow.

In the same manner the voice executes its movements in concentric circles; but while in the case of water the circles move horizontally on a plane surface, the voice not only proceeds horizontally, but also ascends vertically by regular stages. Therefore, as in the case of the waves formed in the water, so it is in the case of the voice: the first wave, when there is no obstruction to interrupt it, does not break up the second or the following waves, but they all reach the ears of the lowest and highest spectators without an echo. ${ }^{30}$

28 Lucretius, The Nature of the Universe, trans. R.E. Latham (Baltimore: Penguin Classics, 1960), 8. 29 Ibid, 149.

30 Vitruvius, The Ten Books of Architecture, trans. Morris Hicky Morgan. (New York: Dover, 1960) 139. 


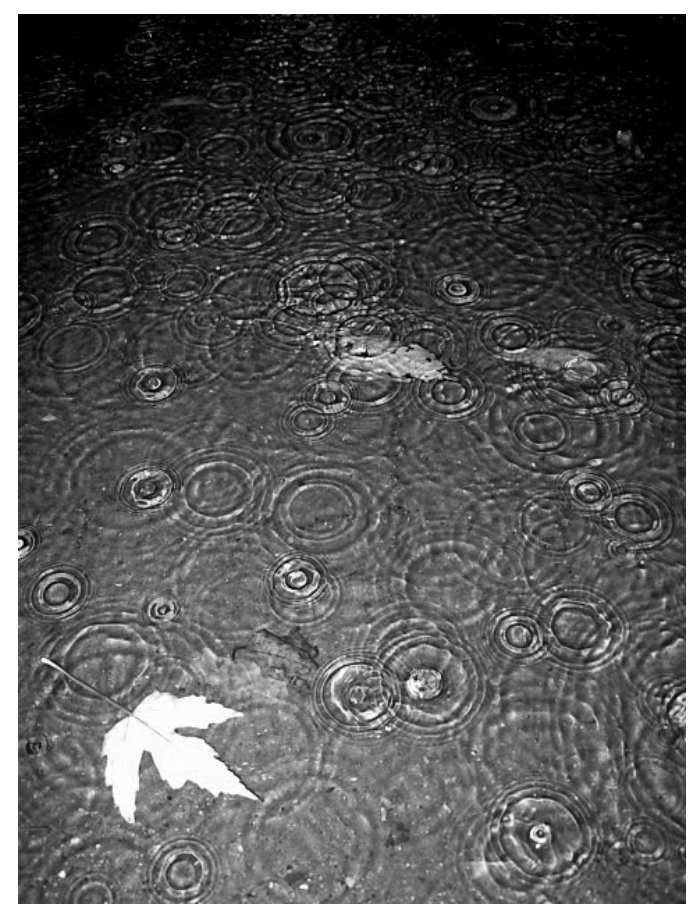

Figure 2. "It moves in an endless number of circular rounds, like the innumerably increasing circular waves which appear when a stone is thrown into smooth water."Vitruvius. In this case, raindrops from rainfall on a street corner in Calumet, Michigan. Photograph by author.

The Quincy Mining Company blacksmith shop, in Hancock MI, built in $1900^{31}$, maintains a presence upon the hill overlooking Portage Lake, just up the hill from the location described by Forster in the earlier descriptive passage. Located among other remains of the Quincy Mine operations, it is now in a state of decay with walls of Jacobsville sandstone still erect but no longer supporting its original roof of white pine timbers and slate.

31 Historic American Engineering Record, A Look at the Architecture and Communities of the Quincy Mining Company, (Hancock, MI: Quincy Mine Hoist Association, no date) 29. 


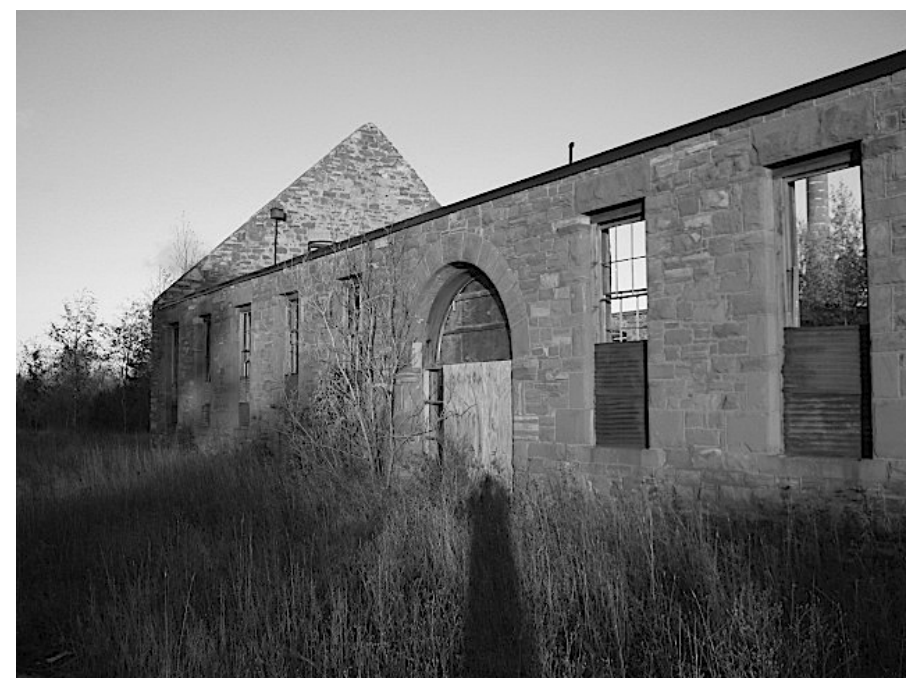

Figure 3. The Quincy Mining Company blacksmith shop in the fall of 2012, north face. Photograph by author.

For residents of the area who have knowledge or recollection of the mine's active years, it now stands as a sentinel of the past, one of many, with a symbolic weight pertaining to industrial might, but its symbolic power does not end there. In general, the "blacksmith shop" as a symbol also carries great significance as the setting for an event that helped shape the nature of Western music as it is practiced and experienced today.

While earlier thinkers of antiquity attempted to define sound through visual metaphors, Pythagoras' musicological legacy (i.e. the 'music of the spheres') is directly attributable to a chance observation of a blacksmith shop in operation. Pythagoras of Samos (570-480 B.C), mathematician, mystic and philosopher, is widely credited with the discovery of a direct relationship of physical proportions with tonal and harmonic attunement while walking past a blacksmith shop. While this event has attained a somewhat mythical aura, finding oneself within earshot of 
the repetitive and ringing presence of metal being struck still persists as a plausible scenario for musical inspiration, even to this day. As told by a later disciple, Iamlichus, Pythagoras was deep in thought as he passed by a forge

where he heard by divine chance hammers beating iron on an anvil, and making mixed sounds in full harmony with one another, except for one combination....he rushed into the forge, and with varied tests he found that difference of sounds was produced by the weights (sizes) of the hammers, not by the force of the blows or by the shapes of the hammers or by the position of the iron being struck. When he had noted accurately the weights and the exact balancing of the hammers, he went home. ${ }^{32}$

Upon arrival, Pythagoras then duplicated this scenario by attaching strings of equal length to his wall, and attaching weights to the strings, noticing that strings with proportional weights produced an octave - they sounded in harmony with one another. ${ }^{33}$

\section{The Repeated Tone of Industrialization: Musical Associations}

The ringing of a blacksmith's anvil, like the ringing of a bell, has a symbolic power of epiphany or discovery, and examples of this are numerous in literature and the arts. The introduction of the repeated "single tone" into Western modernist music is significant; Terry Riley's composition "In C" is a good example of this: comprised of overlapping rhythms of one single frequency, performed by a piano and ensemble of strings and woodwind instruments, this composition has a mesmerizing, hypnotic

32 Christoph Riedweg, Pythagoras: His Life, Teaching, and Influence (Ithaca: Cornell University Press, 2005), 27-28.

33 Ibid, 28. 
quality. The compositions of Steve Reich and Philip Glass also employ the powerful and meditative characteristics of the single repeated resonant tone. Without overtly describing the particular sounds of industrial or mining activities, Douglas Kahn addresses the isolated tone as a form of music unto itself through a discussion of the work of an early modernist American composer, Dane Rudhyar, who was himself a student of Eastern musical practices. According to Kahn, Rudhyar "developed a musical discourse privileging the 'Single Tone' and resorting to 'sound' outside of received musical sound that predated similar developments in the avant-garde of American music. ${ }^{34}$ Contrasting this with the standard model of Western musical composition comprised of relationships between tones, Kahn observes that Rudhyar "celebrated the sounds of gongs and bells as sources of single tones." ${ }^{35}$ Separated from their source origins, when one just simply listens to the sounds themselves, there is a great commonality among the sound forms of early industrial expansion (such as the ringing tone of an anvil being struck), early American minimalist composers such as Riley and Rudhyar, and the repeated single tone of Asian musical traditions. The remains of the Quincy Mine blacksmith shop, then, can safely lay claim to a symbolic power which suggests the possibility of adaptive reuse for musical purposes. But what of the actual lived experience of the people who worked in and around it? What was actually heard there?

34 Douglas Kahn, "Ether Ore: Mining Vibrations in America Modernist Music," in Hearing Cultures: Essays on Sound, Listening and Modernity, ed. Veit Erlman (New York: Berg, 2005), 111. 35 Ibid, 117. 


\section{Industrial Sound: Toward Demystification}

The importance of sound as an integral aspect of the industrial experience is not absent from historical or archaeological literature, but for the most part its presence remains a function of individual predisposition rather than discipline, and references to sound tend to be more parenthetical than sustained and deliberate. Of course there are exceptions to this, and authors who have dedicated their work to the sounds of the past will be given more scrutiny. However, even when sound is not a primary subject, a careful examination of these texts can be very illuminating. Emerging from (as well as creating) the intellectual landscape of the Enlightenment, Denis Diderot compiled, with heroic persistance, a fascinating and detailed account of the particular processes involved in the trades in his Encyclopedie, ou Dictionnaire Raisonne des Sciences, des Arts, et des Metiers, with the first volume printed in $1751^{36}$. From the standpoint of a contemporary individual who tends to take for granted the free exchange of information, this work can seem rather innocuous, but it was a radical gesture at the time, met with charges of plagiarism (and worse) from the outset. ${ }^{37}$ One aspect of the visual component of the Encyclopedia, the engravings, or plates, is worth mentioning: the intentional depiction of the human form, its inclusion into many of the detailed illustrations of artisanal and industrial processes. This suggests a conviction on Diderot's part to enter into the subjective experience of the workers, a conviction stated explicitly in his article "Art":

36 Charles C. Gillespie, ed. A Diderot Pictorial Encyclopedia of Trades and Industry (New York: Dover, 1959), xi.

37 Ibid, xxi. 
Let us at last give the artisans their due. The liberal arts have adequately sung their own praises; they must now use their remaining voice to celebrate the mechanical arts.... We need a man to rise up in the academies and go down to the workshops and gather material about the arts to be set out in a book which will persuade artisans to read, philosophers to think on useful lines, and the great to make at least some worthwhile use of their authority and their wealth. ${ }^{38}$

One conceit of this thesis is that an understanding of the historic industrial soundscape cannot be adequately understood without an attempt to enter into the subjective experience of one who hears it, so the stress is placed on sound as it is perceived rather than as it is produced. Looking through these plates of Diderot's Encyclopedia (and because of the explicit inclusion of the human form within them), one finds many references to sound, to listening, generally in the form of oral communication, speech: figures point with outstretched arms and open mouths, others crane their necks in attentive gestures. In Plate 28, "Preparing Hemp," a figure appears in an open window, delivering a verbal message to a worker who is stripping the hemp fiber in a carding comb. ${ }^{39}$ In Plate 179, "The Cutler," two craftsmen seem to be carrying on an important discussion, their heads close together as frequently happens when oral communication must compete with the bellows, files, anvils, grinding wheels. On the facing page in Plate 180, "The Tinsmiths," an animated conversation ensues within the shop between two figures, possibly the vendor and a customer.

Also projecting an explicitly stated willingness to enter into the sensorial subjective experience of artisans and industrial workers, the authors of The Texture of Industry

38 Ibid, $x$.

39 Ibid, plate 28. 
(1994), Robert B. Gordon and Patrick M. Malone, have created a text that continues in the spirit of Diderot's project. In a passage that seems to answer Diderot's supplication to "rise up in the academies and go down to the workshops," the authors of this volume stress the importance of experiential observation of artisanal practices: "A historical description of a manufacturing operation begins to make sense for the first time when we stand before the actual machine and see the spatial arrangements of controls, feed mechanisms, and belt drives. Watching and hearing a skilled operator run a machine can be a revelation" ${ }^{40}$ (italics added). In a later passage the authors demonstrate the importance of sound and listening in gauging the proper function (or misfunction) of a reconstructed water wheel. ${ }^{41}$ A constant "hissing noise" becomes the crucial clue to understanding why the wheel starts to slow down. Because the designers of the new wheel did not install valves into the buckets to allow the release of water, as the buckets became inverted the water would remain in them. The hissing sound indicated the passage of air through cracks in the joints of the buckets, allowing enough air into the bucket until the water would release with a "splash." Another passage demonstrates the authors' attentiveness to sound as well as the overall sensory industrial experience, specifically referring to the Quincy Mine. ${ }^{42}$ While visiting an "underground classroom" of Michigan Technological University at the Quincy Mine site, the authors recount an experience of a blast demonstration: "The deep, muted sounds of those blasts and the strong waves of air pressure that

40 Robert B. Gordon and Patrick M. Malone, The Texture of Industry: An Archaeological View of the Industrialization of North America (New York: Oxford University Press, 1994), 14.

41 Ibid, 19.

42 Ibid, 193. 
race through the mine leave no doubt that a pile of shattered rock now lies where the group had been standing." ${ }^{43}$ Sound and listening is presented as an important form of knowledge unto itself, as a powerful observational form of verification.

\section{Research Question: Sound As Artifact}

The inclusion of sound as an artifactual component of material culture studies is a conceptual development with some encouraging preceding support. In "Invitation to Archaeology," James Deetz suggests that words themselves (as expressed in spoken form) might qualify as artifacts, stating that "words and artifacts have a lot more in common than it would seem at first glance." 44 Although tentatively framed as a question and reserved for the phenomenon of speech alone, these observations provide a compelling reason to consider all human-produced sound as artifactual. In a footnote, Deetz discloses that his observations spring from discussions with "Professors Loring Brace of the University of California and Margaret Mead of the American Museum of Natural History." 45

Artifacts, like words, are the products of human motor activity, made through the action of muscles under mental guidance on the raw material involved. The resultant form of any artifact is a combination of structural units-attributes-which in any particular combination produce an object which has a specific function in the culture which made it....If this is true, in view of the close similarity between the way in which words and artifacts are created, might not words be but one aspect of a larger class of cultural products which includes all artifacts

43 Ibid, 193.

44 James Deetz, Invitation to Archaeology (Garden City, New York: The Natural History Press, 1967), 86. 45 Ibid, 87. 
as well?"46

While the accepted theoretical framework used to discern archaeological meaning and what constitutes "artifact" has shifted from a strict reliance upon "structural rules" ${ }^{47}$ towards contextuality ${ }^{48}$ sound satisfies both requirements, because, as a physical phenomenon, it does have definable features, and repeated sound is created with consistency, regularity and predictability across the landscape, therefore it is also contextually dependent upon other artifacts for its definition as well as its existence. In this sense, the tangible forms that create a sound form can be seen as "host" artifacts. For instance, the sonifact of a door closing shut is created by the host artifacts of door, frame and the physically unique characteristics of the space itself.

In a recapitulation of some of Deetz's observations, the authors of Field Methods in Archaeology suggest that language is analogous to stratigraphic units of architectural form, making a distinction between "functional" and "interpretative" units. $^{49}$ In clarification of this difference, they state:"An analogy from linguistics may be useful here. The phonetic unit is the smallest distinguishable unit (as is the strati-unit), and the phoneme is the smallest functional unit (as is the interpretative unit). Each functional unit is based on interpretation of the physical evidence, which in turn allows an interpretation of an event." ${ }^{50}$ It should be stated that Deetz also specifically employs the linguistic units of phoneme and morpheme in order to "help us in 46 Deetz, Invitation to Archaeology, 87.

47 Ibid, 86.

48 Bruce G. Trigger, A History of Archaeological Thought (Cambridge: Cambridge University Press, 2009), 455.

49 Thomas R. Hester et al., Field Methods in Archaeology: Seventh Edition (Mountain View, California: Mayfield Publishing Company, 1997), 242.

50 Ibid, 243. 
understanding the structural aspect of archaeological data." ${ }^{51}$

These observations of Deetz as reiterated by Hester beckon for a contemplation of sound on par with tangible artifacts. An insightful and explicit call for such an inclusion is made by Richard Cullen Rath, in How Early America Sounded:

Soundways belong to a world set aside rather than lost. The material culture of soundways is much more permanent than scholars of orality would allow sound to be. Old rings of bells, for example, produce sound in the same ways now as then. Such things provide a record as useful as a text. Changes over time in their design, importance, and uses provide us with a means of better understanding early Americans' mental worlds. $^{52}$

This passage, along with Deetz's observations, helps to lay a strong foundation for an argument for the enduring artifactual nature of a repeated sound. However, the central idea behind this thesis, one which will be a frequent refrain throughout, is that the sound of a bell ringing in the present moment is not simply analogous to the sound of the bell in the past, but rather that it is the same sound, a sonifact. If the bell, as the host artifact, is perceived as a material entity that endures through time, then its corresponding sonifact is equally qualified to be considered as such.

While the discipline of acoustics has certainly secured sound as a physical entity with definable features, it is perhaps worthwhile to devote a little time towards differing viewpoints that aim toward a definition of sound that would shun the connotations of stasis associated with the word "artifact." ${ }^{53}$ At a recent conference at

51 Deetz, Invitation to Archaeology, 83.

52 Richard Rath, How Early America Sounded (Ithaca: Cornell University Press, 2003), 48.

53 It is less challenging when one considers that all physical forms are in a constant state of dynamic motion. As stated by John Cage-- back when people smoked: "Look at this ashtray. It's in a state of vibration. We're sure of that, and the physicist can prove it to us. but we can't hear those vibrations....It would be extremely interesting to place it in a little anechoic chamber and listen to it through a suitable sound system. Object would become process; we would discover, thanks to a procedure borrowed from science, the meaning of nature through the music of objects." (Kahn, 
City University of New York devoted to the artistic discipline known as "sound art," conference attendees spent a considerable amount of time debating the theoretical question of whether sound was an "object" or "event." ${ }^{54}$ The contentious nature of the issue became evident when one presenter suggested that the mere contemplation of the materiality of sound was "dangerous." While a contemplation of sound as object certainly challenges ocularcentric privilege, perhaps archaeologists, artists and other scholars of material culture are more flexible, accustomed to an allowance of the inclusion of multiple forms of sensory data within the material realm. Within the wider intellectual landscape, an acceptance of sound as artifact faces twofold opposition given a general antipathy toward materialist interpretations of reality ${ }^{55}$ as well as a reluctance to grant that sound (and its accompanying applications: hearing, speech, orality, listening) is a primary mode of perception.

There remains a puzzling reluctance among many academicians to allow for the materiality of sound, even though it would certainly seem preposterous to suggest that acoustics, a branch of physics, would be devoted to something outside the realm of matter. ${ }^{56}$ Most definitions of sound indicate that it is a form of vibration, generally "in the air or other medium, some types of which are able to cause a sensation of hearing." ${ }^{57}$ In the introduction of Senses of Vibration: A History of the Pleasure and Pain of Sound, historian Shelley Trower attempts to place vibration- and hence 127).

54 The Status of Sound: Writing Histories of Sonic Art, Graduate Center, City University of New York, Friday, November 30, 2012. Martin E. Segal Theater, 365 Fifth Avenue, NYC.

55 Bjornar Olson, In Defense of Things: Archaeology an the Ontology of Objects (Walnut Creek, CA: Altamira Press, 2010).

56 As defined by Truax, acoustics is "the study of sound and its behavior in various media and environments." It is "the physics of sound, treated in all of its aspects." Truax, 4.

57 Truax, ed., The World Soundscape Project's Handbook for Acoustic Ecology, 114. 
sound, as its audible component- in a somewhat balanced position between object and action: "Vibration is not itself a material object at all, but it is bound up with materiality: vibration moves material, and moves through material." ${ }^{58}$ While John Cage's ash tray and the laws of physics suggest that vibration is itself material, scholars working within an ocularcentric paradigm will continue to insist that sound cannot be considered an entity on par with "rocks." ${ }^{59}$ Without clarifying what exactly it means to be "bound up," Trower steps from balancing sound between materiality and ether, back to state that "vibration is not itself an object or any other kind of material thing..." ${ }^{60}$ and then back again: "Vibration...is neither wholly material nor wholly discursive: it has physical existence but cannot itself be perceived except through its effects." ${ }^{61}$ It is difficult not to find religious (or at the very least, mysterious) connotations to something which is assigned the power to "move material" but which is "not a material object at all." So, in the final analysis, the stated conviction toward the materiality of sound informing this thesis is presented in the same spirit as all attempts towards demystification.

\section{Methodology: An Historic Soundwalk}

In order to gain a greater understanding of the soundscape on Quincy Hill on April 21, 1916 at 3 p.m., material evidence from the blacksmith shop will be combined

58 Shelley Trower, Senses of Vibration: A History of the Pleasure and Pain of Sound (New York: Continuum, 2012), 6 .

59 Ibid, 6.

60 Ibid, 7.

61 Ibid, 8. 
with historical data to form a plausible aural moment in time. All research will culminate in a simple concluding narrative of the experience, as heard from the ears of an individual, as an historic "soundwalk:"62 a trademark activity within the discipline of acoustic ecology where a local environment is traversed by foot-with attentive listening as the primary goal-and sound recordings are sometimes made and/or sound level measurements are noted. This narrative is intended as a way of providing an entry into the complex and highly subjective experience of sound as it is perceived by an individual. It would be impossible to attain an objective assessment of the soundscape of Quincy Hill in the early 1900s, so the effort has be directed toward an accumulation of evidence, a piecing together of what one person might have been hearing during this time period. Once again, this thesis is researched, studied and written from the point of view of a listener, rather than a producer of sound. However, as my argument for the artifactual nature of sound will demonstrate, once it is produced, sound exists by itself as a material entity independent of its source or perceiver. The basic goal of this work is theoretical: to establishsound as artifact through exhaustive research in archaeological, musicological and related disciplines, and to extend this concept into praxis as much as possible by an examination of the Quincy Mining Company blacksmith shop. It is hoped that lessons learned from this experience may be subsequently carried into other structures with other questions.

62 Hildegard Westerkamp, "Soundwalking," accessed September 30, 2011, http://www.sfu.ca/ westerka/writings\%20page/articles\%20pages/soundwalking.html First published in Sound Heritage, Volume 3, No. 4, Victoria B.C., 1974, this essay is a guide for environmental listening. Westerkamp states: "A soundwalk is any excursion whose main purpose is listening to the environment." 
While on the surface the creation of a narrative may seem to test boundaries of scientific credibility, its value has been repeatedly demonstrated in archaeological literature. In The Archaeology of the Colonized (2004) Michael Given assembles a compelling argument for the use of narrative as well as a fair discussion of its limitations. The task, as Given describes it, is to avoid "a study of the 'big men' who changed history, or else of a 'typical' person who is somehow a microcosm of society....The first is a retreat into elitism, and the second denies the subject any agency." ${ }^{13}$ Given recognizes that there is no such thing as "everyman" or "everywoman," and suggests that the individual characters generated by an archaeological narrative will be more easily communicable to a wider audience as "agents, not blobs." ${ }^{64}$ Aware that the act of colonization can occur on the printed page as well as on the ground, Given summarizes the main goals of narrative: "to imagine a lost perspective, form new questions and stimulate new thought." ${ }^{65}$

In "Making the Most of Uncertainties at the Sanderson Farm (2009)," authors Thad M. Van Bueren and Kimberly Wooten conclude their analysis of an "unexpected assemblage" ${ }^{16}$ of artifacts with a series of stories ("Spinning Yarns") that are aimed "not to convince or establish truth but, rather, to more thoroughly expose the thought processes involved in efforts to explain the circumstances that may have created the assemblage....We as researchers hope the stories reveal not only how we thought through our hunches but also each scenario's plausibility, coherence, and

63 Michael Given, The Archaeology of the Colonized (London: Routledge 2004), 13.

64 Ibid, 22.

65 Ibid, 23.

66 Thad M. Van Bueren and Kimberly Wooten, "Making the Most of Uncertainties at the Sanderson Farm," Historical Archaeology 43(2) (2009): 108. 
implications." 67

The importance of the individual person as a subject of archaeological analysis cannot be understated. When thinking about the past, it is all too often the case that the real lived experience of any particular individual will get swept over by rather vague approximations of so-called "collective" experience ${ }^{68}$, political movements, economic mandates, and then forgotten completely, erased from historical awareness. An attentiveness to corporeality, the sometimes unfortunate but strictly unavoidable lot of inhabiting a body, is of particular interest to archaeologists, since their excavations often bring them into direct contact with the material remains of human beings and their activities. A contemplation of a solitary human form (released from the modern confines of the automobile) traversing the landscape on foot is the best way to generate corporeal experience of sound (for as the earlier passage by Gordon and Malone points out, industrial sound is not only heard but felt in the entire body). ${ }^{69}$ Being a discipline that places a great deal of emphasis upon the sensory dependent investigation ${ }^{70}$ of 'the individual,' archaeology is grounded in a theoretical

67 Ibid, 125.

68 The notion of "collective experience," as recalled by "collective memory," is a very tentative concept, custom-made for those who would insist upon knowing what "we" or "they" either experience or remember.

69 As an interesting aside, there is the often recounted experiment by the American composer John Cage, who attempted to experience "total silence" by visiting an anechoic chamber. In his compositions, Cage demonstrates an acceptance and comfort with an allowance of the intrusion of accidental, incidental and environmental sounds. This comfort with 'all sound' emerged from an abandonment of the very idea of so-called 'total silence:' "I heard two sounds," Cage writes of his experience in an anechoic chamber at Harvard, "one high and one low. When I described them to the engineer in charge, he informed me that the high one was my nervous system in operation, the low one my blood in circulation." Cage's experiment demonstrates that there is no possibility of a subjective experience of silence (or sound) without the sounds generated by the listener's own body. (John Cage, Indeterminacy, 5'00 to 6'00, in Die Reihe No. 5, English edition, p.115.)

70 When excavating, the very important task of gauging and classifying soil texture is done by feeling the soil with the fingers. 
conviction that subjective experience can help create the story, the picture, or the song that over time is accepted as 'objective' reality: "Our own body is in the world as the heart is in the organism: it keeps the visible spectacle constantly alive, it breathes life into it and sustains it inwardly, and with it forms a system....All knowledge takes its place within the horizons opened up by perception." ${ }^{71}$

The formation of each individual human identity is intrinsically tied to the sounds we make and the sounds we hear. In her poetic memoire, "First Sound," author Anne-Marie Oomen eloquently recalls the aural memories from her childhood growing up in Oceana County, by the coast of Lake Michigan. Both for its evocative power as well as its insight, this passage is worth including at length:

An earliest memory is something like a flag tying you to a country. For the rest of your life, it waves in your past, emblematic and formative...Because this one memory has to do with sound, it is anthem-like. In that moment in which Grandma Jo is singing in Dutch, French, or perhaps Flemish - another language she may have known - her voice is low and thick. She stops sometimes, breathes against the old machine, murmurs to herself. There is a lot of coming and going in her voice. The light plays over us, sometimes golden, sometimes dark, but it is the sound - hers and the others - to which I am listening....

As I grow up and learn the work of the fields, the sounds take on light, weight, intent - like the antiphonal responses I hear in church and to which I will finally be lured. And I learn not just the way we sound or sing when we are close or dying, but how voices and sounds distort. In the distances of fields, sound shears off the body like chaff. It is carried over air in fragments. Truck to field, field to barn, barn to house, coop to well, room to room, body to body. Our voices are thin threads pulled taut and faint over all the other senses. Our sounds are strands woven together. We strain to hear. If we are lucky, we find meaning. ${ }^{72}$

71 Maurice Merleau-Ponty, Phenomenology of Perception, trans. Colin Smith (London: Routledge 2008) 235, 241.

72 Anne-Marie Oomen, Pulling Down the Barn: Memories of a Rural Childhood (Detroit: Wayne State University Press, 2004) 1-4. 
Notions of personhood are culturally bound, and Western culture tends to emphasize the isolated, discreet, irreducible units of personhood as an individuality, encouraging a separation of one person's being from another. While the maintenance of the individual within historical and archaeological consciousness is of prime importance, personhood cannot simply be defined as a distinguishable or unique corporeality without the influence of others, but neither can this physical fact of 'separateness' be denied. Oomen's metaphor of the human community as a chorus of voices- as "strands woven together"- does not negate the individuality of each strand. In The Archaeology of Personhood, Chris Fowler introduces the concept of dividuality as a "state of being in which the person is recognized as composite and multiply-authored. People are composed of social relations with others to the degree that they owe parts of themselves to others....All of the elements of the cosmos may pass through dividual people."73 The research in this thesis, mostly drawn from historical documents, will result in the imagined (but plausible) experience of an embodied agent, experiencing the interwoven strands that comprised the soundscape of this particular place and time. This is not to say that a "created individuality" ${ }^{74}$ can even approach the organic formation of dividuality, but it is hoped that through the assembly of a myriad accounts and evidence, a convincing sonic moment-in-time may coalesce.

As this thesis is being written, the field of 'sound studies' is rapidly gaining interest

73 Chris Fowler, The Archaeology of Personhood: An Anthropological Approach (London: Routledge, 2004), 8 .

74 I avoid the word "fiction" because of its associations with inaccuracy. 
and validation as a legitimate and independent branch of knowledge. The recent emergence of The Oxford Handbook of Sound Studies (2012), edited by Trevor Pinch and Karin Bijsterveld, is a good example of this new development. Significantly, the first chapter in this volume, written by Mark M. Smith, is devoted to industrial sound. ${ }^{75}$ Expressing a level of excitement and an awareness that something new was happening, Colin Ripley, the editor of a collection of papers originating in a conference in 2006 in Toronto writes: "Out of the amazing barrage of ideas, during discussions after concerts and over dinner, a realization emerged among many presenters at the conference that- although this may be an overstatement- a new field of study was being born." 76 There is a dawning awareness that sound is important for an understanding of the present as well as the past, and this can be seen by the flood of new literature in the field of 'sound studies' emerging from publishing houses in recent years.

\section{The Study of Sounds Past}

This examination of the historic soundscape of the Quincy Mining Company blacksmith shop occupies a space at the intersection of several emerging academic disciplines that have demonstrated an openness to sound and the aural environment of the past as a valid subject of inquiry. Beginning with a mere hunch (during the aforementioned visit to the Quincy smelter) that the sound environment of the past

75 See footnote 11.

76 Colin Ripley, "Introduction: In the Place of sound," in In the Place of Sound: Architecture/Music/Acoustics (Newcastle UK: Cambridge Scholars Publishing, 2007), 1. 
might be a valid subject of inquiry, I began readings in the subject of archaeoacoustics $^{77}$ which provided reinforcement. While initially inspired by the nascent field of archaeoacoustics-the study of the material remains of sound- this thesis is also informed by readings in the relatively young and quickly growing discipline of environmental history. As it pertains to industry, a common subject among environmental historians is industrial "noise" and the subsequent noise abatement efforts in early industrial settings. Archaeoacousticians are generally concerned with forms of sound production within prehistoric timeframes, but their theories and techniques are applicable to 'historic' subjects as well, since there is such a paucity of written information specifically pertaining to sound, regarding even the most recent events. Where the examination of sound is concerned, there is a great deal of commonality between prehistoric and historic sites. ${ }^{78}$

Another branch of inquiry that has provided significant inspiration and direction for this investigation is the field of soundscape studies, or acoustic ecology. Acoustic ecologists are largely concerned with the change of the aural environment over time, and the changing relationship between the human and natural sonic worlds. Truax defines acoustic, or soundscape, ecology as "the study of the effects of the acoustic environment, or soundscape, on the physical responses or behavioural characteristics of those living within it. Its particular aim is to draw attention to imbalances which

77 Without providing an explicit definition, the editors of Archaeoacousics (2006), Chris Scarre and Graeme Lawson state that "archaeoacoustics focuses on the role of sound in human behavior, from earliest times up the the development of mechanical detection and recording devices in the nineteenth century." vii.

78 Without the tangible host artifacts to produce or recreate aural sonifacts, all sounds of the past are equally absent. 
may have unhealthy or inimical effects."79

\subsection{Archaeoacoustics}

The discipline of archaeoacoustics is a dynamic and rapidly evolving line of inquiry that attempts to understand the aural experience of past peoples. The central theme of this study, the consideration and stated acceptance of sound as artifact in and of itself, presents a fundamental theoretical shift for the discipline as a whole in its attempt to give tangible objects and their sounds equal status as artifact. As mentioned earlier, the synthesis of a sound-producing object and sound itself under the same classification relies upon a willingness to allow for listening as a primary mode of perception. Keeping this in mind, the work of musician and archaeoacoustician Iegor Reznikoff is of particular interest, and because of his focused interest on resonant space, his work is also pertinent to the acoustics of abandoned industrial structures. In his acoustic analysis of cave sites, Reznikoff used no sound producing instruments other than the human voice and a tuning fork, and also eschewed recording equipment for electronic capture, insisting that "human sound perception with a trained ear is of unequalled precision, and it also allows a flexibility of approach." ${ }^{80}$ In his meticulous studies of Paleolithic cave paintings in France, Reznikoff was able to ascertain an intentional relationship between the paintings and locations of extreme resonance within the caves by systematically

79 Truax, World Soundscape Project's Handbook for Acoustic Ecology, 127.

80 Paul Devereux, Stone Age Soundtracks: The Acoustic Archaeology of Ancient Sites (London: Vega 2001), 108. 
walking through the caves in complete darkness, while vocalizing a low hum. Whenever a location was reached where the humming sound was significantly amplified by the resonant qualities of the cave's interior, Reznikoff would then turn on a light to find with undeniable regularity, a painting. Sometimes, in the absence of a painting he would find a red dot, about two centimeters in diameter. ${ }^{81}$

A fundamental challenge in archaeoacoustics is the establishment of intentionality, the effort "to convert data drawn from measurement of the ancient phenomena we study into admissible evidence of behavioural connexion; 'admissible', that is, in the sense that they are based on compelling arguments derived from specific evidence." 82 With a large amount of data collected, Reznikoff calculated that the possibility of the relationship between the observed resonance and the paintings was simply a matter of chance was "of the order of a million to one." 83 Reinforcing this discovery through his work measuring the decibel levels at painted sites at the Great Gallery in Horseshoe Canyon, Utah, archaeoacoustician Steven J. Waller firmly states that "the corollary that rock art occurs preferentially at echoing locations is scientifically testable." 84 The importance of Reznikoff's unique research method is that by physically listening for resonance rather than electronically testing for decibel levels, he is able to detect qualitative as well as quantitative differences in the sounds generated. His insistance that the human ear is the best instrument for the detection

81 Iegor Reznikoff, "The Evidence of the Use of Sound Resonance from Palaeolithic to Medieval Times," in Archaeoacoustics, ed. Chris Scarre and Graeme Lawson (Cambridge: McDonald Institute for Archaeological Research, 2006), 79-80.

82 Scarre and Lawson, Archaeoacoustics, viii.

83 Reznikoff, 80.

84 Steven J. Waller, "Intentionality of Rock-art Placement Deduced from Acoustical Measurements and Echo Myths," in Archaeoacoustics, ed. Chris Scarre and Graeme Lawson (Cambridge: McDonald Institute for Archaeological Research, 2006), 34. 
of sound is certainly borne out in his study, but the sound itself, the humming and resulting resonance that Reznikoff so ingeniously uses to determine the exact location of painted sites is not explicitly afforded the status of artifact. The argument is placed here that, by humming (repeatedly), Reznikoff created a sonifact that, through its resonant interaction with the structure of the caves, contextually related to the painted (visible) artifacts on site. It also reinforces a urgent need for the acceptance of hearing, listening, as a primary mode of perception within archaeological research. ${ }^{85}$ In a recent conference presentation, Reznikoff demonstrated his technique in person, "performing" some of these vocalizations that he used to achieve the discovered resonances and their subsequent paintings in the caves. This was done in the somewhat reverberatory space of a lecture hall where electronic amplification was not necessary. Also a vocal performer and scholar of architectural resonance ("...these curved lines are also those of our skull, palate and throat which have in a very real sense an apsidal structure, serving a similar projectory function"86), Reznikoff approximated the groans and calls of possible game animals along with the humming, transforming the presentation into an avantgarde musical performance. ${ }^{87}$ Ann Buckley states that "one of the greatest difficulties at times is to ensure whether an artifact with sound-producing potential may actually

85 In my own presentation at the same conference: "Listening to Industrial Silence: Sound as Artifact," I purposefully mouthed the words of the last sentence of my paper without vocalizing, then I repeated the sentence with sound. I did this to underscore the importance of hearing as a primary mode of perception.

86 Reznikoff, The Evidence of the Use of Sound Resonance from Paleolithic to Medieval Times, 83.

87 Iegor Reznikoff, "On the sound related to painted caves and rocks" (paper presented at XII Nordic Tag, the meeting of Nordic Theoretical Archaeology Group, University of Oulu, Oulu, Finland, April 25-28, 2012). 
have been intended for that purpose." ${ }^{88}$ We have long been accustomed to using sight to ascertain whether or not an artifact may have an auditory function (a musical instrument, for example). Reznikoff's experiment legitimizes the use of hearing (and the production of aural artifacts through vocalization) to locate and identify visible artifacts. As it stands, most efforts to document historic or rare sounds rely exclusively upon the techniques and technologies of electronic capture. However, most scholars would not insist that the only way to save a tangible artifact is to photograph it. This reliance upon recorded sound, even to the point of affording it greater trustworthiness, is a testament to what Schafer presciently identified as "schizophonia," or "the split between an original sound and its electroacoustical transmission or reproduction." 89

Given the ocularcentrism of society as a whole, it may be no surprise that acoustic archaeology has struggled for acceptance within the discipline of archaeology. It is possible that this is due to a reluctance to take the somewhat radical leap towards embracing the artifactual nature of sound. Lamenting this state, Casja Lund notes that archaeoacoustics is generally more accepted within musicology. ${ }^{90}$ Adopting a somewhat more skeptical tone, Catherine Homo-Lechner suggests a level of futility associated with understanding the sound environment of the past: "The attempt to revive a music whose traditions have been lost seems hardly a reasonable 88 Ann Buckley, "Organized Sound and Tonal Art in Long Term Perspective," in Hearing the Past: Essays in Historical Ethnomusicology and the Archaeology of Sound, ed. Ann Buckley (Liege: Etudes et Recherches Archeologiques de l'Universite de Liege, 1998), 10.

89 Schafer, The Tuning of the World, 90.

90 Casja S. Lund, "What is Wrong with Music Archaeology? A Critical Essay from a Scandinavian Perspective Including a Report About a New Find of a Bullroarer," in Hearing the Past: Essays in Historical Ethnomusicology and the Archaeology of Sound, ed. Ann Buckley (Liege: Etudes et Recherches Archeologiques de l'Universite de Liege, 1998), 17. 
challenge....Likewise today, there are people who recognize the utopian nature of attempts to create an exact revival of the past." ${ }^{91}$ Given Hester's aforementioned distinction between functional and interpretive units of stratigraphic analysis (see note 49), it seems logical that sound would fit comfortably into the latter; that sound is a valid 'interpretive unit' of archaeological research. Archaeoacoustics resonates particularly well as a component of industrial archaeology since "I.A.," as it is known among its practicioners, frequently adopts still-standing structures as subjects of study. Structures (such as the Quincy smelter site) maintain a specific aural footprint through time, uniquely formed by the particular spatial configurations on site. The treatment of a building as an archaeological site, "viewed stratigraphically" beckons for an inclusion of sound as an important component of its existence "within the spatial, physical context of (its) surrounding landscape. ${ }^{92}$ On a practical level, sounds of an historic structure, drawn from documentary as well as material evidence, can easily be placed into a stratigraphic matrix ${ }^{93}$ where important historic changes are noted; i.e. the incorporation of a steam stamp into a structure or space would mark a sonic "horizon"94 (provided, of course, that it can be proven that the stamp was in operation).

Taking advantage of recent advances in GIS and associated recording and data-

91 Catherine Homo-Lechner, "False. Authentic. False Authenticity. Contributions and Failures of Experimental Archaeology as Applied to Music Instruments," in Hearing the Past: Essays in Historical Ethnomusicology and the Archaeology of Sound, ed. Ann Buckley (Liege: Etudes et Recherches Archeologiques de l'Universite de Liege, 1998), 29.

92 Gabriel M. Lanier and Bernard L. Herman, Everyday Architecture of the Mid-Atlantic (Baltimore: Johns Hopkins University Press, 1997) 9.

93 Marilyn Palmer and Peter Neaverson, Industrial Archaeology: Principles and Practice (London: Routledge, 1998), 102.

94 Lanier and Herman, Everyday Architecture of the Mid-Atlantic, 7. 
gathering technology, Steve Mills studied the aural environment of a mining landscape in Cornwall UK. This study exemplifies the incorporation of sound as an interpretive category into an assessment of a present day landscape. Mills' stated goal reveals an ambitious conviction, one commonly shared by most archaeoacousticians: "to demonstrate that sound, in general, is a recoverable category of information critical to understanding past ways of life." 95 Employing the concepts of anthrophony, geophony and biophony (more will be said of these later) as interpretive stratigraphic units, Mills made sound samples of five minute duration across an area of roughly one square kilometer. However, it is unclear how digital recording equipment provided superior data collection to a human ear and a notebook. While these recorded data are certainly useful for possible future analysis, Mills' conclusions about the historic soundscape of the area resorted to speculative observations with little specific evidence. Nevertheless, Mills' study is an important precedent for the treatment and isolation of individual sounds as culturally significant units of material culture: as sonifacts.

While a great deal of research in archaeoacoustics is concerned with the possible musical worlds of past peoples, this thesis is written from a Cageian perspective, which casts doubt upon any fixed delineation between music and sound in general. Speaking in Seattle in 1937, Cage stated: "If this word 'music' is sacred and reserved for eighteenth and nineteenth century instruments, we can substitute a more

95 Steve Mills, Applying Auditory Archaeology to Historic Landscape Characterization: A pilot project in the former mining landscape of Geevor and Levant Mines, West Penwith, Cornwall (Cardiff: Cardiff School of History and Archaeology, 2005), 4. 
meaningful term: organization of sound."96 Because many technical journals pertaining to industrial operations contain information regarding the periodicity, mass and force (and sometimes sound quality) of varying devices, this allows for their interpretation as musical scores of organized sound. While an appreciation of industrial sound as rhythmic, repetitive and musical is a common refrain, it is worth mentioning one response in particular, as related by the industrial archaeologist Wolfgang Ebert: "When the composer Max Reger visited the iron works in the north of Duisburg in 1905 he wrote, "How can I convey the impression created by these castles of liquid metal, these glowing cathedrals, surrounding us with wonderful symphonies of whistles and terrible hammer blows....How musical it all is. I fully intend to incorporate it in my music." 97

\subsection{Environmental History}

The study of the soundscape of the past has been warmly embraced by the discipline of environmental history, a research field that emerged from the ecologically-concerned environmental movement of the 1960s and 1970s. Because of this field's preoccupation with human caused degradation of the environment through the deposition of toxic waste, etc., it is not surprising that early writings on the environmental history of sound is mostly concerned with "noise pollution" or unwanted sound. Attributed by many scholars to be the first comprehensive study of

96 John Cage, Silence (Middletown, CT: Wesleyan University Press, 1961), 3.

97 Wolfgang Ebert, Kathedralen der Arbeit (Cathedrals of Work), trans. Ingrid Taylor (Berlin: Ernst Wasmuth Verlag, 1996), 28. 
industrial "noise," Raymond Smilor's Ph.D. thesis has been referenced by numerous environmental historians of sound. ${ }^{98}$ Frequently cited but interestingly never published, Smilor's thesis provides invaluable insights into one very important aspect of the advent of industrial sound (since it was frequently perceived as a "nuisance") and the subsequent noise abatement campaigns that took place across the United States from the early nineteen hundreds onward. This was a serious national movement which viewed the noise problem as tantamount to a form of "barbarism" that threatened civilization. ${ }^{99}$ Smilor also concerned himself with the sound environment within the industrial workplace, compiling many specific examples of industry's responses to the hazards of noise (and vibration) within the workplace, such as the creation of enclosures, dynamic balancing, separation of loud equipment, sound absorption materials, and the silencer. ${ }^{100}$ While it has already been suggested that industrial sound was by no means automatically perceived as "noise," Smilor's history of the popular resistance and aversion to the same offers descriptions of many specific sounds as examples, which might otherwise have been lost. In one fascinating account, Smilor shows how automobile companies used the potential of increased "quiet and comfort" of this new form of transportation (because of its use of rubber tires) over the streetcar, whose steel wheels on steel rail had been deemed too noisy. ${ }^{101}$

With the exception of Deetz's notable allusion towards the artifactuality of sound,

98 Raymond Wesley Smilor, "Confronting the Industrial Environment: The Noise Problem in America,1893-1932," (PhD diss., University of Texas at Austin, 1978).

99 Ibid, 17.

100 Ibid, 124-125.

101 Ibid, 130. 
and Mills conviction that it is a "recoverable category of information," it is interesting that a serious contemplation of the enduring material nature of sound comes from an environmental historian rather than an archaeologist. In general, the writings of environmental historians of sound provide important clues for archaeologists regarding what kind of evidence may actually endure in the form of tangible objects, but as shown earlier (see page 37), Rath suggests that the sounds themselves may endure ("there is no evidence that sonic evidence cannot be assessed with the visual"). ${ }^{102}$ Rath's insight that the many sounds produced by historic artifacts (such as bells) "produce a record as useful as a text"103 may not initially entice historical archaeologists, some of whom are accustomed to viewings texts with suspicion. However, this observation allows an archaeologist to proclaim that they are actually far more useful than a text, since they are the sounds themselves, unencumbered by centuries of interpretation and re-interpretation.

Historical information can be brought into the field to imbue spaces and objects with greater sonic meaning. In How Early America Sounded, Rath presents some broad themes that resonate strongly with material and historic evidence found regarding the blacksmith shop at Quincy Hill. The role of sound as a social ordering device is a commonly understood aspect of its use in daily life, but Rath documents how living within "earshot" (a term first seen printed in 1607) of the village bell was a mandate, a requirement for one's inclusion within the first American community of

102 Rath, How Early America Sounded, 48. 103 Ibid. 
Jamestown. ${ }^{104}$ Rath also recognizes that the existing noisy/quiet or industrial/pastoral ${ }^{105}$ way of thinking about the transition from artisanal-agricultural life to industrial is an oversimplification. "Rather than thinking of early America as a quieter world, I have sought to restore the full complexity of its soundscapes." ${ }^{106} \mathrm{~A}$ recognition of this complexity brings scholars closer to an actual apprehension of the particularities of sound forms as they change over time. Rath provides ample historic evidence of the far more important role of orality and speech in everyday life, and this is also borne out in many forms in a study of the sound environment on Quincy hill. The church bell, also, is an "earcon" of the American soundscape: a powerful and enduring sonic presence only to be challenged later by heavy industry. Writing of this transition, Schafer suggests that "the association of Noise and power has never really been broken in the human imagination. It descends from God, to the priest, to the industrialist, and more recently to the broadcaster and the aviator.... Whereever Noise is granted immunity from human intervention, there will be found a seat of power." ${ }^{107}$ But it should be noted that social power does not reside strictly within a capacity for the projection of volume. In a discussion of speech and oral communication within work environments, Rath astutely observes the power of silence, or sound withheld: "Insubordination and dissent manifested itself in quiet nonverbal vocalizations as well as loud ones." 108

104 Rath, How Early America Sounded, 55. 105 Mark M. Smith, "The Garden in the Machine: Listening to Early American Industrialization," in

The Oxford Handbook of Sound Studies, ed. Trevor Pinch and Karin Bijsterveld. (New York:

Oxford University Press, 2012). 106 Rath, 174.

107 Schafer, The Tuning of the World, 76.

108 Rath, How Early America Sounded, 122. 
Studies of the onset of industrial noise and the subsequent noise abatement programs that ensued show that elitism and the reinforcement of class distinctions undoubtedly played a role in the way "noise" was addressed. ${ }^{109}{ }^{110}$ In his thesis, Smilor shows how noise abatement programs were a component of progressive-era reforms, and that the movement was largely initiated by "middle class reformers" ${ }^{111}$ whose goal stretched beyond a simple decrease in "barbaric" or unwanted sound to an appeal for sanity and the mental health of society as a whole. ${ }^{112}$ While Smilor, Coates and Bijsterveld's sonic histories are largely concerned with the social reactions to industrial and urban sound, and attempts to control these reactions, Emily Thompson's The Soundscape of Modernity is a detailed history of how sound became an increasingly technologically manipulated and controlled medium, tracing the different steps in the transitional process from sound to signal, ${ }^{113}$ through the work of architects and acoustic engineers such as Wallace Sabine, whose work and influence is discussed at length. Initially distancing her work from Schafer's The Tuning of the World, Thompson writes a history of technology and sound that is largely a celebratory account of the persons and places that contributed to the science of acoustics and acoustic engineering. Thompson's assessment of progressive-era noise reform (attempts to control unwanted sound at its source) depicts it as a failure- even with the assistance of the country's first "Anti-Noise

109 Karin Bijsterveld, "The Diabolical Symphony of the Mechanical Age: Technology and Symbolism of Sound in European and North American Noise Abatement Campaigns, 190040,"Social Studies of Science, 31:1 (2001), 45.

110 Peter A. Coates, "The Strange Stillness of the Past: Toward an Environmental History of Sound and Noise," Environmental History, 10: 4 (2005), 640.

111 Smilor, "Confronting the Industrial Environment: The Noise Problem in America,1893-1932,"viii. 112 Ibid, 156.

113 Emily Thompson, The Soundscape of Modernity (Cambridge: MIT Press, 2002), 3. 
Policeman"114 in Baltimore- and presents the efforts of architectural acousticians as being "far more successful (in) exerting control over the soundscape of private life."115

In Thompson's account of the history of the architectural and technological manipulation of sound, one clearly hears the efforts of human beings to control their (largely urban) sound environment, but there was never any claim to attempt to clearly communicate the everyday acoustic reality of an observer on the ground. This is also the case with both Bijsterveld and Coates, who largely provide a survey of others' historical research. Because of its more comfortable relationship with the sensorial world, it is left to the discipline of archaeology to help us attain a visceral understanding of historic sound as perceived by an individual, as experienced on the ground. The work of environmental historians, however, provides extremely valuable data towards the creation of the aural equivalent of archaeological horizon: the formulation of a series of sonic horizons that constitute important cultural changes in the materiality of sound, and this includes sound producing instruments as well as the sounds themselves. For instance, through meticulous historic research, Rath demonstrates the power attributed to thunder as the "'loud speaking voice of God"' and the frequent use of the word "thunder" in early American documents. ${ }^{116}$ The transition from thunder as a primary acoustic force to bells to industrial operations (dynamite, air-blasts in mine operations) constitutes a series of sonic horizons that have largely been completed by the time the Quincy Mine blacksmith shop was built.

114 Ibid, 126

115 Ibid, 167

116 Rath, How Early America Sounded, 17. 
The assemblage of sonifacts produced by the steam locomotive- the heavy roar, bells, whistles and hissing steam- is another important sonic horizon, and its corresponding evidence is to be found in the form of tangible artifacts informing the time period when the blacksmith shop was in operation. The dawning aversion to urban and industrial sound during the progressive era- the need for peace and quiet, so amply documented by Thompson and Bijsterveld and Coates- this suggests yet another sonic horizon; manifested in the real physical changes to the landscape and architectural space through material choices as well as orientation, location and spacing of structures. Another undeniable sonic horizon would be the automobile. Schafer observes that the "internal combustion engine now provides the fundamental sound of contemporary civilization." 117 Within the discipline of historical archaeology, using documentation as a springboard for future research or verification of evidence is an accepted practice. As it applies to historic sound forms, this kind of supporting documentation is absolutely essential. The need to make subtle distinctions is increasingly recognized as an important goal within environmental history of sound.

117 Schafer, The Tuning of the World, 82. 


\subsection{Acoustic ecology}

A comprehensive treatment of environmental sound in all of its complexities, one that places industrial or "modern" sounds within the context of all sounds, is a task taken up by the World Soundscape Project at Simon Fraser University in Vancouver, British Columbia. Initiated by R. Murray Schafer in the late 1960s and early 1970s, this small group of scientists and composers has been steadily creating an opus of writings, recordings, and compositions that constitute a discipline unto itself: acoustic ecology. Aside from the nascent field known as "sound studies," no other discipline or intellectual school of thought has treated sound so comprehensively, in all of its dimensions. Much of the language used to discuss sound is derived from this movement, which was borne out of a concern regarding the intrusion of industrial and urban noise into the Vancouver 'soundscape.' While not denying Schafer's influence, subsequent scholars of aurality have been quick to distance themselves from Schafer's ecological stance, such as Rath, who states that his work is of "limited value," indicating that a preoccupation toward "loss, purity, and pollution imbue his work with nostalgia for a past that probably never existed." ${ }^{118} \mathrm{On}$ the first page of her work, Thompson is also quick to point out that the underlying concerns of Schafer's work "are not what has motivated my own historical study." 119

118 Richard Cullen Rath, "Hearing American History," The Journal of American History 2 (2008): 419. 119 Emily Thompson, The Soundscape of Modernity, 1. 
While it is certainly true that authors such as Schafer, ${ }^{120}$ Krause $^{121}$ and Westerkamp ${ }^{122}$ sometimes reference accounts of aboriginals or other native populations as living closer to the sensorial world than their Western coinhabitants (and that perhaps the soundscape of the continent was more acoustically integrated before European immigration) it seems that the fundamental question posed is not whether or not this is a romantic view, but whether or not it is accurate. If it is true, then does it not comprise an historically important transition? The World Forum for Acoustic Ecology is an outgrowth of the original group at Simon Fraser, with the composer Hildegard Westerkamp as one of its organizers and founding members. ${ }^{123}$

The influence of this group upon all scholars of sound is demonstrable by the adoption of many words and concepts invented and employed by the various composers that have been a part of the group over time. Aside from the widespread use of the simple but very important concept of "soundscape," many other conceptual advances have been incorporated within other disciplines as effective methods for thinking about environmental sound. An important conceptual grouping that has taken hold across the multifarious disciplines that may one day be unified under the umbrella field of "sound studies" was initiated by Bernard Krause in 1987. The categories of biophony, geophony and anthrophony ${ }^{124}$ form a comprehensive way of distinguishing environmental sounds by their origins of production. Biophony

120 Schafer, The Tuning of the World, 84.

121 Bernie L. Krause, "The Niche Hypothesis: How Animals Taught Us to Dance and Sing," accessed May 5, 2012 at http://users.auth.gr/paki/files/soundscape/referances/niche.pdf

122 Westerkamp, Soundwalking, 6.

123 "The World Soundscape Project," accessed January 12, 2013, http://www.sfu.ca/ truax/wsp.html

124 Bryan C. Pijanowski et al., "Soundscape Ecology: The Science of Sound in the Landscape," BioScience 613 (2011): 204. 
includes all sounds produced by living organisms, while geophony constitutes environmental sounds of the earth itself: wind, water, thunder. Anthrophony, or "man-made noise" 125 are the sounds, largely technological in origin, produced by human beings. Krause's "Niche Hypothesis," realized after hours of painstaking recording sessions in the field, demonstrated that in an environment with limited or no anthrophonic interruptions, animals of similar species tend to communicate within distinct frequency "niches" as well as distinct temporal locations in order to limit interference with other species. All of these sounds taken together consequently tended to show how individual places would have distinct acoustic characteristics:

When a bird sang or a mammal or amphibian vocalized, the voices appeared to fit in relation to all of the natural sounds of the immediate environment in terms of frequency and prosody (rhythm). Over a number of years we would return to the same sites only to find, when the recordings were analyzed, that each place showed incredible bioacoustic consistency...much like we would expect to find from fingerprint matching. The bird, mammal and frog vocalizations we recorded all seemed to fit neatly into their respective niches. And the bio-acoustic niches from the same locations all remained the same (given time of year, day, and weather patterns). ${ }^{126}$

This account, describing the enduring nature of environmental sound within a given space and over a significant time span, carries the same level of astonishment that one might read in an account of an archaeologist who returns to a site to find that the artifacts s/he was studying were not stolen, rearranged, damaged or looted. Considering the extent of Krause's research (thousands of hours of recordings) demonstrating the consistency of the acoustic "fingerprint" of particular locations

125 Clive Thompson, "On How Man-Made Noise May Be Altering Earth's Ecology," Wired Magazine 16.06 (2008), accessed January 23, 2012, http://www.wired.com/science/planetearth/magazine/1606/st_thompson

126 Krause, "The Niche Hypothesis," 5. 
over time, bio-geophonic soundscapes that have been maintained with limited or no anthrophonic interruption can be postulated as reasonable locations for the study of sound as ecofact.

Krause's article has had resounding impact upon the way human beings are now beginning to conceptualize their relationship with the natural environment. Considering his work as a contribution to the discipline of acoustic ecology, Krause stresses the urgent possibility of a "rediscovery of a direct cultural link to our natural surroundings before they all disappear." ${ }^{127}$ The recently formed discipline of "soundscape ecology" has attempted to distinguish itself from acoustic archaeology due to the latter's "human-centered inquiry rather than the larger socioecological systems approach"128, in spite of sharing many of the same convictions, the foremost being "the need to conserve natural soundscapes." ${ }^{129}$ This article, which interestingly includes Krause as an author, is essentially a suggested map for a new subset of ecology, including a group of themes for a future research agenda. While its overall tone is more value-neutral than many of the writings from acoustic ecologists, many of the goals are nearly identical (i.e. "Assess the impact of soundscapes on wildlife."130) This distancing from acoustic ecology may be due to the latter's inclusion of musical composition as a valid form of research. Schafer, Truax and Westerkamp, all original members of the World Soundscape Project at Simon Fraser University, are also composers, frequently using recorded environmental sound as a

127 Ibid, 6.

128 Bryan C. Pijanowski et al., "Soundscape Ecology: The Science of Sound in the Landscape," BioScience 613 (2011): 204.

129 Ibid, 203.

130 Ibid, 209. 
source for compositions. One of Westerkamp's compositions, "At the Edge of the Wilderness" (2000), specifically employs recorded "found-sound" from an abandoned factory in British Columbia, Canada. In a discussion of the close relationship between "soundscape composition" and acoustic ecology, Westerkamp states:

...it is also important to remember that the original impetus for soundscape awareness came from composers and musicians. We are the ones that make listening and working with sound and music our profession. It is therefore a logical extension that we would also be concerned about the ecological health of our acoustic environment and all living beings within. If we - who are specialists in listening and soundmaking - are not concerned about the acoustic environment, then who will be? Some biologists have made it their calling to use their special knowledge and education to look at the natural world from the ecological perspectives. Why then should composers and musicians not make it their calling to use their special knowledge and education to listen to the world from the ecological perspective? ${ }^{131}$

In a stated attempt to avoid any narrow assessment of soundscape composition, Westerkamp defines it as "the artistic, sonic transmission of meanings about place, time, environment and listening perception." ${ }^{132}$ Westerkamp's composition is of particular relevance to a discussion of sound's artifactuality because the interactions of the composer with the different material remains on site "brought them to life in surprising ways"133 and it is argued here that through the sonic reanimation of host artifacts (such as an old steam engine or a weathered piano), sonifacts were produced, or rather re-introduced into the soundscape. Westerkamp's discussion of

131 Hildegard Westerkamp, "Linking Soundscape Composition and Acoustic Ecology," Organized Sound: An International Journal of Music and Technology: 7,1 (2002): 2, accessed September 30, 2011, http://www.sfu.ca/ westerka/writings\%20page/articles\%20pages/linking.html 132 Ibid, 2.

133 Ibid, 6. 
the immediate apprehension of an abandoned industrial site (excluding paranormal references, not unlike my experience of the Quincy smelter) is also pertinent to the study of industrial heritage:

...that strange moment of excitement and magic, discovery and adventure, when the contemporary visitor encounters an abandoned industrial site. This moment contains questions and stories about human industrial activities of the past and present; or a sense of the spirits and ghosts still hovering among the skeletal remains while nature is gradually reclaiming its place. It is as if visitor and place are taking a deep breath together during this encounter, convalescing from injury, contemplating the edge where junk and artifact, destruction and new growth, noise and quiet meet; where perceptions of a shameful past in need of clean-up collide with feelings of pride towards a heritage worth preserving. ${ }^{134}$

Westerkamp indicates that soundscape composition also has a component of activism in the sense that the creative act of composition offers an antidote to an endless barrage of corporate music and advertising: "It is a forum for us...to 'speak back' to problematic 'voices' in the soundscape, to deepen our relationship to positive forces in our surroundings or to comment on many other aspects of a society." 135

R. Murray Schafer's Tuning of the World is a comprehensive text, examining the phenomenon of sound from prehistory to the present. While Schafer's interest in sound also originates from a concern regarding environmental degradation, his analysis of anthrophonic sound is detailed and nuanced and thoroughly researched, and serves as a very useful primary text for anyone interested in the sound environment. Many authors who concern themselves with environmental sound are quick to situate their work in relationship to Schafer's work, whether they agree with

134 Ibid, 6. 135 Ibid, 3. 
his premises or not. An early assertion viewing the world "as a macrocosmic musical composition" ${ }^{136}$ is certain to distance Schafer from strict fact oriented researchers who have no time or inclination for poetic rumination. But this Cageian perspective has opened the realm of 'sound studies' to a much wider interpretive and analytical audience. Viewing the reduction of biophonic sounds through the intrusion of anthrophony as a lamentable loss, Schafer's final question seems prophetic as one witnesses the proliferation of 'sound studies' articles and books presently: "Is the soundscape of the world an indeterminate composition over which we have no control, or are we its composers and performers, responsible for giving it form and beauty?"137

Like Krause's categories of sound types based on original source, Schafer offers many conceptual tools to assist a sound researcher. Borrowing terminology from visual art, Schafer forms an important distinction between the aural equivalents of 'figure' and 'ground' as 'signal' and 'keynote' respectively. This is borne out in everyday experience, where certain 'keynote' sounds tend to be omnipresent in any given environment (i.e.: background noise, like the drone of automobile traffic) while other 'signals' are sounds that stand out as isolated and distinct in relationship to the keynote sounds (a bell, a human voice).

Schafer's exploration of the world sound environment is thematically structured around a fundamental change in the soundscape: the onset of industrialization. With frequent reference to accounts of pre-industrial sound, it can be safely said that

136 Schafer, The Tuning of the World, 5. 137 Ibid. 
Schafer views the subsequent displacement of pre-industrial sounds (and silences) as a loss. ${ }^{138}$ As mentioned earlier, some scholars of sound have pointed out a somewhat romantic tone behind Schafer's work- indicating it as a weakness- but with new scientific scholarship emerging every day arguing for the preservation of pre-historic sound forms, it seems that perhaps romanticism and scientific accuracy are not mutually exclusive perspectives. A closer read of Schafer's work demonstrates a detailed attentiveness to the advent of anthrophony which is also somewhat celebratory. The emergence of the unique musical sounds of the artisanal (archetypical) blacksmith shop is described in detail through several different accounts: "Up to the time of the Industrial Revolution, the sound of the blacksmith's hammer was probably the loudest sound a solo human hand ever produced- a brilliant tintinnabulation." 139 The arrival of full-scale industrialization, Schafer argues, ushered in a new "lo-fi" soundscape, a diminished, less rich sound environment, due in large part to "flat line" sound: "The flat continuous line in sound is an artificial construction. Like the flat line in space, it is rarely found in nature." 140 Electrification simply added more kinds of flat-line sounds to the environment in the form of electric motors, but through the advent of electronic capture and transmission, the soundscape, Schafer argues, became 'schizophonic,' referring to "the split between an original sound and its electroacoustical transmission or reproduction." ${ }^{141}$ It could, however, be fairly argued that this split was very short

138 Schafer, The Tuning of the World, 21.

139 Ibid, 58.

140 Ibid, 78.

141 Ibid, 90 . 
lived; that the past half century has been characterized by a general acquiescence toand even preference for- reproduced and electronically enhanced sound over nonelectronically augmented sound. It is, perhaps, an entrenched reliance upon electronic sound capture and transport that has made the contemplation and allowance of simple every day environmental sounds as historic or pre-historic in and of themselves a difficult conceptual transition.

Aside from the introduction of the term 'soundscape' into the popular vocabulary, a lasting legacy of Schafer's book are many conceptual and terminological insights, the aforementioned are only a few. Reading at times as a kind of manifesto and call to action, The Tuning of the World has a comprehensiveness that is a strength as well as a weakness. It has certainly served to inspire and inform many thinkers on the topic of sound, but its breadth of scope precludes detailed analysis of any particular locale, time or phenomenon.

\subsection{Sonic Heritage Studies}

While the disciplines of archaeoacoustics, environmental history and acoustic ecology have created the basic parameters for research and contemplation of sound as artifact and ecofact, writings within the rather broad field of heritage management studies have also addressed sound as an important topic of research. Within all of the work accomplished and proposed by researchers of acoustic heritage, there is an interesting common theme throughout: a reliance upon electronic capture, data 
manipulation and auralization software for the presentation and validation of data. As mentioned before in the discussion of Mills' analysis of the Levant mining area of Cornwall, this approach offers limited results regarding an apprehension of actual past sound environments. This thesis is written in agreement with Iegor Reznikoff's conviction that the human ear is the most sensitive means of acquiring aural data. Also, if one is truly interested in the aural experience of the past, one might also develop a trust and understanding of the means sound was perceived by past individuals; through the ears. By attentive listening in the present moment, one can apprehend past sounds on a regular basis; leaping ahead to electronic capture bypasses this experience and diminishes the importance of preserving the actual existing soundscape, which, of course, includes whatever is left of the past. With specific reference to industrial heritage, Alfrey and Putnam have rightfully indicated that "Visual values have led to emphasis on certain aspects of industry at the expense of others." ${ }^{142}$ This is adequately expressed in a recent assessment of the soundscape of Quincy hill within an otherwise extremely comprehensive examination of the history of the area. A publication of the National Park Service, the Quincy Unit Cultural Landscape Report/Environmental Assessment/Public Review Draft (July 2009) suggests that sound may be outside the parameters of the project: "...soundscape management is dismissed as an impact topic in this document." 143 However, as is the case with many historical documents, references to specific

142 Judith Alfrey and Tim Putnam, The Industrial Heritage: Managing Resources and Uses (London: Routledge, 1992), 7.

143 Keweenaw National Historical Park, "Quincy Cultural Landscape Report," accessed May 15, 2012, http://www.nps.gov/kewe/parkmgmt/quincy-clr.htm, page 27. 
sounds are frequently included to provide an invaluable historic context. The report also includes a poem by Bill Finlan and Margaret Gilbert, one which seems to draw upon specific aural memories of the area under scrutiny: "We miss the sounds of the Quincy Mine/ The sounds of the hoist wheels singing/ The bellow's blow and the blast below/ And the locomotive ringing..." The poets lamentation of the absence of particular sounds ("No whistle's roar/ No falling ore/ No 'lectric signals jangling.") ${ }^{144}$ lends credibility to the account, whereas many 'first-hand' or "earwitness" ${ }^{145}$ accounts can be rather vague and therefore cannot be relied upon to build a plausible historical base.

Fitzjohn notes that the "importance of sound and auditory experience in our lives is without question; it is powerful in signifying existence, generating a sense of life and place." ${ }^{146}$ There seems to be little argument or difficulty in asserting the importance of sound within heritage studies, therefore it can be asserted as a primary heritage value. In order for this to happen, however, the act of hearing and listening must also come to the forefront as a primary mode of perception.. As a way of explaining the dearth of research regarding historic soundscapes, Fitzjohn reiterates a common but somewhat erroneous view of the "fleeting" nature of historic sound-forms: "Sound as a fundamental quality of everyday life has not been examined...probably because of its ephemeral nature. It is temporal, continually coming and going, so we fail to

144 Ibid, 123.

145 Schafer, The Tuning of the World, 8.

146 Matthew Fitzjohn, "The Use of GIS in Landscape Heritage and Attitudes to Place," in Heritage Studies: Methods and Approaches, ed. Marie Louise Stig Sorensen and John Carman (London: Routledge, 2009), 247. 
consider the sounds or experiences...the sonic environment surrounding a person." ${ }^{147}$ While on an immediate level it does seem that sound "disappears" as soon as it emerges, if the host artifacts for an historic sonifact are preserved, then the soundform itself can be reintroduced and repeated with negligible variability. For instance, if a hand forged door hasp on a door in an historic structure has not been touched for two hundred years, once it is touched again (provided it has not rusted or been painted shut) it will make the same sound, albeit slightly modified by the variations of handling. It will always be the specific and unique resulting sonifact produced by the same host artifacts. It will never be the call of a blue whale, a ZZ top concert, a hummingbird, or an excerpt from a speech by John F. Kennedy. ${ }^{148}$ Considering the capacity for high levels of error, failure and manipulation embedded within data storage systems, an increased reliance upon tangible artifacts and spaces for the possible production of sonic artifacts and ecofacts seems like a logical approach for the preservation of acoustic heritage. The trajectory of Thompson's "sound to signal" transition has neared its completion, for human beings now don earphones in order to isolate and listen to "rare" or "disappearing" sounds that still exist in plentiful numbers as airborne sonifacts. The absurdity of this situation has generated a newfound appreciation for the particular acoustic qualities of structures- whether intentionally built for sound or not- among musicians and recording engineers.

While Blesser and Ruth-Salter assert that "there is no evidence that an aural architect can internally auralize- aurally visualize- a novel acoustic space"149

147 Ibid.

148 Or the humming of a mosquito.

149 Blesser and Ruth-Salter, Spaces Speak, Are You Listening? Experiencing Aural Architecture. 70. 
attempts to auralize historic space with computer assistance are well underway. In his abstract "Preserving the acoustical heritage of historical buildings," Jens Holger Rindel states that if a building is partially intact, acoustic readings can be made and used within a computer model to extrapolate how the entire structure may have sounded, though he admits that "modelling a large number of simultaneous sources, e.g. from a crowd is another challenge." ${ }^{150}$ While auralization attempts represent a laudable recent effort toward gaining a closer understanding of past aural worlds, the verification of the accuracy of the results for such projects must nevertheless be based upon existing sonifacts, and this, in turn, depends entirely upon the preservation of tangible objects and spaces.

\section{The Repeated Sound}

From an aural perspective, the discovery of copper in the Keweenaw peninsula led to a rapid introduction of anthrophony into a region whose main sonic features were bio/geophonic. Another descriptive passage from 1826 recounts the impressions of an explorer, Thomas McKenney, visiting the southeastern shore of the Keweenaw:

"'Not a bird warbles to cheer us. Not a living thing presents itself to vary the solitude. Nothing is heard but the roar of the waves on the shore, nor seen, but the forests that line it, the lake, and the sky. Whether stormy or calm, the roll of the wave is heard. It never ceases. This is the music of these shores.' Occasionally, a loon called

150 Jens Holger Rindel, "Preserving the acoustical heritage of historical buildings," (abstract for a paper presented the European Congress on Acoustics, Budapest, Hungary, August 29-September 2, 2005). 
mournfully; otherwise, only a stray songbird and buzzing of mosquitoes could be heard, and a few ducks paddled near shore." ${ }^{151}$ These passages of the bio/geophonic sound environment of the area are instructive for two reasons. First, they provide a useful comparison to the sonic changes incurred as anthrophony dramatically increased due to industrial expansion. Both Forster and McKenney's accounts are interesting in their amazement and reverent attention to the placid, peaceful and relative silence encountered. Second, if one were to subtract the omnipresent drone of the internal combustion engine from the present day soundscapes of the same areas, one might encounter similar features. We can safely assert that geophonic sound forms, in particular, have endured through time with almost no substantial changes, and while there are certainly more people, human vocalization has been reduced to a murmur ${ }^{152}$ in comparison to the boisterous, rowdy sonic world of early European settlement, filled with public gatherings, extemporaneous speeches, bells, bar-fights, etc. The sonifactual evidence of environmental sound, waves upon the shore, coyotes, wolves, loons, provides us with a very reliable foundation for thinking about the aural experience of these early settlers if they ever managed to distance themselves from anthrophonic activity.

Searching for the reasons behind the value ascribed to certain materials can be a somewhat complicated matter, but it is of particular interest to archaeologists, who are largely concerned with discoveries made in the material realm. It can be

151 Arthur W. Thurner, Strangers and Sojourners: A History of Michigan's Keweenaw Peninsula (Detroit: Wayne State University Press, 1994), 35.

152 The transition from sound to electronic signal has led to a reliance upon electronic transmission for most forms of communication, creating an anthrophonic environment largely muted of human vocalization. 
tentatively stated that one of the earliest documented motivational forces behind the industrial expansion of the Keweenaw Peninsula was not the production of copper as an end in itself, but rather the production of sound, with copper serving as a fundamental material in the process of bell casting. Many historical accounts of the copper boom in the Keweenaw tend to work under an assumption that copper is a "naturally" valuable material, and devote little time to the uses that generated such a powerful drive for its initial extraction from the Keweenaw earth. While its conductive properties are well understood, the initial copper rush began in 1843, well before electrification. This has led one historian to view the rush as "premature, absurd and paradoxical." ${ }^{153}$ In general, the use of copper for pots and pans as well as sheathing for shipbuilding is frequently mentioned ${ }^{154}{ }^{155}$, but the only reference which I have found to directly tie early Keweenaw copper to a specific use indicates that it was particularly well suited for the production of bells, which in turn produce sound. Referring to the Cliff Mine, the first profitable copper mine on the Keweenaw Peninsula, historian Arthur W. Thurner provides an important clue: "In his 1849 report, Jackson said that the Cliff was producing 860 to 900 tons of copper annually, averaging 65 percent pure metal. The pure copper required only fusion to cast it into forms required for manufacturers. He said the mix of copper and silver found at the Cliff and the nearby Copper Falls Mine had been 'used in Boston for making church bells, and has proved to be of excellent quality.' So began the widespread use of

153 Angus Murdoch, Boom Copper: The Story of the First U.S. Mining Boom (Calumet: Roy W. Drier and Louis G. Koepel, 1964), 6.

154 Larry Lankton, Hollowed Ground: Copper Mining and Community Building on Lake Superior, 1840's-1990's (Detroit: Wayne State University Press, 2010), 15.

155 Murdoch, 5. 
copper from Michigan in the developing industrialism of the late nineteenth century. Thousands from all over the country, as well as from Europe were attracted to the Keweenaw." ${ }^{156}$ In support of the early use of Michigan copper for bell casting, historian Charles Hyde notes that until 1849, "virtually all the Michigan copper went to the Revere smelter in Boston and the Baltimore and Cuba works," ${ }^{157}$ stating in an earlier passage that Paul Revere's earliest copper products in 1797 were "copper bolts and a bell for the Constitution, which was built a short distance from his foundry. The next year, Revere offered to supply the navy with brass cannon, bells, and copper bolts." ${ }^{158}$ While this assertion needs more evidence to posit with confidence (and until reference can be found that directly ties early Keweenaw copper to other products), one could hypothesize that the single thing, the finished product, that initially served to drive men and women to the peninsula by the thousands was the repeated musical tone as produced by bells made from quality bell metal. Charles $\mathrm{T}$. Jackson was appointed by the U.S. secretary of the treasury to study Keweenaw land and place it in a category of either "mineral" or "agricultural." ${ }^{159}$ Apparently there was no category for "musical." One can safely assume that when he uses the word "quality" in reference to bells, he is refering to the end product of bells, their quality of tone rather than color or patina.

Bell metal is an alloy of copper and tin, with a ratio of 4 or 5 to 1 for "the best combination to produce a good ringing tone; and this mixture is made to vary

156 Thurner, Strangers and Sojourners, 45.

157 Charles K. Hyde, Copper for America: The United States Copper Industry from Colonial Times to the 1990's (Phoenix: The University of Arizona Press, 1998), 24.

158 Ibid, 11.

159 Ibid, 44 
according to the kind of tone desired. If too much tin is used, the metal will be too brittle, and will crack." 160 The desired quality of the bell, its ringing tone, is a complicated physical sonifact involving many variables. In a recent email exchange with a friend and sound engineer, Andrew Ludlam, some basic principles were described clearly and worth understanding, whether we are discussing the ringing of a bell, a blacksmith's anvil, or the vibration of an entire building:

Firstly: when we say 'ring' we really mean resonate. 'Ring' is historically associated with bells, which are made of metal. Resonance is the tendency of a material or System to continue to vibrate at a single or Fundamental frequency when the initial Displacement...has stopped. Think of your car springs without shock absorbers. A guitar string. Feedback at a live gig. A tuning fork (funny shaped bell actually!!) A road bridge in a high storm... Yes, all resonant systems.

So: materials can resonate at low frequencies that we cannot hear but see. Materials that are soft absorb energy and will not self-vibrate. The oil in the shock absorber for instance which dissipates kinetic (moving) energy as heat. Hard metals transmit the energy of the initial shock throughout their crystal structure over time releasing actual physical displacement of their surface area: which causes compression (high air pressure) and rarefaction (low air pressure) which we hear as a single frequency or tone.

Generally hard metals absorb energy the least and so are capable of self resonance...bells, pipes...etc. The frequency of the self resonance is described by the dimensions of the material. Generally larger structures vibrate at lower frequencies. Big Ben Bell...say 80 hertz. Small tuning fork... Concert A: 440 hertz.

The metal structure is stiff. It wants to remain in one physical position. It has a high modulus of elasticity. When elastic materials are displaced from their equilibrium position they will return to starting position; but because the structure has mass it also has momentum and overshoots the starting position and moves in the opposite direction...ad nauseum... setting up a wave... just like the elastic/springy guitar string... and, as mentioned earlier, displaces the air which displaces your eardrum. ${ }^{161}$

160 Satis N. Coleman, Bells: Their History, Legends, Making and Uses (Chicago: Rand McNally and Co., 1928), 60.

161 Andrew Ludlam, e-mail message to author, May 21, 2012. 
Considering the traditional importance of the bell as a social ordering device before the introduction of electronic signals, it is plausible that the production of bell metal was a prime use for Keweenaw copper in its early years of production, but more research needs to be done to posit this with confidence. It is important to momentarily consider the power of the projected sound of a community bell as a predecessor (and at times, a competitor) to the social power of industrial sound, and as mentioned before, this transition delineates an important sonic horizon. Historian Alain Corbin states that "Bells shaped the habitus of a community or, if you will, its culture of the senses. They served to anchor localism, imparting depth to the desire for rootedness and offering the peace of near, well-defined boundaries," 162 and that with the use of bells, "an individual was better able to apprehend the identity of the group to which he belonged. They helped him locate himself in space and time. They audibly proclaimed to him the order of the society within which his life unfolded, and made manifest the power of the constituted authorities." ${ }^{163}$ With its stress upon material evidence, archaeologists can help advance historical knowledge by providing greater accuracy; for it must be stated that bells, in and of themselves, have no power whatsoever. They must be struck. It is the resulting tones produced by bells, the repeatable, recognizable sonifacts that have played such an influential role in human history and prehistory. An example of the protective, or one might say defensive use of the repeated bell tone dates back to the ninth century England - the

162 Alain Corbin, Village Bells: Sound and Meaning in the $19^{\text {th }}$-Century French Countryside (New York: Columbia University Press, 1998) 97.

163 Alain Corbin, "Identity, Bells, and the Nineteenth-Century French Village," in Hearing History, A Reader, ed. Mark M. Smith (Athens: University of Georgia Press, 2004) 200. 
first mention of the "curfew bell" - which was basically a bell rung at dusk to remind people to cover the embers in their hearths in order to reduce the risk of catastrophic fires that might ensue with structures composed mostly of wood and straw. The actual metal cover (also made of copper) had the French name of "couvre-feu" which became "curfew" over time. ${ }^{164}$ A 1903 catalog produced by a bell foundry in Northville, Michigan, "American Bell and Foundry Company," established in 1895, restates the importance of the tone produced by the church bell as a fundamental signal, and as a steel bell foundry, suggests that the lower costs associated with steel bells had a 'democratizing' effect upon accessibility: "Not until steel, as a basis of composition, rivaled copper and tin in the production of bells did the small village church find it possible, except in rare instances, to afford the luxury of this highly essential appurtenance to a completed church. Now, churches in every nook and corner of this broad land have steel to thank for placing within thier reach a bell, strong and beautiful in tone and moderate in cost. The great city churches, too, which spend thousands on church equipment, have come to recognize the superiority of the steel bell, and the saving, in many instances, of hundreds of dollars in their bell equipment alone." 165 Regardless of the respective virtues of steel and bell-metal, this bell catalogue reminds readers that "No other instrument ever devised can take its place. It welcomes the stranger and hastens the tardy. It reminds the careless that they have a duty to perform and the thoughtless that the Sabbath day has come again."166

164 Coleman, Bells: Their History, Legends, Making and Uses, 103.

165 American Bell and Foundry Company: Manufacturers of Church, Chapel, School, Court House, Fire Alarm and Farm Bells. Company catalogue (Northville, Michigan. 1903), 4. 166 Ibid. 
Schafer's bold assertion that "if cannons had been silent, they never would have been used in warfare"167 becomes plausible as one begins to study the highly contested realm of sound production.

\section{Narrative: A Plausible Subjective Experience of Historic Sound}

As previously discussed, the formation of a narrative can serve archaeological investigation by helping researchers enter into a past lived experience. The following narrative is based almost entirely on the subsequent documented evidence- there was very little room allowed for 'artistic license'- but the results, as a piecing together of actual events and accounts, has, it is hoped, formed a plausible moment in time for one solitary individual.

The following is an excerpt from an anonymous journal, found in a desk in a building in Calumet, Michigan, dated April 15, 1916:168

Today I arrived in Houghton after a long journey on the DSS and A railroad. A fellow traveller informed me that these letters, $d-s-s-a$, stand for "Damned slow service and abuse," but I have been too excited about my journey, and also too busy reading to notice any evidence of this or to allow it to intrude upon my experience.

Lately I have been transfixed by a little booklet that was given to me from a friend in Chicago. It is entitled "The Art of Noise," and was written quite recently by Luigi Russolo (in 1914). Now, I am suddenly aware of all of these new sounds of the

167 Schafer, The Tuning of the World, 78.

168 Jeff Benjamin, An Historic Sound Walk: Quincy Hill, Hancock, MI, April 15, 1916. 2013. 
mechanical world - I paid close attention to the rhythmic sound of the train engine as we headed toward Hancock, the bells, the calls of the conductor and other passengers...the squealing of steel on the rails... everything. Is it possible that we human beings have entered a new sonic era? Russolo seems to celebrate all of these new mechanical sounds and seems to consider them a form of music. This is a perspective I have not encountered before, but it is a perspective that I think I can understand.

Upon my arrival at the depot today I committed myself to an experiment, inspired by this little treatise of Russolo. I decided that I would listen intently to all the sounds around me as I encountered them. I am now sitting in my rented room next to a doctor's office in downtown Calumet, and it is evening, I have turned off the electric light and have decided to write these 'memories of sound' under the light of a candle.

At times, I have had to close my eyes in order to force myself to 'truly hear' what was all around me. To really focus on the sounds themselves. As I sat on a bench outside the depot the voices of my fellow passengers gradually dissipated, but there were many languages I could not make out. Could this be Finnish? Another man sounded like he was speaking English but with many words that were unfamiliar to me. He met a friend at the station and as they left they were singing. I could hear the steel wheels of a cable car crossing the bridge that spans the lake. I was told by the conductor that this was my way to Calumet, but I decided to walk for a while. I needed to stretch my legs. 
From several locations around the lake, I could hear the rhythmic pounding and tapping of what I think were pilings being driven into the water for docks. I paused on the bridge and closed my eyes. I could hear this coming from both sides of the bridge, along each waterfront. There is a very active waterfront here, and the trains run on both sides of the water. As I crossed the bridge I could barely make out the sound of waves lapping against the wooden pilings. At one point, far off in the distance I heard a gunshot, I think. The rumbling and exhaust of automobiles, motorcycles and the clopping of horse and buggy crossed busily from both directions. At one point on the bridge I was startled by the deep, long whistle of a steamship docked further north. The sound carries across the water so clearly, I could even hear a group of children laughing as some were swimming near the shore.

After crossing the bridge I had to walk through a fair amount of the town of Hancock until I found the sign: "Road to Calumet." Every now and then, in Hancock, I paused to listen. This place is buzzing with activity. I hear wood being chopped, children playing and laughing, from inside one house I could hear a piano being played-- a beautiful song. Horse and carriage trotted and rolled by and automobiles buzzed away in the distance, one operator blew his horn for what seemed like an eternity, but I could not see what was causing the disturbance. I passed several bars, and inside I could hear men singing and laughing. Outside one bar there was a group of men engaged in an animated conversation, they were gesticulating wildly. A man leaned his head out of the window of a house and called 
down the street in a language I couldn't understand. Croatian? Austrian? A woman was beating a carpet with a stick on the front porch of a house, thump, thump, thump. A baby was crying in another house.

As I walked up the hill on the dirt road, the busy sounds of Hancock receded. I was stopped in my tracks by a deep rumble which shook the ground. Have I arrived here just to get caught up in an earthquake? I still haven't found out what that was. Perhaps it really was an earthquake... A man walking down the hill as I was ascending seemed to be a bit unnerved by it, though. Another horse and buggy slowly overtook me coming up the hill. The driver smiled and said "Huva," but I have no idea what that means. The sound of hooves on the dirt was soft and rhythmic. The hill was largely absent of trees, and there were a few new saplings planted along the road. I could hear their new leaves fluttering gently in the breeze. Downhill-- the chug, whistles and bells of a train. Another deep steamship whistle from the lake seemed to fill the whole valley.

As I continued walking uphill the sounds became polyrhythmic. Cables were stretched taut overhead from one structure to another, and as they moved they created high pitched melodic tones. Up ahead and to my right I could hear the repetitive banging of steel on steel and the hissing of steam or pressurized air. The windows of a red sandstone building were open, and as I walked closer along the street a deep roar flowed out, along with a heavy pounding that I could actually feel in my feet. Now and then I could see workers appear and disappear from view, they were manipulating large pieces of steel. As I stood there I began to think that this 
building would be a paradise for Russolo. The sounds were syncopated, layered, the tap-tap-tap of a chorus of machines and the ringing of steel being struck on anvils. And every now and then, one of the smiths calling out loudly. I moved closer to take it all in, the front arched door was partially open so I leaned against the stone entryway, closed my eyes and listened. I purposefully listened without looking at what was making the sounds, I wanted to think of it as a performance of a musical piece, and if any of them had seen me the performance would have changed! The clinking of steel on steel and loud repetitive tap tap tap, and several machines doing this at once, like a call and response. One machine would make this sound, and then another from another part of the building. Then the long drawn out sound like a chain being pulled over a wheel, steel wheels rolling over steel rails, and creaking wood. Behind all of these sounds I could hear the drone of an electric motor I think, and the deep roar of fires being kept hot with blown air. A voice called out from close by "Berryman!" and I could hear the slam of a wooden door and the metallic ring of a door hasp closing. There were also some houses and even a church across the street. As all of this was going on in the shop I could hear a mother calling for her child to return home. Deep explosive sounds coming from a distance. A dog was barking. And then suddenly, A Bell! The church bell across the street struck three times and shook the air with a deep, low tone. There was another high bell ringing from the same direction, which I decided was the streetcar. As I turned toward the direction of the church I could hear a single melody being played on an organ inside, and as I came closer I could hear a choir singing. Every now and then they would 
pause and a man would speak and sing alone in his own voice. Their music had the syncopated accompaniment of the percussive thumping, ringing, roar, jangling of steel on steel emanating from the shop.

I walked along about a quarter of a mile into a group of houses, until I found the steel rails for a streetcar line. I was simply hoping that the conductor would stop for me. At this point the rhythmic sounds of the steel shop and melodies from the church were in the distance. I was standing close to a house and a man came out on his front porch, his shoes sounded like they had metal studs on them, the clicking sound they made on the porch was interesting. He swayed a squeaking metal lunch bucket and smiled.

I could hear the distant screeching of the streetcar as it approached up the hill. The wires above my head vibrated and hummed. The streetcar bell rang a few peals and it thankfully slowed down for me. Luckily I had the five cents for the trip to Calumet in my pocket. The electric humming and buzzing of the streetcar picked up as it gained speed, and the rolling steel got louder. The car was full of people dressed up as if they were going to an outing, they were chatting happily, except for one man who was speaking abruptly in harsh tones, again, in a foreign tongue. I later learned that there was an amusement park up the hill, called "Electric Park." I managed to find and empty cane seat, and sat down. I closed my eyes once again. The cane seats crinkled and crunched with the passengers' shifting weight as the car rolled up the hill. 


\section{Components of the Quincy Hill Soundscape}

From a broad perspective, the soundscape of the Quincy mine location has heard a long succession of sonifactual changes pertaining to anthrophony, and these anthrophonic changes are directly attributable to mental developments in human beings which, in turn, have manifested themselves in technological developments. To recapitulate Fuller's maxim, the challenge faced by anyone who dares study the history of industrialization is one of complexity and its overwhelmingly comprehensive nature. Whereas the digital age of information manipulation has brought us 'the singularity,' we are still mired in 'the totality' of the mechanized, industrialized world. Industrial sound as an artifactual remnant is difficult to ponder with objective distance because it is still so close. With the possibility in mind that a significant part of the initial magnetic pull towards Keweenaw copper was for the production of sound, we can now begin to consider the ensuing myriad anthrophonic sound forms that accompanied the copper rush of the late 1800 s and early 1900 s. The stillness and serenity described by Forster and Cass was quickly displaced by the activities of a human population in Houghton County that grew from 708 in 1850 to 88,098 in $1910 .{ }^{169}$ The population of the town closest to the Quincy mine location, Hancock, grew from 1772 in 1890 to 8981 in 1910 . While it might be tempting to declare that this kind of growth was accompanied by a corresponding level of "noise," this would oversimplify a very complicated and profound transition of the

169 Thurner, Strangers and Sojourners, 158. 
aural environment. Historical evidence suggests that the anthrophonic texture of the Keweenaw in 1916 was significantly different, in qualitative as well as quantitative terms, from the contemporary soundscape which inhabitants and visitors now experience. It should be noted that as of this time, there is no proven direct relationship between the proliferation of anthrophonic sound-forms and human population, this is simply assumed, however an historical survey of references to environmental sound may prove instructive. Borrowing Schafer's "figure/field" or "soundmark/keynote" conceptual method of approaching soundscapes may be helpful in situating the blacksmith shop proper within a wider aural context. While none of these accounts pertains directly to the location or exact time in question, it is hoped that the accumulation of an assemblage of "earwitness" and newspaper accounts of environmental sound from the first two decades of the twentieth century may serve to help define certain soundmark and keynote sonifacts, such as might have occurred or informed the soundscape of the location in question.

What follows may seem somewhat exhaustive, and one may wonder what is the purpose for including sonic accounts from areas outside the blacksmith shop. This is because, from an archaeological viewpoint, one cannot separate the sound of a choir practice from a steam hammer forging an ore car linkage- if these sounds are simultaneous, as sound often are. The only plausible reconstructed soundscape is one that reflects the complexity of sound as we know it to exist. The simultaneity of everyday sonifacts forms an assemblage, and these sonifacts are contextually related and cannot or should not be separated for the same reason that archaeologists no 
longer 'treasure hunt,' looking for the desired artifacts and disgarding the rest. For the reader, this may also serve to coax individual sonic memories out of hiding, and may help to give the past a more rich, deep texture. As Birdsall has observed "The value of examining sound memories is that they can encompass both individual and group uses of sound for creating a sense of the past." ${ }^{170}$ In his chapter "The Garden in the Machine: Listening to American Industrialization," Mark M. Smith suggests that environmental or pastoral sounds were "braided" with the sounds of industrialization, ${ }^{171}$ employing this metaphor numerous times throughout the essay. This is also reminiscent of Oomen's beautiful poem of past childhood sounds as "strands woven together"(see page 74) from which we may discern meaning. Both of these metaphors tend to suggest a guiding hand, a sense of order or harmony tempting to conjure in hindsight. I will not attempt to add my own metaphor, but will simply state that sound-forms are coincidental, simultaneous, layered and very complex.

A certain amount of skepticism is necessary when approaching local 'aural histories,' which are often compiled as celebratory records of individual communities and tend to neglect aspects of community life that may be less flattering. As one reads them, one begins to notice certain biases: first, they tend to be nostalgic and (as evidenced by the curiously omnipresent and unmistakable 'nostalgic sound poem'

170 Carolyn Birdsall, "Earwitnessing: sound Memories of the Nazi Period," in Sound Souvenirs: Audio Technologies, Memory and Cultural Practices, ed. Karin Bijsterveld and Jose van Dijck (Amsterdam: Amsterdam University Press, 2009) 172.

171 Mark M. Smith, "The Garden in the Machine: Listening to Early American Industrialization," in Trevor Pinch and Karin Bijsterveld, eds. Oxford Handbook of Sound Studies (Oxford: Oxford University Press, 2012) 41. 
phenomenon), and second, references to sound tend to focus overwhelmingly on anthrophony, the accumulation of which might generate an imagined and erroneous human cacophony. For this reason, it is important to reiterate that geophony (and some biophony) has persisted in its pre-historic forms remarkably well throughout time: waves, wind, thunder, rain. These sounds are often removed from historical accounts, and the absence of anthrophony is frequently labeled "silence." An account of a local Keweenaw "hermit" relates a quality uncommon to human beings: "With his 'mountains' in the background, he reflects: 'Not many people can live primitive and in silence - I can.... Gave up reading a long time ago - I'm mostly a listener now."172

\subsection{Silence}

As mentioned earlier in a discussion of the work of Raymond Smilor, the noise abatement component of progressive era reforms were in full swing during 1916, and this fact is represented in newspaper accounts from the time. Intrusive anthrophony was viewed as barbaric and "noise abators in the United States associated silence with 'civilization."'173 Organizations such as the "New York City Society for the Suppression of Unnecessary Noise" were achieving certain reforms, such as the formation of silent areas around schools and hospitals, "and for the reduction of

172 Mac Frimodig. The Copper Harbor Stare. (The Fort Wilkins Natural History Association and Michigan Department of Natural Resources, no date), 4-6.

173 Karin Bijsterveld, "The Diabolical Symphony of the Mechanical Age: Technology and Symbolism of Sound in European and North American Noise Abatement Campaigns, 1900-40." Social Studies of Science 31:1 (2001), 51. 
fireworks, both noisy and unsafe, on the Fourth of July."174

The following excerpt from an article in the Evening Copper Journal on July 5, 1916, shows that the Portage Lake area was likely affected by this reform movement:

\section{FOURTH WAS A VERY QUIET ONE IN HANCOCK}

The Fourth was a very quiet one in Hancock and the day passed without the slightest thing happening to mar the pleasure of those who remained here instead of spending it elsewhere.... While there was very little noise throughout the day there was a goodly number of people in the city and the business places that were open did much better than was expected. ${ }^{175}$

Written only four days earlier in the same newspaper, another interesting story seems to have been directly inspired by the ideas informing progressive era noise-abatement reforms. Written as an impassioned plea or even a plaintive supplication, it is worth quoting in its entirety:

DOING AWAY WITH NOISE: 'Chugless' Locomotive Is Declared to Be More Than a Possibility of the Future.

The seekers after noiselessness will owe much to Hiram P. Maxim if he is able to carry into effect his plan for a 'chugless' locomotive. Future ages are likely to find our era uncivilized largely in this, that 'man's fitful uproar mingling with his toil' was the rule rather than the exception, and that we were as noisy as we were busy. At present a hideous racket seems to be inseparable from our notion of progress. In our insistence upon high-speed living and the conservation of time we demand night labor, yet we conspire to give those who 'have to go to bed by day' no chance to sleep.

The list of needless noises is long and varied, and as the strident clamor increases each new voice must raise itself above the already prevailing pandemonium in order to be heard. Since the wayfaring man no longer startles at an ordinary 'honk,' the motorist must be able to fill the air with the shriek of a demon in agony. Every new building that storms the skies of modern Babylon sets the steam riveters

174 Ibid.

175 No author, (July 5, 1916). "Fourth Was a Very Quiet One in Hancock." Evening Copper Journal, Page . Microfilm Collection, MTU Archives and Copper Country Historical Collections, Michigan Technological University, Michigan. 
hammering like mighty woodpeckers, and the role of Macbeth, who murdered sleep, has a thousand mechanical impersonators every time building work on a grand scale is undertaken anywhere.

Nobody wants to see the hand of progress stayed, especially in this day when a bloody carnival of demolition is in full swing, and millions of men are under orders to tear down all that the ages have upreared. But surely the future years will see to it that this amazing turmoil we make is muted to a comparative whisper in order that the still small voice of the life of the spirit may gain a hearing. ${ }^{176}$

While the affective responses to industrial sound has been mentioned and will be discussed further, this article clearly demonstrates that the noise of industry was certainly not appreciated by all, and the author is not likely to "miss the sounds of the Quincy Mine" (see note 146). This article also reflects the fact that during 1916 most mines on the Keweenaw were operating "full three shifts," and that "more rock was stoped, mined, and hoisted that year than ever before; and more copper milled, smelted, and refined."177

An interesting magazing coming out of Menominee, Michigan: Clover-Land, carried many articles extolling the natural beauty of the Upper Peninsula (which it also endeavored to name "Clover-land"), or "the garden spot of Michigan." ${ }^{178}$ In general, the magazine seems to have a target audience for the more well-to-do or environmentally minded, as well as potential tourists to the area. Several articles present the less populated areas of the peninsula as destinations for escape, echoing a need to achieve respite from the aforementioned 'pandemonium of progress.' In the

176 No author, (July 1, 1916). "Doing Away with Noise." Evening Copper Journal, Page 3. Microfilm Collection, MTU Archives and Copper Country Historical Collections, Michigan Technological University, Michigan.

177 Angus Murdoch, Boom Copper: The Story of the First U.S. Mining Boom (Calumet, Michigan: Roy W. Drier and Louis G. Koepel, 1964) 230.

178 Editorial Statement, Clover-Land Magazine, Menominee, Michigan. April, 1916, p. 16. Vol.1, No.3. 
article "In the Silent Places of Clover-Land's Forests," author Chase S. Osborn concludes with a passage that also suggests that silence (as absence of anthrophony) fulfills a spiritual need: "Brahamanists find their Yogi in the gloom of the Himalayas. Men and women of Michigan and their children whereever they are scattered over the face of the earth, may attain a still more perfect poise and peace of spirit and soul and body along the streams and by the lake shores and in the big woods of their own Fatherland."179

Another article in Clover-Land, republished from the magazine Hunter-TraderTrapper tells of a hunting trip in the Upper Peninsula on November 8, 1915. Relating a moment of solitude in the woods, the author, Herbert Brooks, expresses momentary reverence for "that mysterious communion with the silent forces of nature." ${ }^{180}$ Transfixed by the tall white pines, Brooks imparts upon them a powerful voice, reminiscent of the Anishnaabe tale mentioned at the beginning of this thesis:

Tales of gnomes and fairy folks are told by the whispering branches. The tall straight commanding trunks of these ancient monarchs of the forest breathe to you of their strength and power. They impress you with their splendid health. they impart to you their fellowship. They seem to say to you- come out! Come out! Why do you worry and toil. Give it up! Give it up! Let it go and be free. Come breathe the air which will give you health and strength, and live with us, by so doing, you will gain life and eternal happiness. ${ }^{181}$

Accounts such as this seem to lead to the conclusion that 'silence,' as an absence of anthrophony, seems to be vital human need. The forests that once covered the slope of Quincy hill were gone by 1916, and while it has been asserted that geophonic

179 Ibid, 3.

180 Herbert Brooks, "A November Outing in the Forests of Clover-Land," in Clover-Land, December, 1916, p. 13. Microfilm Collection, MTU Archives and CCHC, MTU, Michigan. 181 Ibid. 
sound-forms are enduring through time, the sound of the "whispering branches" of an old growth white pine forest is now gone and certainly different from the wind blowing through a second or third growth stand of spruce, birch and aspen.

\subsection{Biophony}

The cover of Clover-Land Magazine from July 16, 1916 is a photograph of two elegantly poised dancers in stylized Native-American costumes on a grassy field. The figure in the foreground is standing and reaching skyward, dressed in an all white dress with a white head band. The figure in the background is dressed in a darker costume with beads dangling, kneeling with clasped hands as in prayer or supplication. The caption of the photograph reads: "'Song of the Robin' Dance, a Feature of Escanaba's Wonderful 1916 Pageant." ${ }^{182}$ Although this is not an explicit account of biophony, it does demonstrate an awareness and appreciation of the importance of bird song during this time. Also, a newspaper column written by Mary Graham Bonner called "Daddy's Evening Fairy Tale" tells the story of a family of robins who sing to impress a group of "Faeries:" "'I am not surprised they had a concert,' said Nancy, 'as I'm sure I've heard them practicing for it on the mornings when I've been awake very early."'183

182 Front Cover, Clover-Land Magazine, Menominee, Michigan, Vol. 2, No. 3, July 1916. Microfilm Collection, MTU Archives and CCHC, MTU, Michigan.

183 Mary Graham Bonner, (May 20, 1916)."Robins' Spring Concert," in "Daddy's Evening Fairy Tale." 
The wilderness as a place of sonic enchantment also carried the potential for fear as day gave way to night. In a story coming from Pelkie in the early 1900 s, the narrator relates the experience of children on their way home from a day's excursion: "Hoping to ride the train back home if it was dark, they would often find the train gone. Hurrying home, they would hear the occasional hoot of an owl 'Who are you? Y-OU!' The occasional screech which followed only added to their fears of encountering wolves." ${ }^{184}$ While this experience of walking as a child through the evening woods and taking fright by the sounds of nocturnal life is likely to be familiar to most, other accounts describe sounds that are far more obscure, such as the sound of body lice popping when a lumberjack's clothes were laid on the hot rocks of a sauna. ${ }^{185}$

The sounds of domesticated animals was likely prevalent, as numerous photographs from the time show that many people had dogs as pets, and roads carried a combination of foot traffic, horse and buggy, automobile and trolley. Although horse racing had ended by $1913,{ }^{186}$ the following account of a race describes a sonic encounter between animal and machine:

It seems that 'Hicky' Ethier's horse named 'Copper Bill' was a very speedy animal; however, he was also very temperamental. He was unable to keep a steady trot when he heard the sounds of the puffing of a railroad engine.... It seems that from the time the race started until it ended, a Mineral Range steam engine was running down its track, keeping pace with the horses, puffing and snorting and clanging its bell. The horse Copper Bill could not hold his gait, and it was soon

Evening Copper Journal, Page 6. Microfilm Collection, MTU Archives and CCHC, MTU, Michigan.

184 Sturgeon Valley Historical Society, Inc., Pioneering in Pelkie (Pelkie, Michigan: Sturgeon Valley Historical Society, 1985), 4.

185 Hazel Froberg, ed., Trestles and Tracks: A Study of Keweenaw Bay and Arnheim (L'Anse, Michigan: Keweenaw Bay and Arnheim Extension Study Group, 1983), 16.

186 Clarence J. Monette, Hancock, Michigan Remembered (Lake Linden, Michigan: Self-published, 1982), 101. 
known that it was a clinch for Dom Pedro. Hicky charged that Crowley had bribed the engineer of the steam engine. ${ }^{187}$

While some species benefit from human presence (such as lice) it can be safely hypothesized that human intrusion into the Keweenaw led to species depletion, and hence a reduction of biophony. As demonstrated by the pages of this thesis, human beings tend to be fascinated by themselves, and earwitness accounts of the soundscape often ignore the sounds of other species and emphasize the sounds made by people. Bernard Krause has provided an invaluable service in this regard by making thousands of hours of recordings of biophony that no longer exists since he began some forty years ago.

\subsection{Speech: Word as Sonifact}

Before the era of electronic signal, airborne sound was the only form of sonic transmission, through the compression and rarefaction of air molecules. While this may seem strange to a contemporary individuals accustomed to a myriad forms of electronic communication, in rural locations the social need to reach out to others meant that people were forced to walk long distances to do so. Several accounts recall the sight of lanterns swinging in the distance as a neighbor would approach, and people learned to know who was coming by the distinctive motion of the swinging light. Another observation by Forster, as related by Arthur Thurner, of the early days of Hancock and Houghton suggests that speech was of prime importance

187 Clarence J. Monette, Hancock, Michigan Remembered , 101. 
through the "long, dark, dreary winter evenings of that north land, dancing and card playing were the only recreations," with folks coming from miles about to Hancock and Houghton, wading through snow drifts and intense cold "for the sake of society." 188 Speech and vocalization was a primary form of communication during the Keweenaw mining expansion, and led directly to the generation of 'hype' or 'buzz' among miners regarding specific locations, and this exchange frequently took place at bars. Although pertaining to the rush for silver in the late 1800 's, the following account effectively dramatizes such an event:

Over a drink at the Bigelow House bar, they would tell you that a man shot a hog and that the threshing about of the expiring animal exposed a mineral lode the like of which was never known before. Or, with your "bending an elbow," you would be permitted a fleeting glimpse of a rock specimen out of a coat pocket and hear a terrifically convincing monologue in the mining jargon of mines to be developed "where that came from," richer than those of Ormus or of Ind. There was a fascination in the mysticism of the terms of the jargon. You could work yourself into a trance-like spell by merely uttering the sound of enough of them. ${ }^{189}$

Douglass Houghton must have been well aware of the power of word of mouth and gossip when he prophesied that his observations of the region's mineral wealth would trigger a flood of prospectors and the inevitable "ruin of hundreds." ${ }^{190}$ In 1846 , Forster also observed a manic frenzy regarding the copper rush in Sault Ste. Marie, generated by rumor and hearsay: "On streets, in barrooms and reading rooms everywhere men congregated - they jabbered about copper.... creating a 'perfect

188 Thurner, Strangers and Sojourners: A History of Michigan's Keweenaw Peninsula, 79.

189 James K. Jamison, This Ontonogan Country: The Story of an American Frontier (Ontonogan, MI: Ontonogan Herald Company), 213.

190 Thurner, 39. 
whirlwind of excitement."' 191 Interestingly, in certain workplace situations such as the dining halls of logging camps, silence was imposed as "some dining tables forbade talk." ${ }^{192}$

Another very different kind of vocalization seems all but missing now from the contemporary soundscape - the 'call' of parents retrieving their children home. Referring to the Perrow area near Pelkie in the early 1900s Otto Erikainen relates a childhood memory of searching for cows: "Mother usually called when darkness came if we weren't home, but we didn't hear her this night. There were big virgin maple trees and tall ferns. We had found the sandy path when all of a sudden our dog began to bark fiercely and backed tightly against us. She kept on barking and growling for a while and then relieved her pressure on us and quit barking. We went back along the same path in the morning to again look for the rest of the cows and saw bear tracks." ${ }^{193}$ Although probably more akin to bells than vocalization, another story of the hazard incurred by searching for cows comes from Anna Broemer, relating an event near Green, Michigan in April, 1905: "Some years later, Matt was able to return the favor when Jonas Ruuttila got lost when searching for his cows. The family became alarmed as it was getting dark and asked the Store family for help. Matt climbed on the roof of their house and banged on some iron pipe, which Mr. Ruuttila heard, and was able to find his way home." ${ }^{194}$

191 Ibid, 46.

192 Thurner, 160.

193 Sturgeon Valley Historical Society, Pioneering in Pelkie (Pelkie, Michigan: Sturgeon Valley Historical Society, 1985), 39.

194 Ontonogan Herald Company, Pioneers of Green: A Collection of Contributed Historical Data (Ontonogan: Ontonogan Herald Company, 1976), 17. 
Known as a "hearing" for a reason, town meetings were often centers of boisterous speech. A meeting in South Range regarding the town's incorporation "was one of the most spirited meetings that had ever been held there and the decision was unanimous.... For a time discussions were in order, and the speaker's stand was kept in use by enthusiastic citizens who seemed to take delight in making their opinion known on the subject." ${ }^{195}$ As we think of the spoken words of the past, however, it would be erroneous to extrapolate from present day speech patterns to understand the spoken soundscape. Some attempts to phoneticize the distinctive dialect of Cornish settlers is illuminating in this regard and highlights the dramatically unique sonic reality of Keweenaw mining communities that were comprised of diverse immigrant groups. ${ }^{196}$ Although perhaps presented in exaggerated form, a newspaper cartoon related the particular speech of two Cornish miners:

Arry: 'Eow are ee gittin hon, Tommy?'

Tommy: 'some slight, yeow, sure nuff, Arry.'

Arry: 'Eow's that , 'en?'

Tommy: 'Wy, hi was goin' hup the stope, yeow, an'hi put me foot 'pon the plank, an' the plank wadden there, an' deown goes hi, plank an' all!'

Arry: 'ee's a wonder to me you wadden killed.'197

In support of this, the unique language of the Cornish is related in an account from

Copper Harbor:

Some mining communities were almost entirely Cornish, and old

195 Clarence J. Monette, Early South Range, Volume One (Lake Linden, MI: Self-published, 1995) 6.

196 Thurner lists immigration from "Cornwall and parts of England, Scotland, and Wales. Other were Germans, Austrians, Belgians, Bohemians, Bulgarians, Croatians, Danes, Dutch, Finns, French, Greeks, Hungarians, Irish, Italians, Lithuanians, Norwegians, Poles, Rumanians, Russians, Slovaks, Slovenians, Swedes, and Swiss. Still other emigrants were Armenians, Turks, Syrians, Chinese, Japanese, and Austrialians..." (Thurner, 131).

197 Arthur W. Thurner, Calumet Copper and People: History of a Michigan Mining Community. 1864-1970 (Hancock, Michigan: Self published, 1974), 38. 
country expressions and words lingered to such an extent that a native American almost needed an interpreter to communicate with the townfolk. A mine was a bal and it had a hore body that must be got hout of the ground. Personal pronouns were applied to inanimate subjects and a shovel or pick was always an 'e. An old Cornish story says, We call all things 'e 'cept ol' Tom Cat and we calls she 'er. ${ }^{198}$

In his book The People of Michigan, George P. Graff also notes the importance of the Cornish presence in the mining districts, stating that Cornish speech has had an enduring impact on the area:

Common Cornish words still used freely in the Upper Peninsula include: 'lode,' a vein of ore; 'vug,' a cavity; 'stope,' the chamber of excavation in which mining is being carried on; 'a brave keenly lode,' a fine load of ore; and 'deads,' wasted rock....if you stand on the hill above Hancock on a cold January night, you might still hear (at least in memory)... far off in the distance... the singing of Michigan's Cousin Jacks as they head for another night's work at the 'Old Reliable Mine. ${ }^{199}$

Taking the unique and distinctive examples of Cornish speech as only one example of the numerous languages spoken in the Keweenaw during early mining operations, one begins to piece together a verbal soundscape of great richness and diversity.

The difficulty in immediately discerning the origin of a particular sound is a topic that could be addressed at length, having been used over the ages as a tool of deception in warfare as well as hunting. As this pertains to verbalization, one account from Green, Michigan (near Ontonagan) during prohibition is rather amusing, as related by Edna E. Niska. When a local drinking hangout was paid an unexpected visit by a deputy, the owner of the speakeasy made a very clever move:

Afraid of getting arrested for selling whiskey, the owner started

198 Frimodig, The Copper Harbor Stare, 26.

199 George P. Graff, The People of Michigan. Second Edition, revised. Bicentennial Publication (Lansing: Michigan Department of Education. State Library Services, 1974) 37. 
moving towards and entered another room. Once there he began making odd noises and loud arguing that sounded like a fight was about to take place. The deputy couldn't help but hear it and rushed in the other room right away. As soon as the deputy had gone, one of the card players emptied the whiskey bottle in a sink. Some moments later the owner and deputy came back and as the evidence was gonenobody was arrested. ${ }^{200}$

A notoriously tragic result of the use of disruptive language is the (still debated) event of the Italian Hall tragedy in Calumet on December 24, 1913, where "One shouting fiendish word, "Fire," brought the party to a tragic end."201

In his analysis of the spoken soundscape of early America, Rath examines the development of characterizations of speech that are still considered outside the boundaries of civil discourse. ${ }^{202}$ Murmur, clamour and rant are all aspects of this phenomenon, with 'clamour' in particular being defined as "unwelcome critiques." 203 Written in a cautionary tone, a small story in the Evening Copper Journal entitled "Makes complaint for street car disturbance" provides an illustration of this kind of speech and its legal response:

On complaint of Harry Matthews, assistant superintendent of the Houghton County Traction company, Ulrich Garon, had a hearing before Justice William Fisher Saturday evening, the charge against him being noise and disturbance and using obscent (sic) language in the presence of women and children. The policy of the company is to protect their conductors in such cases and more especially to safeguard women and children who patronize the line and every case will be prosecuted in the future to the extent of the law. ${ }^{204}$

200 Ontonogan Herald Company, Pioneers of Green: A Collection of Contributed Historical Data (Ontonogan Herald Co., 1976) 55.

201 Wilbert B. Maki, Hancock: A Mosaic of Memories (Calumet, Michigan: Greenlee Printing Company, 1984) 49.

202 Rath, How Early America Sounded, 121.

203 Ibid.

204 No author, (April 24, 1916). "Makes Complaint for Street Car Disturbance." Evening Copper Journal. Page 7. Microfilm Collection, MTU Archives and Copper Country Historical Collections, Michigan Technological University, Michigan. 
A boisterous and oddly legal custom from the time which is also probably not highly missed was the "shivaree," a noisy racket inflicted upon recently married couples which could only be silenced by payment in the form of drink:

When newlyweds retired for the night, large groups of people, young, old, even children gathered near the house where the newlyweds would be sleeping. Each one carried a noisemaker-- pots, pans, dishpans, cowbells, horns, etc. When it was assumed that the couple was comfortably settled in bed, a signal was given and that was followed with a loud blast of noise as each one tried to outdo the other with his noisemaker. This was accompanied by hoots, whistles and catcalls. The noise could be heard for miles....Sometimes the shivaree went on for three weeks. ${ }^{205}$

An interesting aspect of speech is how it can be evoked in the imagination by the sight of the printed word. In contemporary e-mail communication, writing a portion of a message in all capital letters is considered to be tantamount to 'yelling,' and is discouraged except in cases where this emphasis is justified. Rath also discusses the remarkable power of the printed word to evoke sound, and this is demonstrated by newspaper articles and advertising even up to the present day. An advertisement for fertilizer from The M. Van Orden Company in Houghton placed in the Calumet News on April 21, 1916 begins with the word "HIST!" set in all capitals, bold, and in a far larger font than all surrounding words on the page. The advertisement continues: "Your garden's calling you and so is your lawn." ${ }^{206}$ Interestingly, during this time the 'call of the garden' competed with 'the call of war' upon the printed page of the local

205 Sturgeon Valley Historical Society, Inc., Pioneering in Pelkie (Pelkie, Michigan: Sturgeon Valley Historical Society, 1985) 114.

206 The M. Van Orden Company, (April 21, 1916) Advertisement. The Calumet News, Page 4. Microfilm Collection, MTU Archives and Copper Country Historical Collections, Michigan Technological University, Michigan. 
newspapers in the Keweenaw. An alarming front page cartoon entitled "The West Is Calling" depicts a soldier standing in a wheatfield holding a megaphone with the inscription "West." From the megaphone the repeated call "Help!! Help!! Help!!" emerges, written in increasing large, bold letters. ${ }^{207}$

\subsection{Sounds of War}

Because of the power of the printed word in newspapers, the soundscape of the Keweenaw during 1916 was also imbued- as was the rest of the country- with the aural subtext of war. Sounds of World War One, though fortunately not experienced on American soil, were introduced into the home through news reporting that paid particular attention to the songs and sounds of battle. On Sunday, December 6, The Daily Mining Gazette reported that "The British soldiers' repertoire of marching songs includes two hymns which share top-notch popularity with the 'Marseillaise' and 'Tipperary.' They are 'Onward Christian Soldiers' and 'Oh Come all Ye Faithful.' The one thing which the soldier at the front demands in a song is marching rhythm." ${ }^{208}$ Another article relates the now famous momentary truce when English and German soldiers stopped firing on Christmas Eve and sang Christmas carols

207 Magnus Kettner, (July 6, 1916). "The West Is Calling." Evening Copper Journal. Page 1. Microfilm Collection, MTU Archives and Copper Country Historical Collections, Michigan Technological University, Michigan.

208 No author, (Dec. 6, 1914). "Army Sings Hymns on March." Daily Mining Gazette. Page 5. Microfilm Collection, MTU Archives and Copper Country Historical Collections, Michigan Technological University, Michigan. 
together:

The Englishmen go out their hymn books, with which most of the soldiers are provided, and sang Lead Kindly Light, Abide With Me, and While Shepherds Watched Their Flocks by Night....

Gradually a few of the groups from the two sides drifted closer together. Everybody was unarmed. One of the foremost German groups waved a bottle of wine toward the nearest English groups.... The men shook hands all around, and immediately cheers and clapping came from both sides of the field, where English and Germans alike had been anxiously watching this meeting....All the time in the distance could be heard the sound of artillery fighting. ${ }^{209}$

The sonic introduction of large guns and bombs was an unprecedented change in anthrophonic sound- forms as well as the overall soundscape of the world. This was noticed at the time, and reported in the Evening Copper Journal:

\section{CANNONADE AT YPRES HEARD IN LONDON}

London, July 12- The sound of the big guns at Ypres has been heard on rare occasions in various parts of London, ooccasionally (sic) at a point in Essex county, 150 miles away and repeatedly at points in the country 125 miles from the scene of the firing, according to Miller Christy, a widely known member of the Royal Meteorological society. The speaker said that windows in the Temple, a huge building of law offices almost in the heart of the city, were rattled violently many times by the Ypres guns.

Lloyd George, minister of munitions, and Sir A. Conan Dooyle (sic), the speaker added, were among those who heard the sounds. ${ }^{210}$

Another report from Germany underlined the capacity of the sound of warfare to

travel long distances:

\section{ROAR OF GUNS HEARD 340 MILES}

209 Associated Press, (Jan. 15, 1915). "Holiday Cheer in the Trenches: German and British Soldiers Participate in Christmas Festivities." Evening Copper Journal. Page 1. Microfilm Collection, MTU Archives and Copper Country Historical Collections, Michigan Technological University, Michigan. 210 No author, (July 13, 1916). "Cannonade at Ypres Heard in London." Evening Copper Journal. Page 1. Microfilm Collection, MTU Archives and Copper Country Historical Collections, Michigan Technological University, Michigan. 
Berlin, July 14- Herr Wilhelm, director of the Holstein 'Weather and Sun Observatory' at Schnelsen, writes to the Lokal-Anzelger that the roar of the guns in the battle of Jutland was plainly heard by his two adult daughters at Schnelsen, which is 340 miles from the scene of the fight. The young women claim to have heard plainly ten individual salvos about 6 p.m. on May 31 at intervals of five to ten seconds.

Herr Krobs reports that the rumble of artillery fire at Verdun has been heard at Ziegenbain (in Hesse-Nassau) which is 211 miles from the battlefield. In both cases, he explains, favoring winds facilitated the extraordinary long transmission of sound. ${ }^{211}$

This singular development, the capacity for anthrophony to rival and even surpass biophony and geophony in intensity, was not lost upon contemporary listeners to the soundscape. To extend Schafer's figure/field analogy, these accounts of the guns also suggest a level of surrounding quiet where they were heard, allowing for the sounds of the guns to be perceived. Perhaps the steady state drone of the internal combustion engine had not yet reached its current level of omnipresence. The significance of these accounts to the Keweenaw reader is to suggest that sounds of war were not that far away. Since reading about a sound can evoke that sound in the imagination, such accounts brought the trauma of World War One (the very war which brought us the term 'shell-shock') closer to home. Even for a contemporary reader with a nearcentury of temporal distance, if they have experienced bombings, such accounts may reawaken such trauma, where Birdsall notes, "the past 'spills' into the present:"

While the sounds associated with bombings, such as sirens, were referred to as memories located in the past, the actual event of the bombing was acted out as occurring in the present. The vivid sensations of traumatic memory offer a stark contrast to the common understanding of memory diminishing with time. Indeed, the basis for

211 No author, (July 11, 1916). "Roar of Guns Heard 340 Miles." Evening Copper Journal, Page 1. Microfilm Collection, MTU Archives and Copper Country Historical Collections, Michigan Technological University, Michigan. 
discussing 'sound memories' is challenged when traumatic sounds are encountered as part of the present....reencounters with traumatizing sounds can disrupt past and present distinctions, and test the efficacy of language for describing the auditory and sensory inscriptions of a traumatic event. ${ }^{212}$

Judging by the vehement response to industrial sound expressed by some noise abators, it was not only the sound of guns that was traumatic to some early twentieth century listeners. Nor does a sonic memory need to be traumatic to bring a past moment into the present; the memory of a gentle whisper can do the same. A single note on a piano, the song of a cricket. This is because, as argued earlier, such sounds are artifactual; real, physical objects that have endured through time, and which may reemerge at any moment. The contemplation of sound as artifact, or sonifact, is to grant sound a conditional reprieve from the confines of time.

\subsection{Song}

As evidenced by numerous accounts, music and song was an integral component of the soundscape of Quincy Hill during the early 1900s. Most mining communities had a town band, and there were also community choirs ${ }^{213}$ such as the Portage Lake Glee Club, which was in existence in $1914 .{ }^{214}$ There were also bands for organizations such as the Salvation Army. ${ }^{215}$ On July 17, 1916, The Sunday Mining Gazette assured readers of a "Rare Musical Treat" to take place on the south side of the bridge

212 Carolyn Birdsall, Earwitnessing: Sound Memories of the Nazi Period, 178.

213 No author, (December 2, 1914) "Carol Singers Will Organize Choruses." Daily Mining Gazette, Page 7. Microfilm Collection, MTU Archives and CCHC, MTU, Michigan.

214 Arthur Thurner, Strangers and Sojourners, 183.

215 Clarence J. Monette, Early Red Jacket and Calumet in Pictures (Lake Linden, Michigan: Self published, 1988), 10. 
spanning Portage Lake, with the arrival of a cornet soloist from John P. Sousa's band in combination with the Calumet and Hecla Band, promising to be "one of the biggest musical offerings the community has ever had the good fortune to enjoy." 216 In Electric Park, midway between Calumet and Hancock, "amid birch and poplar trees" one could hear "ten and twelve piece orchestras playing for dances." ${ }^{217}$ Another musical event organized two years earlier in Houghton was predicted to be a choir of "1,800 and probably 2,000 children from the public and parochial schools who will join in singing 'Silent Night! Holy Night!' under the direction of Miss Warmington." ${ }^{218}$ The habit of singing and reading out loud is evidenced by the daily inclusion of a "Jests and Jingles" column in the Evening Copper Journal, which incorporated poems, jokes and songs.

Apparently, song was incorporated into elementary school curriculum, as related by Bertha Ruutila Kekke remembering a teacher in Green, Michigan in the early nineteen hundreds: "Some of those songs she taught us, I've never forgotten, but have never seen in print. Such as 'Beautiful May With Notes So Gay' and 'Come Down In The Meadow' were so fitting for the beautiful spring days in the country. The trips for wild flowers were unforgettable experiences...." 219

Churches provided a forum for song and music making, and was seen as a form of recreation for many miners. In reference to Cornish miners, George P. Graff recounts:

216 No author (July 16, 1916) "Portage Lake Assured a Rare Musical Treat." Sunday Mining Gazette, Page 8. Microfilm Collection, MTU Archives and CCHC, MTU, Michigan.

217 Thurner, 186.

218 No author (December 19, 1914) "Children and Elders Join in Christmas Song." Daily Mining Gazette, Page 6. Microfilm Collection, MTU Archives and CCHC, MTU, Michigan.

219 Bertha Ruutila Kekke, "Recollection of Early School Days," in Pioneers of Green: A Collection of Contributed Historical Data (Ontonogan: Ontonogan Herald Co., 1976), 39. 
"Every Sunday morning and evening their deep, rich voices could be heard singing hymns brought over from England. All laymen took their turn at preaching the sermon and it is said that 'many a wooden pulpit has rung with the sound of Cornish boots."'220 The sound of organ playing was also in the air. In Laurium, Michigan's Early Days, Clarence Monette recalls St. Paul's church and "the organ music and singing that came from the open windows of that church. The Reverend Frank Schulz was often the organist, and while practicing, would provide the neighborhood with a beautiful organ concert. We would sit on our front steps and listen to him play."221

While the songs of groups of people singing and playing musical instruments was an integral part of the soundscape, so too was the individual musician within the home, playing the piano. There are numerous newspaper advertisements for pianos, most from "Hermann Bros. Co." in Calumet. ${ }^{222}$ Thurner relates: "As a young girl, Alma W. Swinton took the train from Ontonagan to Calumet at the turn of the century to study piano.... Hundreds of Copper Country girls and boys studied piano and played 'pieces' by Schubert, Grieg, Beethoven, and Mozart."223

\section{6 "Just Like the Fourth of July Every Day"}

In the early nineteen hundreds, a notable new sound was introduced to the

220 George P. Graff, The People of Michigan (Lansing: Michigan Department of Education. State Library Services, 1974), 37.

221 Clarence J. Monette, Laurium, Michigan's Early Days (Laurium, Michigan: Self-published, 1986), 60.

222 (No author), April 24, 1916. Advertisement. Evening Copper Journal, Page 9. Microfilm Collection, MTU Archives and CCHC, MTU, Michigan.

223 Thurner, Strangers and Sojourners, 184. 
Keweenaw because of Quincy Mining Company practices: the air blast. Decades of inadequate supporting structures in the shafts underground led to a situation where large sections of the mine began to collapse, compressing the displaced air and creating a deep and powerful rumble that could be heard and felt above ground. ${ }^{224}$ This phenomenon, which could be classified as "anthrogeophonic," as a resulting sonifact of combined human and geological agency, had its only aural equivalent in earthquakes. An account of "The Calumet Earthquake of 1905" recounts an initial confusion over whether the rumbling and vibration of this quake occurring on July 26 was an air blast (an all-too-regular occurence at this point) or earthquake. ${ }^{225}$ Since it was felt through much of the Upper Peninsula, the general concensus is that it was an earthquake, not an air blast (while some suggest that it was a combination of both) but the uncertainty itself is quite instructive: for the first time in the history of the Keweenaw, the activities of human beings had introduced a sound and vibration that was capable of approaching the quality and force of an earthquake. On May 16, 1916, The Evening Copper Journal reported "the most severe air blast that has occurred in the Calumet district in several years...being so severe that hundreds of people were awakened."226 One account characterized air blasts as "artificial earthquakes"227 and likened them to the contemporary sound of a "'sonic boom' from a high flying plane out of Marquette." ${ }^{228}$ Noting that there was one hundred miles of 224 Lankton, Hollowed Ground, 125.

225 No author, "The Calumet Earthquake of 1905," Copper Country Vertical File: Earthquakes. MTU Archives and Copper Country Historical Collections, Michigan Technological University, Michigan.

226 No author, (May 16, 1916), "Air Blast Shocks Calumet District." Evening Copper Journal, Page 5. Microfilm Collection, MTU Archives and CCHC, MTU, Michigan.

227 Wilbert B. Maki, Hancock: A Mosaic of Memories, 60.

228 Ibid, 62. 
tunnels under Calumet by 1916, Thurner writes: "Underground blasting or the settling of a mass of ground in a long-abandoned mining area could cause windows to shake violently." 229

Other explosive sounds filled the air, as well. One account states that during the summer blasting stumps out of farmland was a common occurence: "Many carloads of dynamite were used....The whole summer was a constant blasting- just like the Fourth of July every day." 230 The use of explosives was not confined to rural areas alone. An interesting article in The Daily Mining Gazette tells the story of a resident of Laurium, John Leppala, who allegedly "set off some dynamite on his property near enough to the home of a neighbor to frighten the inmates of the neighbor's house....The charge of drunkenness has not been answered. The charge of setting off dynamite promiscuously is one to be decided upon by the court and it is likely to prove rather interesting to show whether or not a man can dynamite his own property, even in the vicinity of the home of a neighbor, particularly if he can show reason for using the dynamite." 231

\subsection{Sounds of the Mines}

Of course, when thinking of the Keweenaw soundscape, the sounds of the mining operations themselves cannot be ignored. On the first page of his survey of the area,

229 Arthur Thurner, Calumet Copper and People: History of a Michigan Mining Community, 40.

230 Sturgeon Valley Historical Society, Pioneering in Pelkie, 15.

231 No author, (December 5, 1914). "Use of Dynamite Gets Highway Man to Court." Daily Mining Gazette, Page 6. Microfilm Collection, MTU Archives and CCHC, MTU, Michigan. 
The Copper Mines of Lake Superior, T.A. Rickard points out "a single stamp that crushes 700 tons of ore per diem has a thunderous way of proclaiming its importance." ${ }^{132} \mathrm{~A}$ recollection of the stamp mill at Mass Mining Company in Keweenaw Bay conveys a similar power: "The thump of the crushing was so hard, the railroad station across the tracks trembled and the tremor could be felt on the street in Keweenaw Bay."233

While this thesis is most interested in sounds above ground-level, accounts of the underground sounds within the mines, in "the drifts once echoing with drills and hobnail boots, ${ }^{1234}$ are also worth mentioning since they were a vital part of the aural experience of the miners. It should be noted that in a painstaking (and painful) search through over 700 medical records (all of those available) of miners at the Quincy Mine, only three cases make reference to hearing loss. This supports R. Murray Schaefer's observation that "The inability to recognize noise during the early phases of the Industrial Revolution as a factor contributing to the multiplicatory toxicity of the new working environments is one of the strangest facts in the history of aural perception." ${ }^{235}$ Moreover, two of these three accounts of hearing loss are associated with external injuries, leading one to assume that if a miner was not visibly wounded, they were not considered injured. On October 13, 1913, Andrew Wessels reported by letter the condition of a miner, Swante Maki, to the chief physician of Quincy Mining Company, Arthur F. Fischer. Wessels used a tuning fork to determine

232 T.A. Rickard, The Copper Mines of Lake Superior (New York: Engineering and Mining Journal, 1905), i.

233 Hazel Froberg, ed., Trestles and Tracks: A Study of Keweenaw Bay and Arnheim, 20.

234 Wilbert B. Maki, Hancock: A Mosaic of Memories, 74.

235 Shaefer, The Tuning of the World, 76. 
that the miner's right ear "shows a reduction of all the tones and giving 20/90 when normal is $90 / 90$ watch at 8 inches. I see no reason why hearing should be reduced as much as it is in the right ear....The left ear is no longer a very useful ear and hearing will never be very much improved although the injury was external to the nerve..." 236 The initial "Surgeon's First Report" form filled out by Fischer states that the twentytwo year old Maki's injury was sustained in an air blast, causing "Compound fract (sic) thigh/ Injury upper joint/ Fracture base skull (?)"237

In a letter directly to the director of the mine, Charles Lawton, on August 7, 1917,

Dr. Dean E. Godwin of Houghton reports his examination of Mr. Hedley Wills:

\section{Dear Sir,}

At the request of your office, I have today examined Mr. Hedley Wills.

He has a deafness of Middle Ear type that is gradually growing worse and is not likely to be benifited (sic) by treatment. The hearing in his right ear is $1 / 40$ normal, and in his left ear is $1 / 80$ normal, that is, sounds that a normal ear should hear at twenty feet he cannot distinguish beyond six inches with his right and beyond three inches with his left ear.

I should not consider a man with this amount of hearing suitable for any position in which the safety of himself or others depends on his hearing of signals.

Very truly yours,

D.E. Godwin ${ }^{238}$

Bells were used as signals underground in all of the mines in the area and a chart from the Calumet and Hecla mine indicates that bells signals were crucial for survival underground. Of the three medical reports mentioning hearing loss, this is

236 Maki, Swante. Medical record. Quincy Copper Mining Company Collection., Box 001, File 300. MTU Archives and CCHC, MTU, Michigan. 237 Ibid.

238 Wills, Hedley. Medical record. Quincy Copper Mining Company Collection, Box 351, Folder 017. MTU Archives and CCHC, MTU, Michigan. 
the only one that does not associate it with an external injury, perhaps drawing the attention of Lawton.

In another letter addressed to Dr. Fischer from February $18^{\text {th }}, 1920$, a particularly distressed miner, Rudolph Adolphson, pleads for help, after sustaining a severely fractured jaw:

I went (to work) on the night of the $16^{\text {th }}$ although I knew that I was not fit, in decending (sic) I had fearful pain in the ears, it was just as if a steel rod had been thrust through from one ear to the other.... got up and started the drilling machine, the noise of the machine effected my ears to such an extent that I had to stop the machine, my heart began beating violently again...

I am requesting that you would examine my ears thoroughly. I syringed my ears this morning with the medicine you gave me. After syringing out of both ears came black clotted blood; second I wish you would examine my heart.... am in need of work in the open air, some light work and that way try to regain my strenght (sic). My nerves are bad and I have bad dreams at night... ${ }^{239}$

Adequate hearing was crucial for survival underground, but this is a fundamental contradiction for any industrial worker. Wearing hearing protection will save ears, but it also may cost lives. At the beginning of shifts, miners would examine the walls and ceiling of the drifts and shafts "striking and sounding it with an iron bar or other metal tool. A dull thud indicated unstable rock, and miners immediately barred it down or propped it up."240 There are several tragic accounts of miners who lost their lives, or caused the demise of others, because they did not hear the audible warnings of bells or shifting rock, or interpreted them incorrectly.

The aural shock incurred by only a momentary visit underground gives an idea of

239 Adolphson, Rudolph. Medical record. Quincy Copper Mining Company Collection, Box 002, File 552. MTU Archives and CCHC, MTU, Michigan.

240 Clarence J. Monette, Trimountain and Its Copper Mines (Lake Linden: Self published, 1991), 85. 
the sound level endured by miners, day after day. In a tour of White Pine mine in 1916, Mrs. Clarke Fulkerson relates the sound of "Fred Donaldson at work drilling with a black diamond drill (noise nearly deafened us)."241

Perhaps already aware that there might be a market in the Keweenaw Peninsula, the manufacturer of an elixir of dubious usefulness placed an advertisement in The Daily Mining Gazette on December 5, 1914, with the headline "Deafness Cannot Be Cured." The ad goes on to boast: "We will give you One Hundred Dollars for any case of Deafness...that cannot be cured by Hall's Catarrh Cure." 242

\subsection{Comfort and Nostalgia}

In historical accounts of industrial locales, sound is often mentioned to add 'ambiance', to provide a background, setting or dramatic embellishment. Many of these accounts also attest to the calming or reassuring effects of industrial sound. Describing a mining district in Cornwall, England, an earwitness to this particular industrial soundscape clearly demonstrates this:

All night long, in these valleys, the ear is greeted with the merry rattle of the iron lifters or the more serious thug-thug of the older wooden stamps, as they work on unattended through the hours of darkness. Such is the 'music of the stamps,' once so well known to almost every Cornishman that, on leaving home, many of them lay awake at night, missing this rhythmic accompaniment to their slumber, and of such I have heard men say: 'when the stamps stopped we felt as if we had

241 Fulkerson, Mrs. Clarke, "1916 Diary: Notes by Mrs. Clarke Fulkerson," in Chris Chabot ed., Tales of White Pine: An Illustrated Oral History of White Pine, Michigan and Environs (Ontonogan, Michigan: Ontonogan Herald Company, 1979), 37.

242 "Deafness Cannot Be Cured," Advertisement (December 5, 1914), Daily Mining Gazette, Page 11. Microfilm Collection, MTU Archives and CCHC, MTU, Michigan. 
lost our best friend. ${ }^{243}$

Concluding a history of the Champion copper mill in Freda, Michigan, historian

Clarence Monette describes the closing moments of a copper mill:

...residents came out on their porches and saluted and wept as the old mill ground to a halt, and an eerie silence crept over the town site.... Many residents still remember the sound of the crusher which used to be very loud, but also comforting, as it put them to sleep at night. (Monette 105-106, 111-112).

Another similar account comes from Henry Hobart, a twenty year old schoolmaster at the Cliff Mine. The town of Clifton, where Hobart lived, was well within earshot of the mill, and an early entry in his journal is a prophetic recitation of a poem and song "Ben Bolt," written in 1843 and put to music in 1848. One cannot help but think that Hobart sang this song to himself with the rhythmic mill as a metronome:

Oh don't you remember the wood, Ben Bolt, Near the green sunny slope of the hill

Where oft we have sung 'neath the wide spreading shade, And kept time with the click of the Mill ${ }^{244}$

The absence of industrial activity seems to conjure nostalgic memories of sound, and these memories are often expressed poetically. Ruminating over the ruins of the Central mine, L.W. Leskinen laments:

Times past, these ruins grim and gray Looked, too, on manhood, robust, gay, Echoed to ringing teamsters cry Heard boots of miners hurry by

Now their bulk looms strange and still Silence envelopes deserted hill

243 Mills, Applying Auditory Archaeology to Historic Landscape Characterisation, 34.

244 Henry Hobart, Copper Country Journal: The Diary of Schoolmaster Henry Hobart, 1863-1864, ed.Philip P. Mason (Detroit: Wayne State University Press, 1991), 90. 
The host has gone, these sentinels stay

In memoriam to a bygone day. ${ }^{245}$

Another 'nostalgic sound poem' resurrects sounds of the past in the imagination, and

presents the soundscape of the Quincy Mine as a place full of sonic activity:

We miss the sounds of the Quincy Mine:

The sounds of the hoist wheels singing:

The bellow's blow and the blasts below

And the locomotive ringing....

No whistle's roar;

No falling ore;

No 'lectric signals jangling.

We miss the sounds of the Quincy Mine;

Old sounds, oft repeated.

Can such a long, tenacious life

Really be completed? ${ }^{246}$

And yet another, evoking sonic memories from the same hill:

When a thrusting streetcar rolled up a lonely hill,

With its natural cane seats and a bell with its familiar clang;

When carbide lamps were common and lunch pails to fill,

As fenced yards had lines where miners' clothes would hang....

When seasoned chopped wood was piled in neat long rows,...

When a towering shafthouse dominated the Hancock terrain,

And tales about copper and miners were voiced all about town;

When a holiday was heralded by a long parade down Quincy street lanes,

And honored veterans marched to patriotic drum and bugle sounds....

When the Tionest or Octorora passed Portage waters late in the afternoon,

As frolicking young swimmers greeted her with friendly shouting sounds;

When trains with steam locomotives whistled their lonesome tune,

When at five the mine whistle echoed from a nearby hill,

And contented cows in pastures awaited their master's call.... ${ }^{247}$

Another poem in the same volume also carries important sonic information,

supporting the earlier passage of "hoist wheels singing," with "lofty spinning cabled

245 Keweenaw County Historical Society, Central Mine: On the 100 Year Anniversary of the Closing of the Central Mine. 1898-1998. (Keweenaw County Historical Society, 1998), 44.

246 Ruth Malmgren, "Shut Down," in Larry Lankton and Charles Hyde, Old Reliable, 146.

247 Wilbert B. Maki, Hancock: A Mosaic of Memories, 72. 
wheels chant their unisonant sound."248

All of these poems suggest that the perpetuation and maintenance of familiar sonifacts constitutes a vital human need. Not only were human beings drawn to the Keweenaw because of copper's ability to produce sound, but their presence was also maintained by the rhythmic, repetitive, narcotic quality of the 'repeated sound.' Although outside the scope of this thesis, I have addressed this phenomenon in a paper delivered at a conference in Turku, Finland. ${ }^{249}$

The preceding survey of sonic evidence, memories and "earwitness" accounts may serve to help form a sonifactual assemblage. Standing in front of the blacksmith shop on Quincy hill, in the spring of 1916, one could have plausibly heard the simultaneous sounds of the bell and wheels of an electric trolley rolling up the hill on steel rails, a dog barking, the distant explosions of stumps being blown out of a field, the chopping of firewood, a pair of hobnail boots walking along a boardwalk, a greeting in Cornish or Finnish, the faint melody of a piano, a robin singing, the hoist wheels and cables above pulling out a car laden with ore, the bell and whistle and pneumatic exhaust of a steam locomotive, a group of miners singing, a mother calling a child home for dinner, a church organist practicing a hymn, and all of these mingling with the sounds emanating from within the blacksmith shop itself.

\subsection{A Sonic Horizon}

248 Ibid, 75.

249 Jeffrey L. Benjamin, "Lessons from the Kinetic Past: Repetition and Trance in Industrial Social Formation," (paper presented at The Cultural Memory of Sound and Space: The $17^{\text {th }}$ Finnish Music Researchers' Symposium, Turku, Finland, March 13-15, 2013). 
I have reserved one final 'soundmark' that had a well documented presence upon Quincy hill because it illustrates an important sonic horizon, a transition. Schafer notes that "During the industrial revolution, Sacred Noise sprang across to the profane world. Now the Industrialists held power and they were granted dispensation to make Noise by means of the steam engine and the blast furnace, just as previously the monks had been free to make Noise on the church bell or J.S. Bach to open out his preludes on the full organ... association of Noise and power has never really been broken in the human imagination. It descends from God, to the priest, to the industrialist, and more recently to the broadcaster and the aviator." ${ }^{250} \mathrm{~A}$ series of letters from Quincy Mining executives concerning local church bells and organs is indicative of this transition.

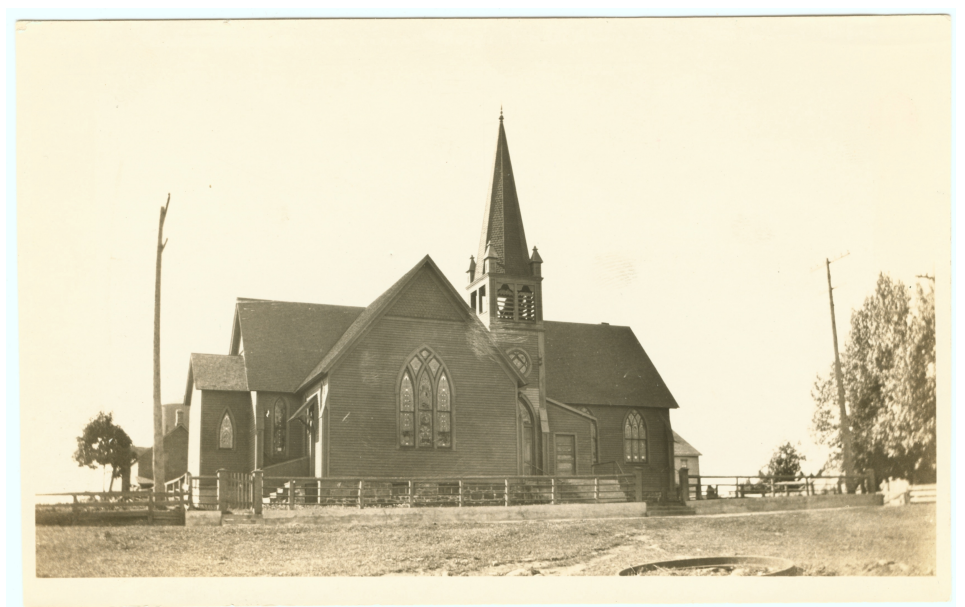

Figure 4. Pewabic Methodist Episcopal Church. Koepel 4x5 Prints, N. A. Eilertson photos, 115 (Pewabic MEC) Keweenaw National Historic Park Archives.

250 Schaefer, The Tuning of the World, 76. 
Directly across the street, less than fifty yards from the blacksmith shop was situated the Pewabic Methodist Episcopal Church. It was an active parish, with the Reverend Lewis Keast presiding. On Saturday, July 22, 1916 the church held its twenty-third anniversary concert. This was comprised of an organ voluntary, vocal solo performance, anthem, choir, another vocal solo, followed by a duet, another vocal solo, another duet and then a final reading. ${ }^{251}$ It is reported that Reverend Keast was "a linguist with an English flare for writing. He read and spoke... German, French, Spanish and Italian"252 and the author of numerous religious articles. Geneological information shows that Rev. Keast was born around 1879 in Cornwall (Liskeard), England, ${ }^{253}$ and started out as a miner, working at Iron Mountain and Ishpeming until he had earned enough to study at Albion College. ${ }^{254}$ Thurner notes that, in general, the Cornish were very religious, and "produced fluent and original speakers, lay preachers, men who mined all week and then delivered 'eloquent, earnest sermons."'255 Apparently the 'sacred power' of church sound was not lost on Keast, for there is an interesting letter from William Rogers Todd, President of Quincy Mining Company from 1902-1924 to Charles Lawton, director of the mine, relating a correspondence he had with Keast. The letter dates from August 1, 1910 and reads:

I have a recent personal letter from the Methodist minister at Pewabic,

251 No author, "Pewabic Church Anniversary," Page 3. Daily Mining Gazette, Microfilm Collection, MTU Archives and CCHC, MTU, Michigan.

252 "History of Methodism in the Upper Peninsula of Michigan," (Published by The Historical Society of The Detroit Annual Conference, 1955) 55. CCVF: Churches. MTU Archives and CCHC.

253 http://adupree.com/Gen800/getperson.php?personID $=$ I385957\&tree=adupree. Accessed March 14, 2012.

254 "History of Methodism in the Upper Peninsula of Michigan," 25.

255 Arthur Thurner, Strangers and Sojourners, 138. 
which somehow I have mislaid and consequently cannot answer directly as I do not remember the Reverend gentleman's name. Will you, therefore, kindly tell him that I do not feel like accepting his kind proposition to present a church organ as the "Todd Memorial". While I feel interested in the welfare of the parish I do not care about doing what he has suggested.

$$
\begin{aligned}
& \text { Yours very truly, } \\
& \text { W.R. Todd } 256
\end{aligned}
$$

This letter is difficult to interpret, but it does clearly document a kind of negotiation of power that involves 'sacred' sound. It is unclear why Keast would want to dedicate a church organ as "Todd Memorial" to a man still living, and understandable why Todd chose to defer.

Another, earlier letter from Thomas Mason to Captain Harris shows that the mine was willing to pay for a bell for "the new Church on the hill." ${ }^{257}$ Dated July 31, 1895, the letter reads:

\section{Cap't Harris}

I can't get any satisfactory information as to procuring a "Bell" for the new Church on the hill- so I conclude to have you tell the Domini to procur such an one as is suitable or desirable and have him send the bill to your office when you can pay it and charge to my account

Truly yours, Thos F Mason ${ }^{258}$

It is difficult to draw firm conclusions from these correspondences. Both of these letters carry an air of perfunctory cordiality, but are also somewhat dismissive.

Neither Todd nor Mason seem to be particularly concerned about the sonic needs of

256 Todd, William Rogers. Letter to Charles L. Lawton. Quincy Copper Mining Company Collection., Box 336, Folder 008. MTU Archives and CCHC, MTU, Michigan.

257 According to "History of Methodism in the Upper Peninsula," the Pewabic Methodist Episcopal Church was erected in 1893. (p. 35)

258 Mason, Thomas F. Letter to Captain Harris. July 31, 1895. Quincy Copper Mining Company Collection., Box 366, Folder 008. 
the church across the street. It is interesting and enlightening however, to have the privilege to witness a dialogue that was taking place as industry wrested sonic authority from the church, as the church bell became sonically irrelevant. If it had been argued to Todd or Mason that bells and organs could have served to pacify the miners, then perhaps there might have been a different tone. In reference to "Father Kron of the Catholic Church," Todd writes in a letter to Charles Lawton:

We believe the Rev. Father Kron may prove a desirable resident and may be of some value to us in case of any misunderstanding with our men, and if he can do as he writes 'train the minds and hearts in the fear of God and in respect for authority, law and order' he should prove a good man to keep among us. ${ }^{259}$

259 Todd, William Rogers. Letter to Charles L. Lawton. June 6 ${ }^{\text {th }}$, 1913. Quincy Copper Mining Company Collection, MTU Archives and CCHC. Box 366, Folder 008. 


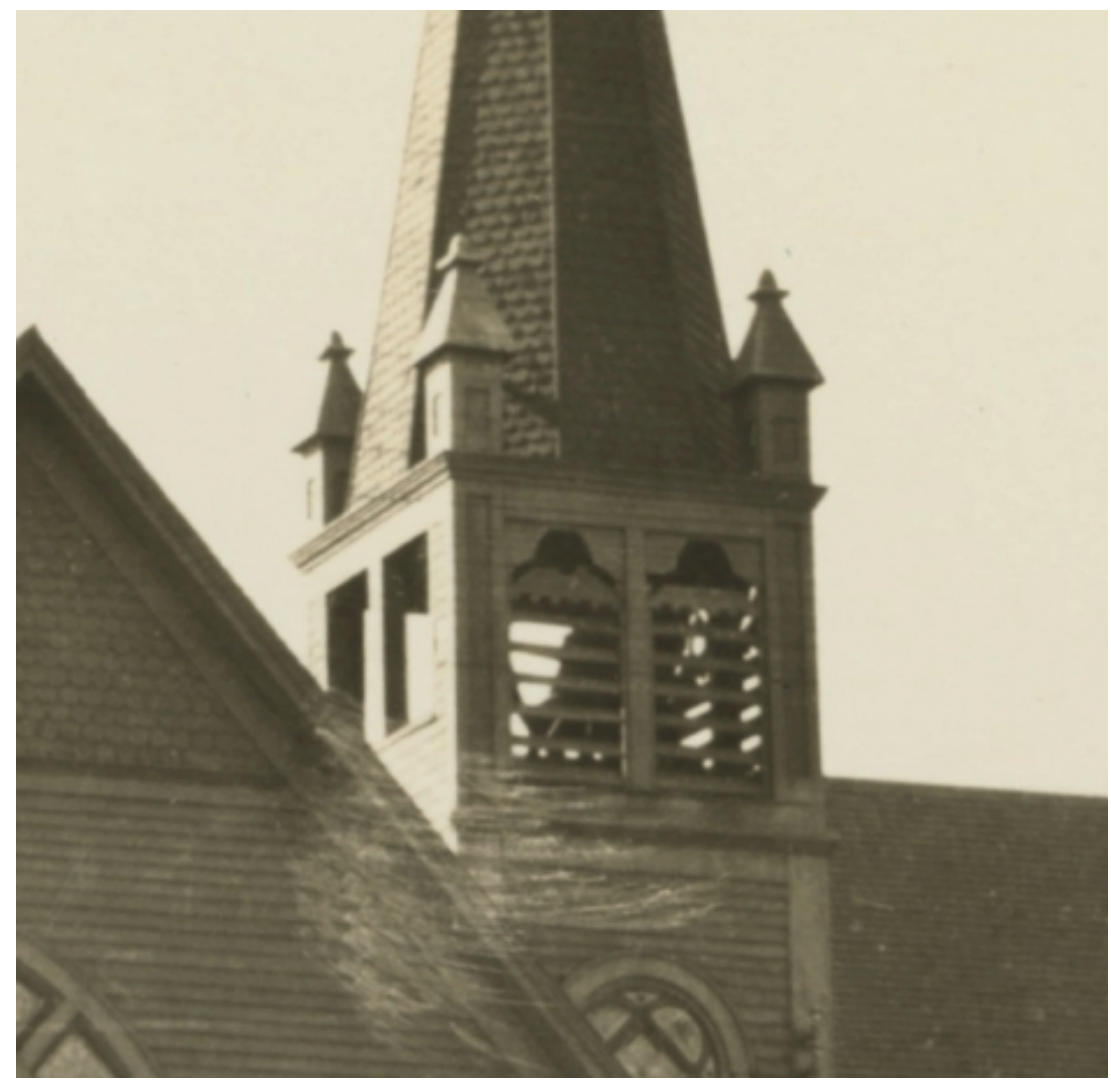

Figure 5. Close-up of Pewabic Methodist Church steeple with bell silhouette, taken from Figure 4.

A closer look at the Koepel photograph of the Pewabic Methodist Church reveals the silhouette of a bell in the steeple. The height of the bell is approximately equivalent to seven rows of siding on the facade of the church. The diameter of the bell is approximately equivalent to ten rows of siding. In general, the standard dimension for a revealed portion of horizontal siding is $4-4 \frac{1}{2}$ inches, so the bell's height can be estimated to be around 30 inches, with a diameter of approximately 45 . The 1903 catalogue from American Bell and Foundry Company shows bells with diameters of 46 and 48 inches, weighing 1180 and 1460 pounds respectively. ${ }^{260}$ The 260 American Bell and Foundry Company: Manufacturers of Church, Chapel, School, Court House, Fire Alarm and Farm Bells. Company catalogue (Northville, Michigan. 1903), 19. 
catalogue also states "the larger the bell the stronger and deeper the tone," ${ }^{261}$ so it is likely that this bell had a significant reach. Its location, directly across the street from the blacksmith shop, is indicative of a significant sonic transition that was taking place all across the country.

\section{The Quincy Mine Blacksmith Shop: A Sonic Midden}

Let's walk together...with the ear more attentive than the eye, and we will vary the pleasures of our sensibilities by distinguishing among the gurglings of water, air and gas inside metallic pipes, the rumblings of rattlings of engines breathing with obvious animal spirits, the rising and falling of pistons, the stridency of mechanical saws, the loud jumping of trolleys on their rails, the snapping of whips, the whipping of flags. We will have fun imagining our orchestration of departments stores' sliding doors, the hubbub of the crowds, the different roars of railroad stations, iron foundries, textile mills, printing houses, power plants and subways. ${ }^{262}$

$$
\text { Luigi Russolo- The Art of Noise, } 1913
$$

A celebratory and inspirational text for sound artists and musicians even to this day, Russolo's manifesto shows that there were attentive listeners who were aware of the profound sonic changes occurring as the industrial revolution was taking place. Russolo's ambition was to turn the new sounds of industry into music: "we get infinitely more pleasure imagining combinations of the sounds of trolleys, autos and other vehicles, and loud crowds, than listening once more, for instance, to the heroic or pastoral symphonies. We want to score and regulate harmonically and

261 Ibid, 9.

262 Luigi Russolo, The Art of Noise: Futurist Manifesto, 1913 (New York: Something Else Press, 1967), 7. 
rhythmically these most varied noises." 263

It is particularly interesting to compare Russolo's perceptions of the newly emerging soundscape with the sentiments expressed earlier by the writer celebrating the possible arrival of a "chugless" locomotive. In fact, these sentiments are diametrically opposed, and may very well provide insight into a possible debate regarding the process of industrialization as it was happening.

A detailed and fully comprehensive analysis of a plausible sonic moment as experienced by an individual at the blacksmith shop on April 15, 1916, for even a few seconds, would require volumes. But a great deal can be learned by an analysis of the overall size and structural properties of the shop, the different types of machinery and processes within, and the sequence of operations. As stated earlier, all of the sounds within the shop occured within the wider context of the sound environment of Quincy Hill, and many of the unique sonic characteristics of the hill have been presented, so the following analysis must be kept in that perspective.

While certain aspects of the history of Quincy Mining Company are pertinent to this investigation, effort is being placed upon the reconstruction of a plausible sonifactual assemblage. This entails making an effort to separate the sounds themselves from their meanings or origins ${ }^{264}$, a task that has thus far proven quite difficult, since there

263 Ibid, 9.

264 The need to attach meaning or ascribe source of origin to sound is a deep one, but it can lead to misinterpretation. While working as a carpenter in New York City in the mid 1990's, I spent an entire day using a nail gun driving nails into concrete with the assistance of 22 caliber gunpowder shells. At the end of the day, a friend and I decided to go to the Whitney Museum of Art to see a show. I walked to Madison Avenue to withdraw some money from the nearby bank machine on the street. From inside the bank, I heard the same sound I had been hearing all day long, and assumed that someone was laying down some metal track on a concrete floor. A bank robbery was in progress. 
is no real descriptive language of sound-forms. A successor to Russolo's efforts in many ways, Pierre Schaeffer, founder of musique concrete recognized the need for a "science of music" and also argued for the materiality of sound, to "emphasize our dependence, no longer on preconceived sound abstractions, but on sound fragments that exist in reality and that are considered as discrete and complete sound objects." 265 Although working with this goal in mind, Schaeffer's "Aha" moment came when he was making and manipulating recordings of bells. The removal of the initial bell strike, or "attack" portion of the bell "sound envelope" produced a sound that was similar to an oboe, showing a definable interior structure to the sound itself. While the goal of this project is arriving at an understanding of how sound was experienced in the past, this is best accomplished by isolating and identifying the sounds themselves. In our standard contemplation of sound, there is still a neglected intermediate step in between production and perception, a place where the sound exists by itself without the assistance of the host artifact or the perceiver. Schaeffer relates the difficulty in gaining acceptance of this idea at a meeting of musicologists, where he asks the question:

...(Is there) between the moment when the composer finishes his work and the moment when a listener perceives it...yes or no, a zone that is objective, i.e., independent of the subjects who have composed or who will hear, where the music exists in itself, either as a score or a performance?... We only have to allow that there is a gap, a no-man's-land where nobody ventures. It is not surprising that until now there has been no real science of music, since the very object of such knowledge has not been clearly perceived. ${ }^{266}$

265 Pierre Schaeffer, In Search of a Concrete Music, trans. Christine North and John Dack (Berkeley: University of California Press, 2012), 14.

266 Schaeffer, In Search of a Concrete Music, 132. 
A HAER map of the Quincy Mine Location in 1902 shows the existence of two blacksmith shops. Built in 1860, the first blacksmith shop was about half a mile downhill along 'the road to Calumet' (now known as highway 41) from the blacksmith shop in question, which was built in 1900 .

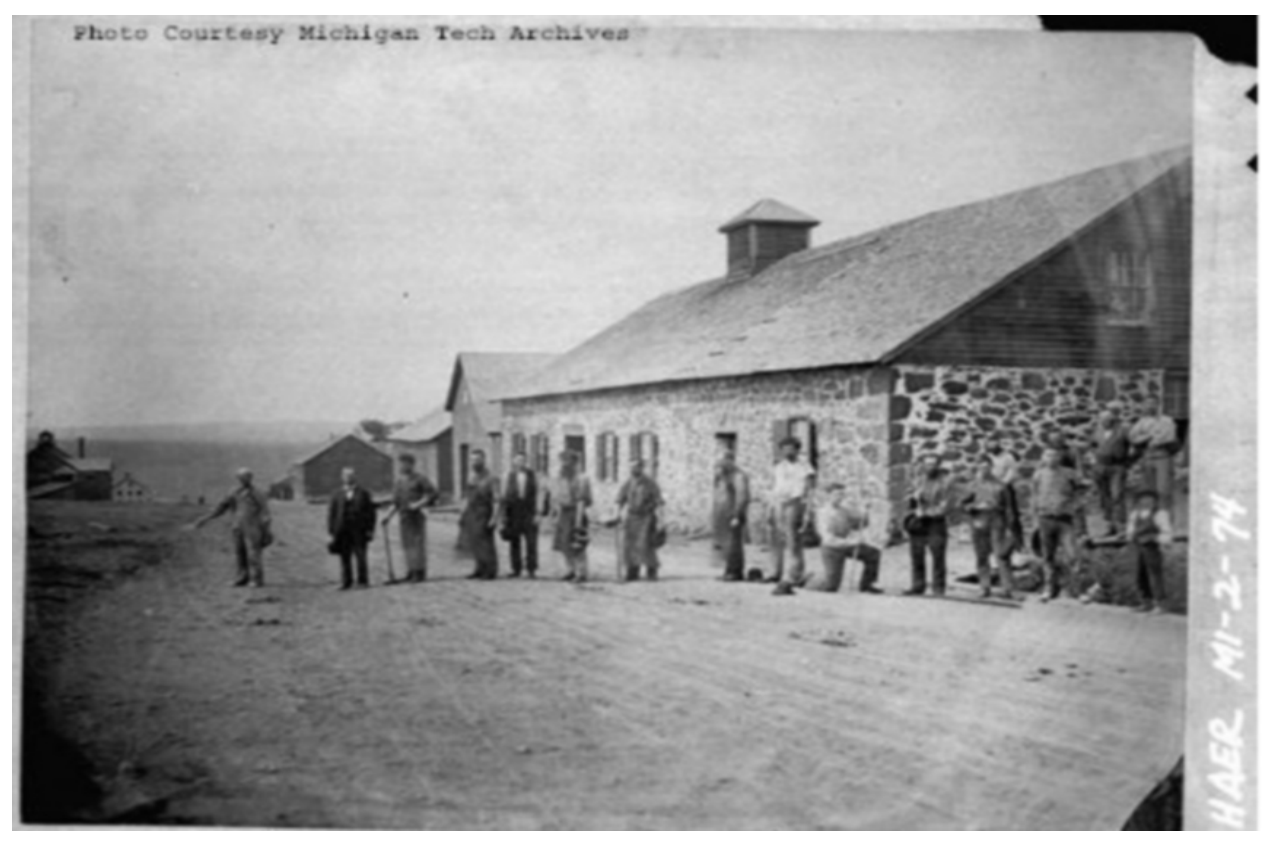

Figure 6. First blacksmith shop at Quincy mine location, built in 1860 . Date of photograph unknown. (Image\#:MS015-MI-2-74. Michigan Tech Archives and Copper Country Historical Collections) 


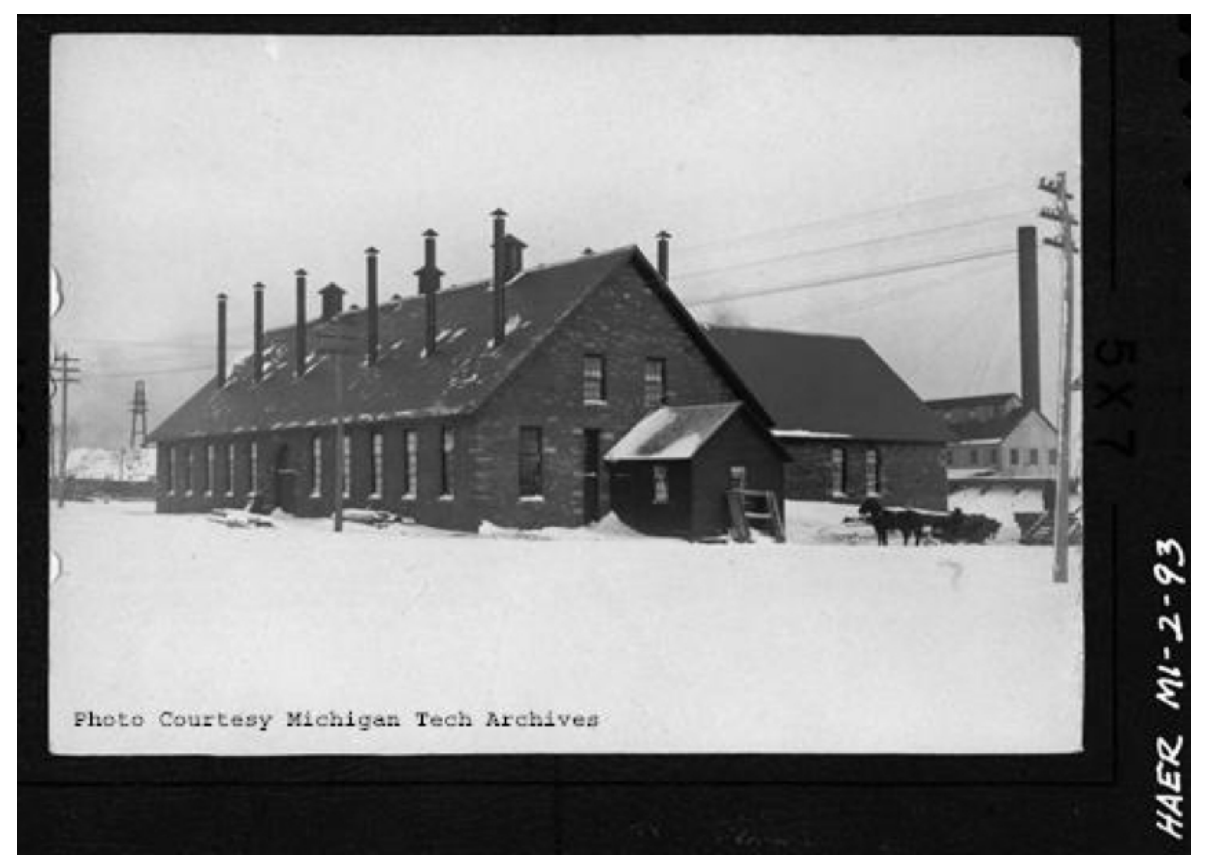

Figure 7. The "new" blacksmith or "drill" shop, built in 1900. (Image \#:MS015-MI-2-93. Michigan Tech Archives and Copper Country Historical Collections). 


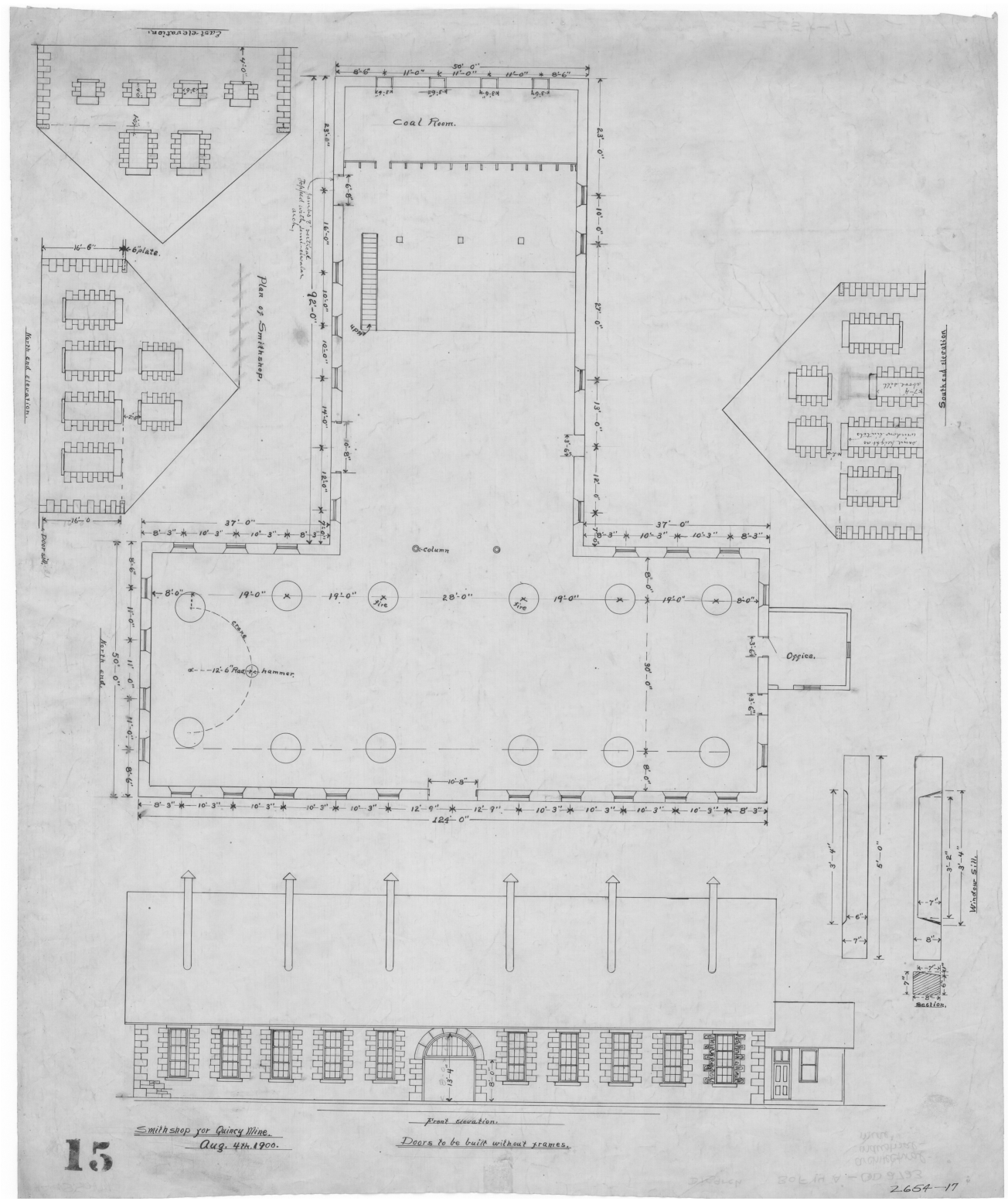

Figure 8. "Smithshop for Quincy Mine. Aug. $4^{\text {th }}$, 1900." (Map \# 30F14A-QD2723, Michigan Tech Archives and Copper Country Historical Collections). 


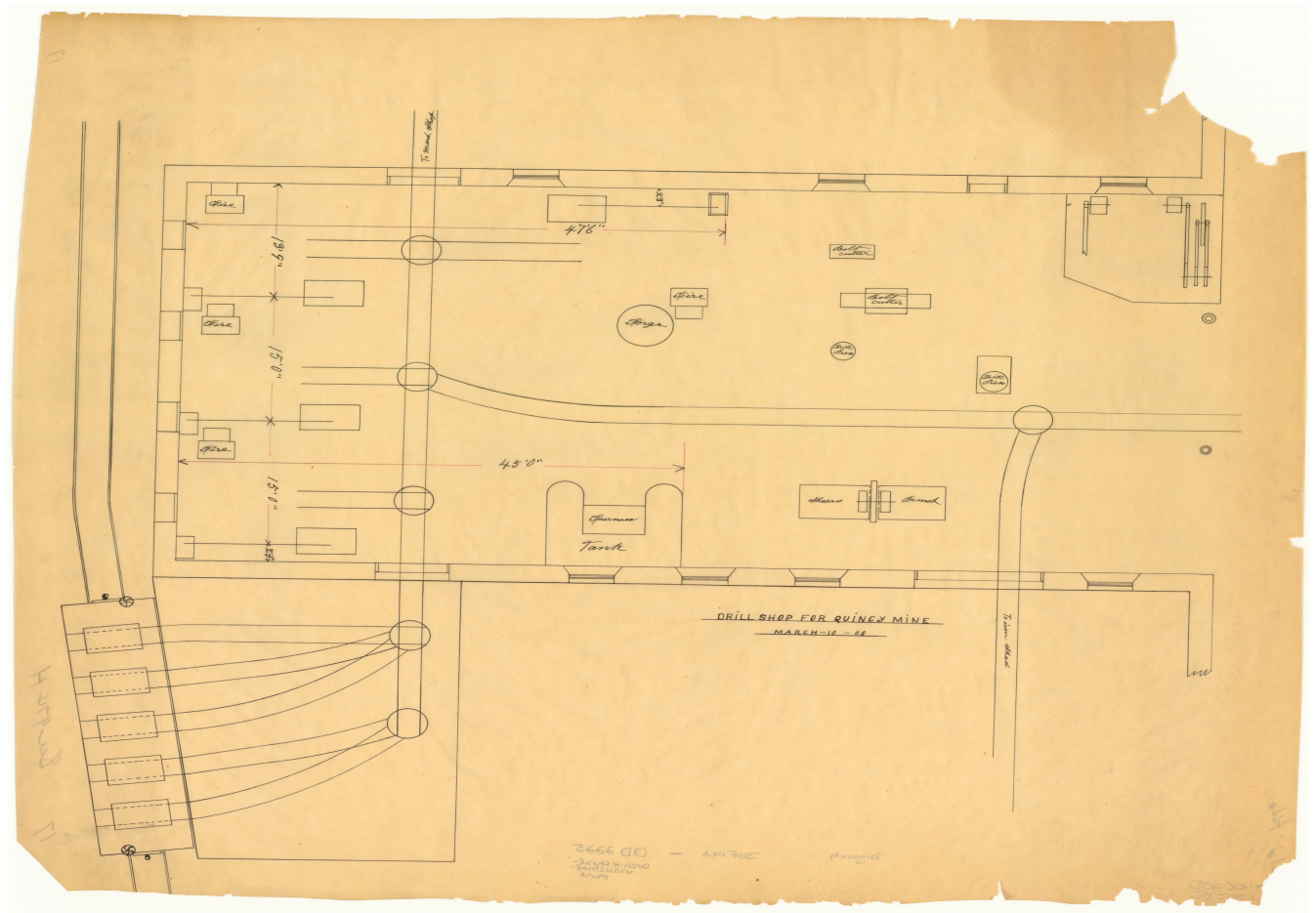

Figure 9. "Drill Shop for Quincy Mine. March 10, 1908." (Map 30F14A-QD2225. Michigan Tech Archives and Copper Country Historical Collections). 


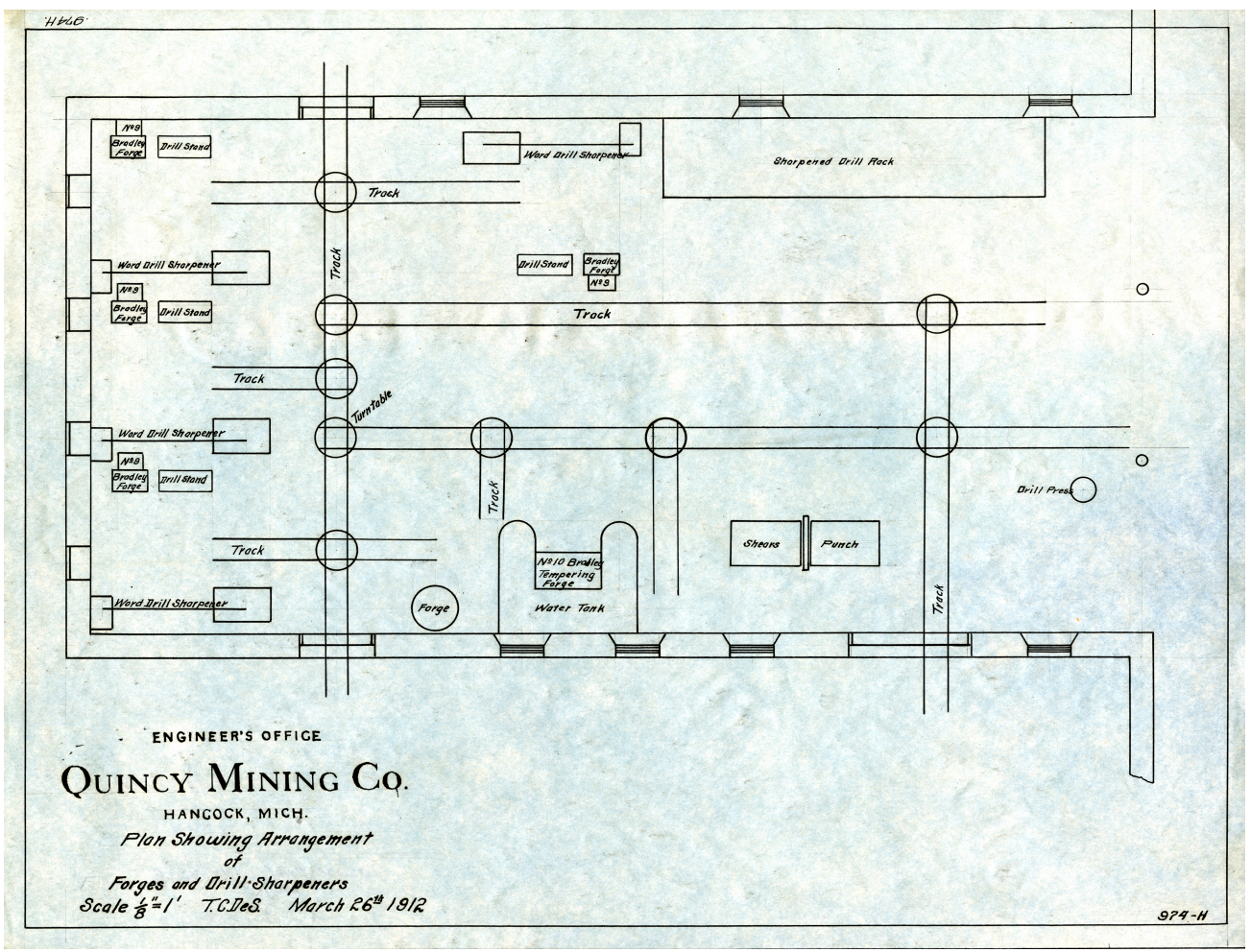

Figure 10. "Plan Showing Arrangement of Forges and Drill Sharpeners, March 26 1912" (Map 30F14A-QD2722, Michigan Tech Archives and Copper Country Historical Collections) 


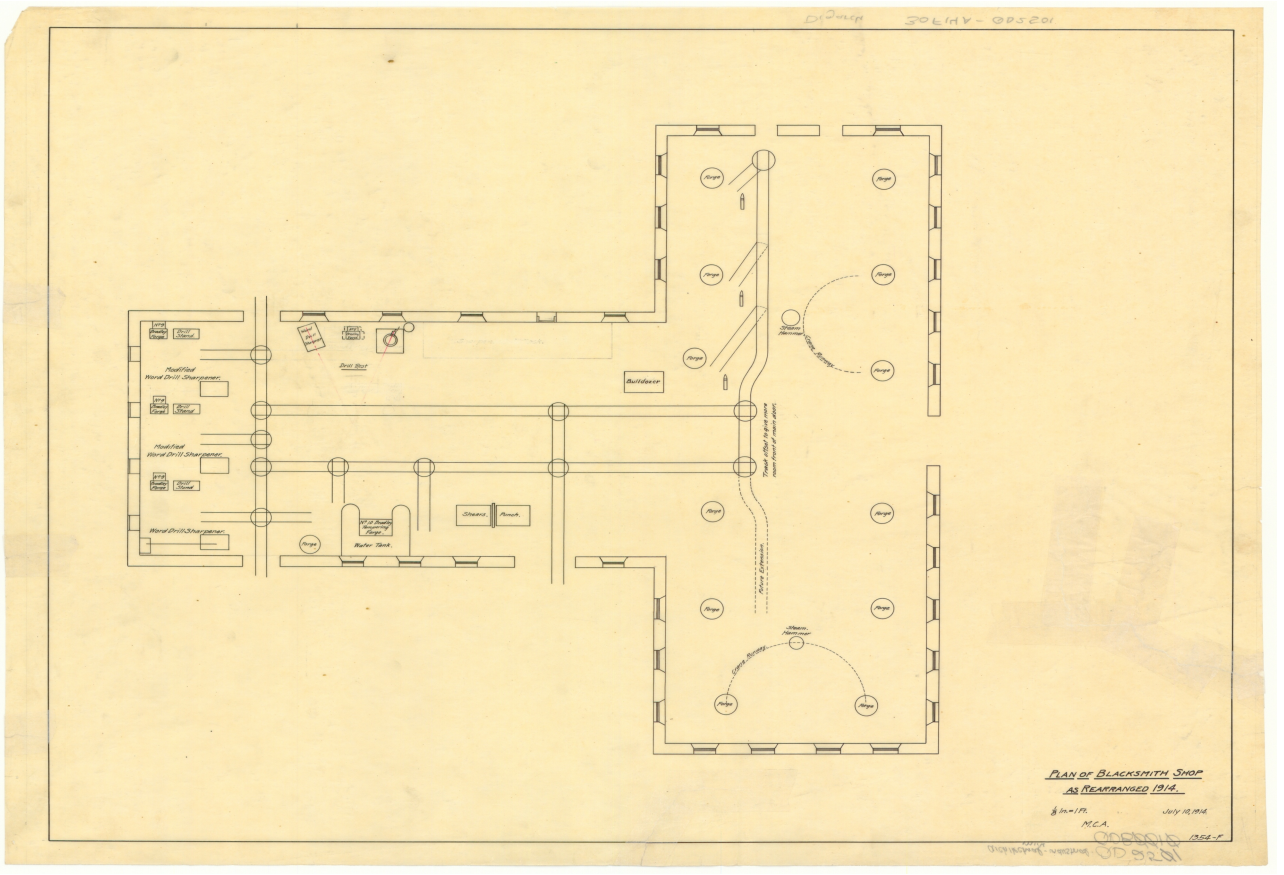

Figure 11. "Plan of Blacksmith Shop as Rearranged 1914" (Map 30F14AQD2501. Michigan Tech Archives and Copper Country Historical Collections.)

The existence of two structures labeled "Blacksmith Shop" on this map provides evidence of an important technological transition which was accompanied by a corresponding sonic change (a sonic horizon): the shift from hand-sharpening to machine sharpening of rock drill bits. This also corresponds with historical evidence pertaining to a steady ramping up of mining activity at Quincy. The construction of the new blacksmith shop in 1900 (see plans, Fig. 8) was an answer to a need to 
"repair, maintain and fabricate much of its own equipment" and incorporated the use of electric motors for the operation of some of its machinery. ${ }^{267}$ Another main purpose was consolidation. A 1908 annual company report states this clearly:

The changes in the blacksmith shop and drill shop finally resulted in our remodeling old No. 6 Change-House into a steel and iron storehouse, together with a storehouse for coke and coal for the blacksmith shop. A short connecting railroad track was laid, and all the stock of iron, steel, coal, and coke in the blacksmith shop was removed to this building, which is exceedingly well located and adapted for the purpose. That portion of the blacksmith shop made vacant by this transfer was installed with all of the power drill sharpening machines from the No 7 drill shop, so that now all of the blacksmith work and drill sharpening, of whatsoever kind, is done under one roof and directly under the eye of the foreman.

There were many changes made in the arrangement of the blacksmith shop to increase its efficiency. A new 1200 pound steam hammer was installed to meet the increased needs about the mine, so that the blacksmith shop is fully equipped to meet all of the requirements of the mine for some years to come. ${ }^{268}$

While the drawing "Smithshop for Quincy Mine: Aug, 4, 1900," (Fig. 8) portrays an open plan with very little specific information on the location of the devices and sharpeners, subsequent drawings show the evolution of the shop as it changed over time. A drawing from 1908 clearly depicts some of the changes described above in the company report of the same year, showing the positions of the forges with the sharpening machines next to them, along with a loft structure with blowers (still in situ, May 2012) for a steady supply of air for the forges (see Figure 9). In 1912, the layout remains largely the same, and the sharpeners are identified individually as "Word Drill Sharpener" and the forges are identified individually as "No.9 Bradley

267 Larry D. Lankton and Charles K. Hyde, Old Reliable: An Illustrated History of the Quincy Mining Company (Hancock, MI: The Quincy Mine Hoist Association, Inc., 1998), 77.

2681908 Annual Report. Quincy Mining Company Collection, Box 358, File 034. MTU Archives and Copper Country Historical Collections, Michigan Technological University, Michigan. 
Forge" (see Figure 10).

The attention paid to the location and orientation of the drill sharpeners and forges as evidenced in the company reports and drawings of the blacksmith shop demonstrates the importance of the sharpening operation to the function of the mine: the sharpened drill end being the "business end of rock excavation" ${ }^{269}$. While it may seem obvious, the interface of the drill steel with the rock is a location of prime importance for the success of the mine, and the drill steel "must be able to present a cutting edge to the rock as hard or harder than the rock itself." ${ }^{270}$ If the drill steel is faulty, or if the bits are not sharpened quickly enough, the ore cannot be drawn from the mine. This is a good example of a "pinch point" within a technological system. A later company report of 1915 refers to the particular kind of drill bits recently introduced to the mine: "The only large expenses in this direction have been the introduction of the "Baby" drilling machines and their equipment: the remodeling of the drill sharpening machines in the drill shop, in order to promote economy in sharpening the small hollow drill bits..."271 Figure Ten, "Plan of Blacksmith Shop as Rearranged 1914" shows the changes made to the shop layout.

While the functions of the blacksmith shop were numerous, preserved time sheets from the period of $1892-1904$ consistently show that the most time consuming operation taking place on site was "drill sharpening." Itemized on a time-sheet for June 1904, recorded man-days for drill sharpening amounted to 234 (see Table 1).

269 Gilman, "Ideal Shop for Sharpening Drill Steel," 585.

270 Eustace Weston, Rock Drills: Design, Construction, and Use (London: McGraw-Hill Book Company, 1910), 151.

2711915 Annual Report. Quincy Mining Company Collection, Box 358, File 034. MTU Archives and Copper Country Historical Collections, Michigan Technological University, Michigan. 
Interestingly, man-days for "mining" is recorded as $1653 / 4$, indicating that many of the blacksmiths also worked underground. An oral interview with Don Dodge, performed by Jo Urion, historian at Keweenaw Historic Park in Calumet Michigan, corroborates this major function when Dodge states "we called it the drill shop, where they sharpen the drills. My Uncle Harry used to do that." ${ }^{272}$ In reference to the other functions Dodge states "they repaired everything that they used in the mine and a lot of them- like the skips, you know? The skips would get all beat up and they'd braise them or- braising is like welding. They'd fix the skips and repair the skips and they'd sharpen the drills for the miners..."273 Before the arrival of machine sharpeners, blacksmiths would sharpen rock drill bits by hand, with a set of specialized dies and swages to form the proper profile on the head of the bit, which was in turn dependent upon the kind of rock being drilled. ${ }^{274}$

272 Dodge, Don. Transcription of recorded interview with Jo Urion, Historian (Calumet: Keweenaw National Historic Park, February 24, 2005), 15.

273 Ibid, 17.

274 Eustace Weston, Rock Drills: Design, Construction, and Use, 157. 
Table 1. Man-days per operation for Blacksmith shop at Quincy Mine, for the month of November, 1892. ${ }^{275}$

\begin{tabular}{|c|c|c|}
\hline Distribution of Time & Days & Remarks \\
\hline Quincy Hoisting & $13 \frac{1}{2}$ & \\
\hline \multirow[t]{2}{*}{ Pewabic Hoisting } & 10 & repairs \\
\hline & 17 & New Work \\
\hline \multirow[t]{2}{*}{ Quincy Mining Cost } & $43 \frac{1}{2}$ & \\
\hline & 10 & Man Engine \\
\hline Pewabic Mining Cost & 15 & \\
\hline Quincy Rock House & 48 & \\
\hline Pewabic " " & $53 \frac{1}{2}$ & \\
\hline Air Drills & $154 \frac{1}{2}$ & \\
\hline Trowbridge and Co. & $21 \frac{1}{2}$ & \\
\hline Machine Shop & 6 & \\
\hline Quincy and T.L. Railroad & $12 \frac{1 / 4}{4}$ & \\
\hline Lapps Adit & 1 & \\
\hline Surface & $1 \frac{1 / 4}{}$ & \\
\hline Coal Dock & $1 \frac{1 / 2}{2}$ & \\
\hline Quincy Compressor & $1 / 2$ & \\
\hline Doctor Downer & $1 / 4$ & \\
\hline Tools & $2 \frac{1}{2}$ & \\
\hline Quincy Old Mill & $1 \frac{1 / 2}{2}$ & \\
\hline Supplies & 7 & \\
\hline Clayton Compressor & $4 \frac{1}{2}$ & \\
\hline Carpenter's Shop & $1 / 2$ & \\
\hline Dwellings & $1 / 2$ & \\
\hline Pewabic Dry & 1 & \\
\hline Pewabic Fire Department & $1 \frac{1 / 4}{4}$ & \\
\hline Capt. C.G. Neale & $1 / 4$ & To plating boots. \\
\hline Mo. Jas Moore & $1 / 4$ & To 4 new horse shoes. \\
\hline Cap't. J. Blythe & $1 / 4$ & To 4 shoes set. \\
\hline Cap't. T Whittle & $1 \frac{1 / 2}{2}$ & To repairing cutter. \\
\hline Mo Johnson Paymaster & $1 / 4$ & To 2 new shoes and 2 set. \\
\hline Mo Angus Macdonald & $1 / 4$ & $\begin{array}{c}\text { To } 4 \text { shoes set and repairs } \\
\text { on cutter. }\end{array}$ \\
\hline Mo R Morrison & $1 / 4$ & $\begin{array}{c}\text { To } 2 \text { new shoes and } 2 \\
\text { shoes set. }\end{array}$ \\
\hline & 431 Days & \\
\hline
\end{tabular}

275 Time: Blacksmiths. Quincy Mining Company Collection, Box 122, Folder 005. MTU Archives and Copper Country Historical Collections, Michigan Technological University, Michigan. This timebook entry counts a total of sixteen employees for this time period. 
Table 2. Man-days per operation for Blacksmith Shop at Quincy Mine, June $1904 .^{276}$

\begin{tabular}{|c|c|}
\hline Distribution of Time & Days \\
\hline Mining & $1653 / 4$ \\
\hline Drill Sharpening & 234 \\
\hline No. 2 Hoist & 7 \\
\hline$" 4 \quad$ & 3 \\
\hline " 64 & 11 \\
\hline " 7 " & 8 \\
\hline " $8 \quad$ " & 3 \\
\hline " 2 Skip repairs & 5 \\
\hline " 6 " & 7 \\
\hline " 2 Boilers & 2 \\
\hline " 7 " & 2 \\
\hline Machine Shop & 17 \\
\hline Blacksmith " & 14 \\
\hline Carpenter " & 2 \\
\hline Teaming & 3 \\
\hline No 2 Compressor & 3 \\
\hline " 6 " & 2 \\
\hline " 2 Rock house & 3 \\
\hline " 6 " & 8 \\
\hline No $7 "$ " & 3 \\
\hline Locomotives & 21 \\
\hline R.R. Cars & 42 \\
\hline Maintenance of Way & 19 \\
\hline New Drills & 17 \\
\hline Rand drill supplies & 98 \\
\hline " $\quad$ repairs & 34 \\
\hline Pump Station & 5 \\
\hline Stamp Mill No 1 & 2 \\
\hline " $\quad$ " 2 & 2 \\
\hline Mine Equipment Electric & 28 \\
\hline No 7 water skip repairs & 2 \\
\hline Telephone Con. under ground & 6 \\
\hline Electric haulage repairs & 20 \\
\hline \multirow[t]{2}{*}{ No 4 Man Car } & 1 \\
\hline & $806 \frac{3}{4}$ \\
\hline
\end{tabular}

276 Time: Blacksmiths. Quincy Mining Company Collection. Box 122, Folder 005. MTU Archives and Copper Country Historical Collections, Michigan Technological University, Michigan. This timebook entry counts a total of 32 employees. 
Table 3. Quincy Mine Blacksmith Shop. Comparison of Man-days per operation to number of employees over time ${ }^{277}$

\begin{tabular}{|c|c|c|c|c|c|c|c|c|}
\hline Month & $\begin{array}{l}\text { Number of } \\
\text { employees }\end{array}$ & & Man & Days & Per & Operation & & \\
\hline & & $\begin{array}{c}\text { Drill } \\
\text { Sharpening }\end{array}$ & $\begin{array}{l}\text { "Rand } \\
\text { Drill } \\
\text { Supplies" } \\
\text { and } \\
\text { Repairs }\end{array}$ & Mining & Railroad & $\begin{array}{c}\text { Hoisting } \\
\text { (house, skip, } \\
\text { boilers) }\end{array}$ & Rock House & $\begin{array}{l}\text { Mach } \\
\text { ine } \\
\text { Shop }\end{array}$ \\
\hline $\begin{array}{c}\text { November } \\
1892\end{array}$ & 16 & $\begin{array}{l}\text { "Air } \\
\text { drills" } \\
154 \text { 1/2 }\end{array}$ & $\mathrm{n} / \mathrm{a}$ & $681 / 2$ & $12 \frac{1}{4}$ & $401 / 2$ & 48 & 6 \\
\hline June 1893 & 17 & $\mathrm{n} / \mathrm{a}$ & 174 & 67 & 9 & 23 & 35 & 7 \\
\hline $\begin{array}{c}\text { January } \\
1897\end{array}$ & 23 & 204 & $\begin{array}{c}\text { "Air } \\
\text { Drill" } \\
\text { supplies } \\
\text { and } \\
\text { repairs: } \\
71\end{array}$ & 130 & 25 & 25 & $161 / 2$ & 8 \\
\hline $\begin{array}{c}\text { January } \\
1898\end{array}$ & 28 & 225 & 90 & $1653 / 4$ & 15 & 9 & 14 & 11 \\
\hline $\begin{array}{c}\text { October } \\
1899\end{array}$ & 14 & $\mathrm{n} / \mathrm{a}$ & $\begin{array}{c}\text { "Rand } \\
\text { Drill" } 136\end{array}$ & 66 & 2 & 53 & 67 & 3 \\
\hline $\begin{array}{c}\text { January } \\
1900\end{array}$ & 29 & 234 & 89 & 112 & 13 & 33 & 84 & 11 \\
\hline $\begin{array}{c}\text { January } \\
1901\end{array}$ & 34 & 236 & 89 & $2193 / 4$ & 52 & 46 & 18 & 15 \\
\hline $\begin{array}{c}\text { January } \\
1902\end{array}$ & 34 & 234 & 179 & 198 & 39 & 42 & 25 & 15 \\
\hline $\begin{array}{c}\text { January } \\
1903\end{array}$ & 32 & 234 & 150 & $1731 / 4$ & 10 & 75 & 18 & 9 \\
\hline $\begin{array}{c}\text { January } \\
1904\end{array}$ & 35 & 128 & 82 & $1431 / 2$ & 25 & 53 & 11 & 7 \\
\hline $\begin{array}{l}\text { June, } \\
1904\end{array}$ & 32 & 234 & 132 & $1653 / 4$ & 63 & 49 & 16 & 17 \\
\hline $\begin{array}{c}\text { December } \\
1904\end{array}$ & 32 & 181 & 145 & $1961 / 4$ & 19 & 69 & 17 & 19 \\
\hline
\end{tabular}

277 The data from this table is collected from a selection of time sheets from the same source cited in footnote 276 . 
While the Quincy Mine drill shop now lies in a state of dignified ruin, enough historical research has been done to accurately reconstruct it if this were to be desired. The white pine roof beams and joists from the loft are stacked nearby, and the roof slate is also stacked and piled in heaps within the space. Architectural drawings have been archivally preserved and show the original plan for the structure, and many of the original machines are still in their 1914 locations. While auralization software could perhaps approximate the interior of the space, a "sure-fire" method of reconstructing the sound environment would be to reconstruct the host artifact, in this case the structure itself, as it existed when it was built and used.

Because sound, as it is perceived, "happens" within a space of time, a particular moment can been isolated for examination. The most valuable source of documentation for the physical configuration of host artifacts within the blacksmith shop comes from an extensive research project completed by the Historic American Engineering Record in $1978 .{ }^{278} \mathrm{~A}$ drawing dedicated to the blacksmith shop indicates that the spatial arrangement represented "reflects the 1914 layout according to a blueprint dated July 10, 1914, 'Plan of Blacksmith Shop as Rearranged 1914."'279 While the "drill shop" (as it was colloquially known because of its major function) was built in 1900, the drawing depicts the location of the sharpeners and other devices as positioned in 1914. This is noted in a parenthetical comment. Significantly, many of the features depicted in the drawing(s) are still present on site,

278 Historic American Engineering Record. A Look at the Architecture and Communities of the Quincy Mining Company. Hancock, MI: Quincy Mine Hoist Association, 1978.

279 Ibid, 29. 
helping to verify the drawings' accuracy.

Since these drawings provide the most detailed information regarding the locations of host artifacts within the drill shop at any time, and many of them are still in situ, it would be reasonable to attempt a sonifactual reconstruction at precisely the time period as depicted in the drawings. However, because of the disruption to operations caused by the strike of 1913-1914, as well as a dearth of historic information from this time period, I decided to shift the time period under consideration a few years later, to April 1916.

\subsection{The Structure}

Documentary evidence regarding the design of the Quincy Mining Company blacksmith shop supports Betsy Bradley's observation that many early industrial structures were designed internally by company management, because the separate disciplines of "industrial engineer" or industrial architect were not yet in existence. ${ }^{280}$ What appears to be an architectural plan for the shop (Fig. 8) seems to leave room open for future development, as one whole section of the " $\mathrm{T}$ " layout is without equipment. This was an act of foresight assuming future technological development, and is reflected by the goals of an engineer studying drill sharpening shops in 1921:

While on a business trip to some mines in Arizona, I received instructions to visit as many blacksmith shops as possible and to make sketches showing the location of the various machines, particularly rock-drill sharpeners, and study the sequence of operations required

280 Betsy Hunter Bradley, The Works: The Industrial Architecture of the United States (New York: Oxford University Press, 1999) 16. 
for sharpening drill steel. The object in view was the arrangement of a series of drawings, whereby expansion of the blacksmith shop could be made with the minimum amount of rearrangement of the machines already in place; if possible, making it unnecessary to stop work at any time during the period of expansion to change the location of the equipment already installed. ${ }^{281}$

The importance of designing open space for future development is repeated by another author, and the fact that both of these accounts were written after the Quincy Mine blacksmith shop was constructed suggests that mining engineers were in open communication, and learning from each others' successes and failures:

...it should be so constructed that by adding space and certain features of equipment to one end only of the building the capacity may be increased further at slight expense without making any change in the original equipment. ${ }^{282}$

Visually, the plan for the blacksmith shop is "quiet," that is to say that there are very few written directions, special instructions, etc., included on the drawing. It has a certain serenity, and may also support Bradley's assertion that during the early years of industrial design "American builders drew upon a vernacular, or nonverbal, practice of building design." 283

281 R.J. Day, "Mine Blacksmith Shops," in Engineering and Mining Journal, October 15, 1921. 609 (609-613).

282 Gilman, "Ideal Shop for Sharpening Drill Steel," 585.

283 Betsy Bradley, The Works, 16. 


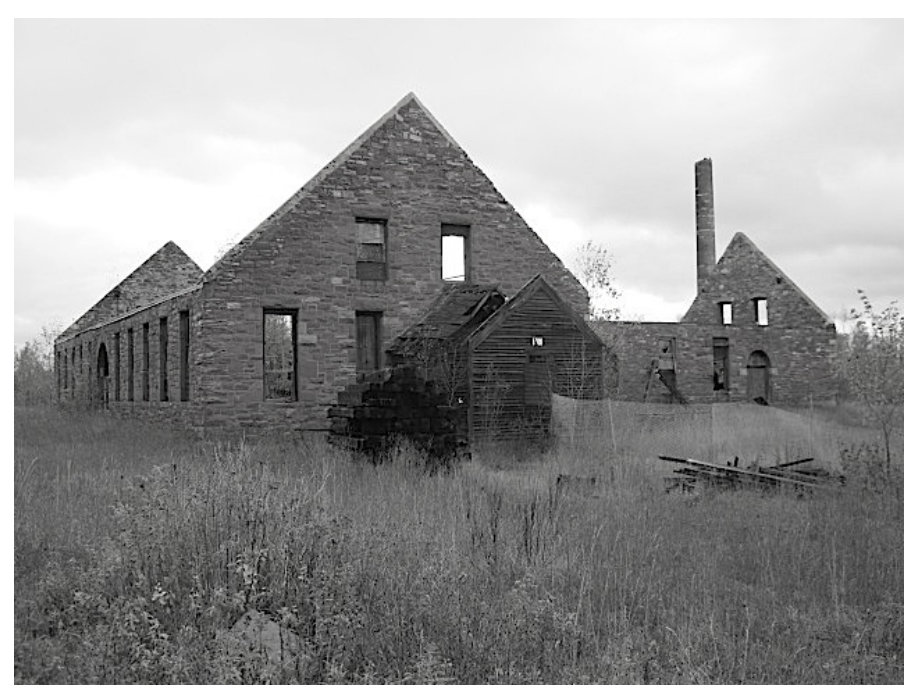

Figure 12. Quincy Mine Blacksmith Shop in its present condition (October, 2011). Office is the wood structure in foreground. Photograph by author.

Looking at the remains of the structure today (see Fig. 12) it would be tempting to assume that the small structure to the side (labeled "Office" on the drawing) was an afterthought. But it was clearly planned as a part of the original structure: separate, but part of the whole. Without the plans as supporting evidence, it would be difficult to assert that this wooden structure as it now stands was designed and built as a part of the larger whole, which is composed primarily of sandstone block. With the use of coal and coke as fuel for the forges, the interior of the blacksmith shop was undoubtedly smoke-filled, but the percussive impact of the steam hammers and the steady roar of the forges created an environment where speech could only occur with great difficulty. This small structure illustrates the importance and usefulness of "keeping sound in mind" when looking at structures and landscapes. Separated from the interior of the shop by a wall of sandstone block, this office space was a sonic 
sanctuary, and also perhaps intentionally designed as such. Its construction was an additional expense; more costly than simply building a partition wall within the main "T" structure. The physical transition from sandstone to wood structure provides a breaking point for the transmission of sound and vibration, and is an example of "insulation through structural separation:"284

Although sometimes difficult and almost always expensive to achieve, a significant increase in transmission loss is made possible by structural separation. The total insulation value is greater with equal mass if the structure is separated and has none or few rigid connections. Typical examples of separated constructions are floating floors and multiple shell floating 'room-within-room' constructions. ${ }^{285}$

A plan and section of the foundation required for the placement of the NilesBement Steam Hammer shows that the hammer's base is set well below floor level. The HAER drawing of the shop identifies the floor material as "dirt" and this is in keeping with a visual survey of the shop as it now stands. From the standpoint of sound and vibration, this is very significant- it means that the force of the impact as well as all other vibrations of the steam hammers (as well as the sharpeners, bolt forge, punch and shear, grinder, and internal steel rail for the pushcarts) was transmitted directly down into the earth, not into the building itself. From this simple fact, one can safely conclude that the structure of the blacksmith shop was largely free from the vibration created by the force of these devices, although it was most certainly felt through the feet. A study of contemporary forges and foundries in England states that "drop hammers can cause detectable ground vibration up to around 100 metres away, and sometimes at greater distances in some ground 284 Peter Grueneisen, Soundspace: Architecture for Sound and Vision (Basel: Birkhauser, 2003), 68. 285 Ibid. 
conditions." 286 With the exception of the belt driven tools (vertical drill press, blowers for forges, etc.) and the overhead cranes, most of the mechanical vibration in the shop was directed and transmitted downward into the earth, so most of the noise created by the steam hammers and other "grounded" devices was airborne, but as a porous and variegated substance, the earth floor also absorbed sound energy from the air. The nearby machine shop, whose machines were all placed upon a plank floor and connected to the truss system via drive belts for power, was possibly a much louder environment when in full operation, because the steady-state vibration of all of the equipment was transferred into the structure itself, becoming structureborne sound within the shop ${ }^{287}$, a resonant system in itself. Significantly, no mention of sound or noise is made in Bradley's history of industrial architecture of the United States, but vibration and oscillation is presented as a major concern for structural design:

Industrial buildings that housed mechanized equipment had to withstand both vibration and oscillation. Vibration, the shaking of a building due to the movement of its elastic floors and beams, was not caused by a lack of structural stability. It was reciprocating machinery that put walls in motion and could shift buildings off their foundations....Floor construction was tailored to the intended use of the building. The jarring and reciprocating pounding movements of machinery in wood and metalworking shops required floors with properties that were different from those used in lofts filled with steadily operated textile spinning and weaving equipment. ${ }^{288}$

The floor of the blacksmith shop served the space well from the point of view of vibration as well as fire, but the decision to have a dirt floor was not universally

286 Bob Davis, "Reducing Noise from Forges and Foundries: The Handbook of the Black Country Forging and Foundry Project," (Southhampton: ISVR University of Southhampton, 2002), 4. 287 Grueneisen, Soundspace: Architecture for Sound and Vision, 16.

288 Bradley, The Works, 109. 
condoned. In one article from 1917 examining the layout of several mining blacksmith shops closely, the author maintains that the floor of an "ideal" shop "should preferably be of concrete, poured after the wood base plates of the various fixtures, including ties for the track system, are placed in position." ${ }^{289}$ This is a perfect example of how an archaeoacoustic investigation can hit the brick wall of ascertaining intentionality. It would be tempting to assert that in the decision to have a dirt floor there was embedded an intentional desire to dampen sound, but this claim cannot be made. However, it is safe to claim that the decision to have an earth floor did result in a sound environment far superior than would have existed with a (highly reflective) concrete floor. Another good reason for having a dirt floor was for easy access to the underground pipe which carried blown air down from the blowers mounted on a loft structure to each of the individual forges.

A casual pedestrian passing by the Quincy Mining Company blacksmith shop in 1916 was unlikely to have heard the isolated, rhythmic, steady ringing of hammer on anvil described in Pythagoras' experience or in any other numerous poetic and fictitious accounts, such as Longfellow's well known poem "The Village Blacksmith," 290 although the anvils were still in place and were used as a part of the sharpening process. In the manual Machine Blacksmithing, author James Cran notes that the best way to discern an anvil's integrity is by its sound:

The quality of an anvil can generally be judged by its "ring," a good anvil giving out a sharp, clear sound when struck with a hammer; if soft or not free from flaws, the sound will be dull. A good anvil

289 Gilman, "Ideal Shop for Sharpening Drill Steel," 592.

290 An advertisement for films being presented at the Lyric Theatre in the Calumet News on April 21, 1916 features the film "The Village Blacksmith," starring Hank Mann and Bert Gillispie. 
mounted on a block in such a manner that it gives out its full volume of sound is easier to work upon than one where the ring is deadened. ${ }^{291}$

The tendency of a metal form to resonate when struck is largely contingent upon its being unbound by external forms or internal flaws, allowing the displacement of its mass to continue to vibrate. A brief examination of several hollow drill bits found on the ground at the drill shop was able to produce this ringing sonifact, but only when the bits were held loosely. In the operation of drill sharpening, the bits were bound firmly to the device, with the resulting sound probably more percussive than resonant. Also, heated metal is soft and does not "ring," so the same is also true for the sonifactual component of steam hammer operations. The archetypical ringing sonifact of the blacksmith shop was most evident during the process of straightening the cool, loosely held bits by hand with hammers on the anvils.

While no specific information is available regarding the particular reflective or absorptive properties of Jacobsville sandstone, it is generally accepted that rough, uneven surfaces disperse sound, and slightly porous surfaces absorb sound. Jacobsville sandstone fulfills both of these requirements. While slate in itself is certainly more reflective, the exposed underside of the roof slate was broken every ten inches or so by wood lathe, necessary to secure the slate to the purlins. This uneven surface also served to form a dispersive sound environment, along with the shape of the roof itself.

From an acoustician's standpoint, the Quincy Mine blacksmith shop was acoustically "dead" with little reverberation, and whether this was by design or accident, these 291 James Cran, Machine Blacksmithing (New York: The Industrial Press, 1910) 23. 
material properties served to protect the hearing of those working within it. Viewed as a sonic midden, the shop is somewhat sparse, because the roof is gone as well as many other host artifacts that were once there, but when constrasted with a reconstructed sonifactual assemblage from April 15, 1916, the existing sonifactual assemblage on site demonstrates a dramatic change. As it now stands, the dominant sonifacts within and around its confines are the sounds of the friction of rubber tires on pavement and the internal combustion engine produced by automotive traffic on US Highway 41. As these sonifacts disperse, one can sometimes hear the wind blowing through the leaves of trees now growing within the structure. 
Table 4. Sound absorption coefficients for materials in Blacksmith Shop. ${ }^{292}$ Note: a value of 1 is equivalent to full absorption.

\begin{tabular}{|c|c|c|}
\hline Material & $\begin{array}{l}\text { Sound absorption coefficient at } \\
\qquad 250 \mathrm{hz}\end{array}$ & Other Properties \\
\hline Dirt (floor) & $\mathrm{n} / \mathrm{a}$ & \\
\hline Sandstone block (walls) & .44 (raw concrete block) $)^{293}$ & $\begin{array}{l}\text { Rough, variegated, porous surface. } \\
\text { Diffusive at high frequencies. Also } \\
\text { absorptive. }\end{array}$ \\
\hline Glass panes (windows) & $0.25^{294}$ & Reflective \\
\hline Slate (roof) & $\mathrm{n} / \mathrm{a}$ & Rough surface. Diffusive. \\
\hline Wood (roof structure, loft floors) & $0.11^{295}$ & $\begin{array}{c}\text { Reflective } \\
\text { Diffractive (sound waves change } \\
\text { direction in contact with roof } \\
\text { beams) }\end{array}$ \\
\hline Air & $.20^{296}$ & $\begin{array}{l}\text { Refractive (heat from forges creates } \\
\text { temp. differentials, changing } \\
\text { direction of sound) }\end{array}$ \\
\hline Iron, steel plate & $0.01^{297}$ & Reflective \\
\hline Open window & 1 (theoretical value) & Full absorption \\
\hline
\end{tabular}

\subsection{Tools and Operations: A Sonifactual Assemblage}

The main function of blacksmith shop was drill sharpening, so emphasis will be placed upon these operations, but as indicated in the time sheets of an earlier year, the shop was also actively involved in railroad repairs as well as repairs throughout other facets of the mine. Besides the Word drill sharpeners, there were several other host artifacts contributing to the sonifactual grouping within the shop. On a now teetering loft structure, one can see a large Sturtevant blower for the supply of air for

292 Sound absorption levels for materials vary dramatically depending upon the frequency of the sound. The frequency chosen, $250 \mathrm{hz}$, is close to "Middle C" on a piano.

293 Grueneisen, 14.

294 Ibid.

295 Ibid.

296 file://Users/jeffbenjamin/Desktop/Sound\%20Absorption\%20Coefficients.webarchive

297 Grueneisen, 14. 
the forges, one of two such blowers on site. While the sharpeners used compressed air from a compressor house downhill, a visual survey of the site suggests that the forges were supplied blown air by these blowers (see Fig. 12). Patents issued to B.F. Sturtevant for blower designs reach back to March 2, $1869^{298}$, and these patents are aimed at achieving maximum efficiency, to "intercept the air-currents as they are thrown off tangentially from the ends of the fan blades"299 and redirect this flow to the fan outlet. The need for a steady supply of blown air for the forges was crucial for the sharpening operation, and this flow likely continued day and night as the mine was in operation 24 hours and needed a constant supply of sharpened drill steels. This blown air, as it entered into the tuyeres below each forge (see Fig. 14) combined with the fuel to create a "combustion roar" 300 that was a steady sonifactual presence in the shop. Although interestingly labeled "Noiseless" on their cases, the blowers were powered by an electric motor through a belt drive mounted on a wooden platform (now collapsed, see Fig. 13). Belts and motors are prone to vibration, and this was likely transferred to the structure of the platform, contributing to the structure-borne sound within the shop.

298 B.F. Sturtevant, "Design for a Blower-Case," Design No. 3,399. March 2, 1869. United States Patent Office.

299 B.F. Sturtevant, "Improvement in Pressure-Blowers," Patent No. 92,489. July 13, 1869. United States Patent Office.

300 Bob Davis, "Reducing Noise from Forges and Foundries," 9. 


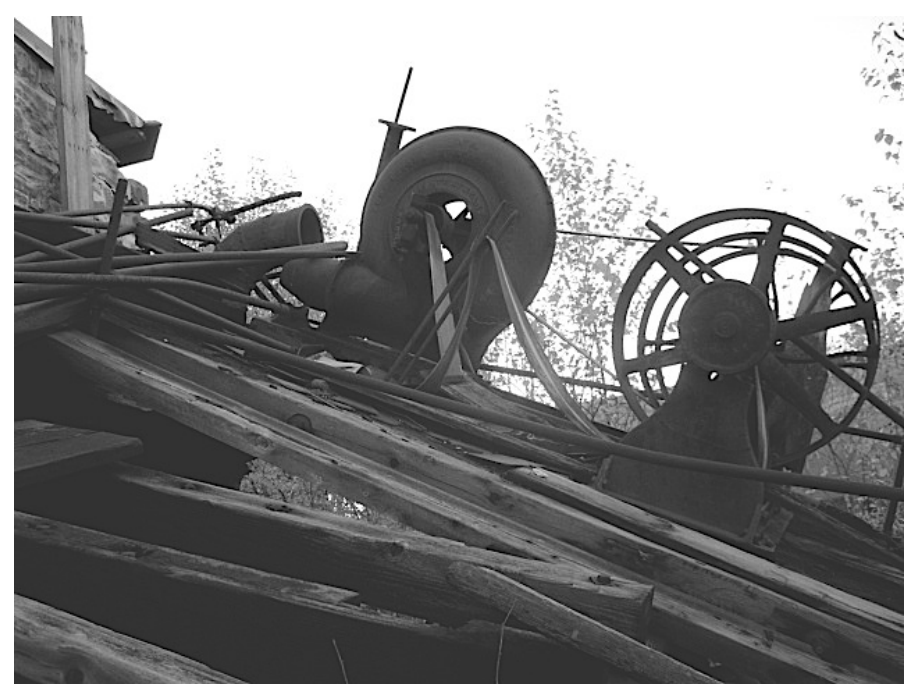

Figure 13. Sturtevant blower mounted on overhead loft. Quincy Mine Blacksmith Shop. October, 2011. Photograph by author.

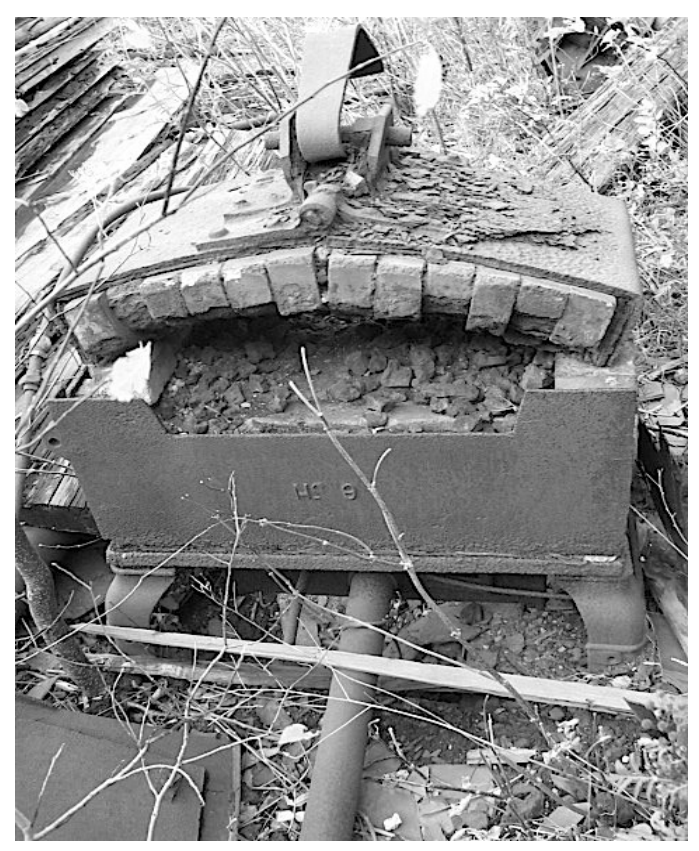

Figure 14. No.9 Bradley Forge. Quincy Mine Blacksmith Shop. October 2011. Photograph by author. 


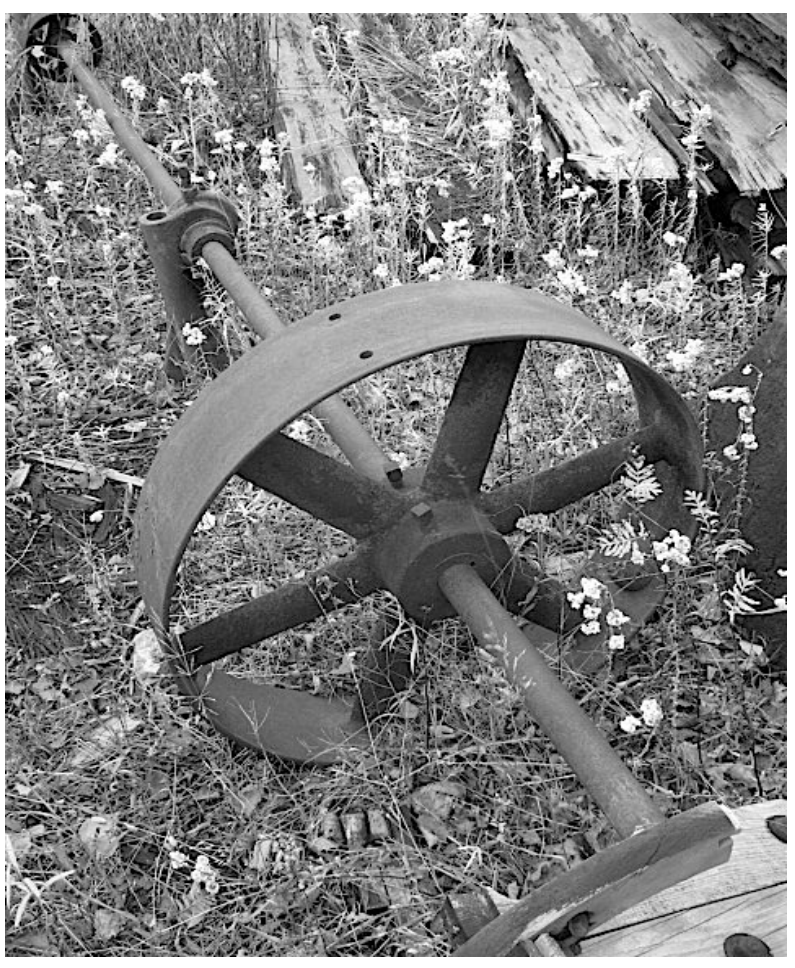

Figure 15. Wheel for belt drive system. Quincy Mine Blacksmith Shop. October 2011. Photograph by author.

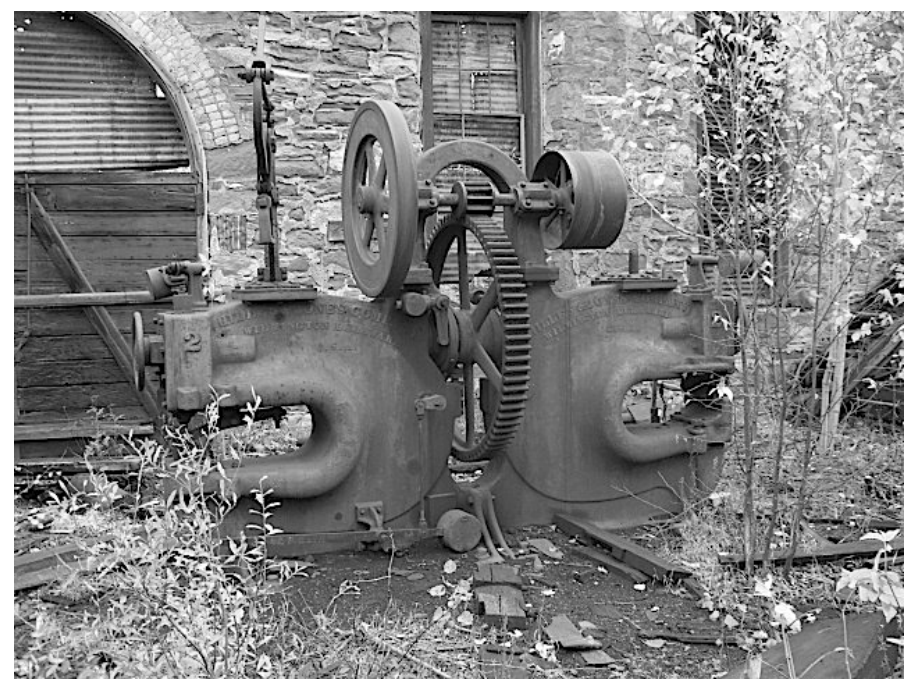

Figure 16. No. 2 Punch and Shearing Machine. Hilles and Jones, Wilmington, DE. Quincy Mine Blacksmith Shop. October 2011. Photograph by author. 


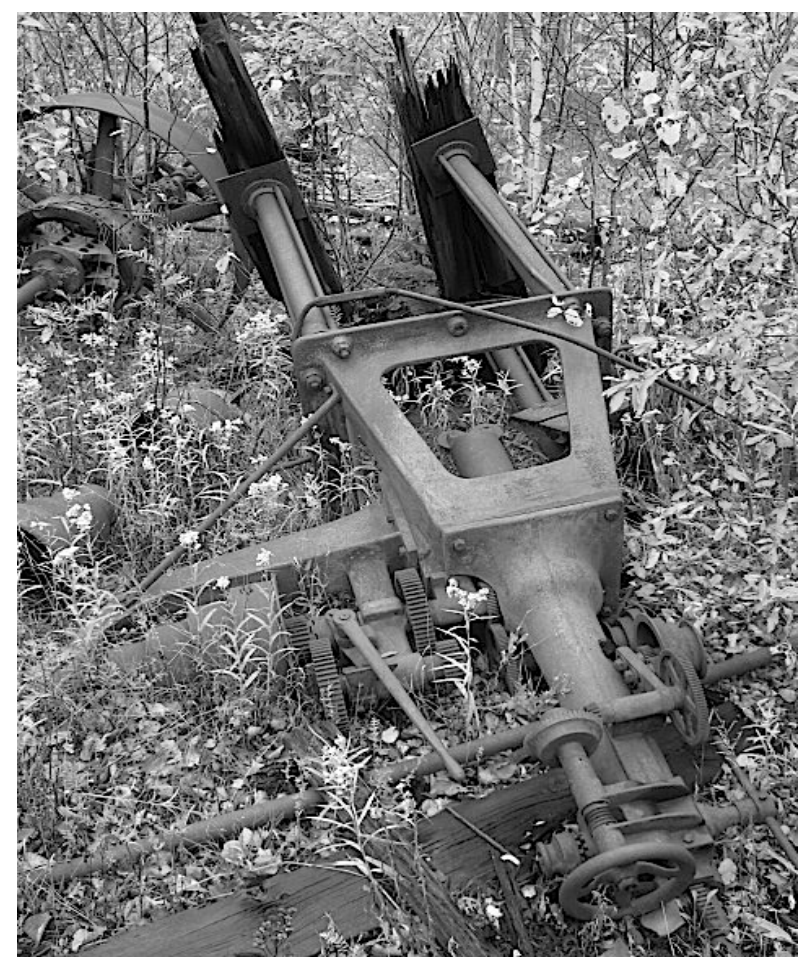

Figure 17. Prentice Bros. Co. Overhead Drill Press. Worchester, Mass. Quincy Mine Blacksmith Shop. October 2011. Photograph by author.

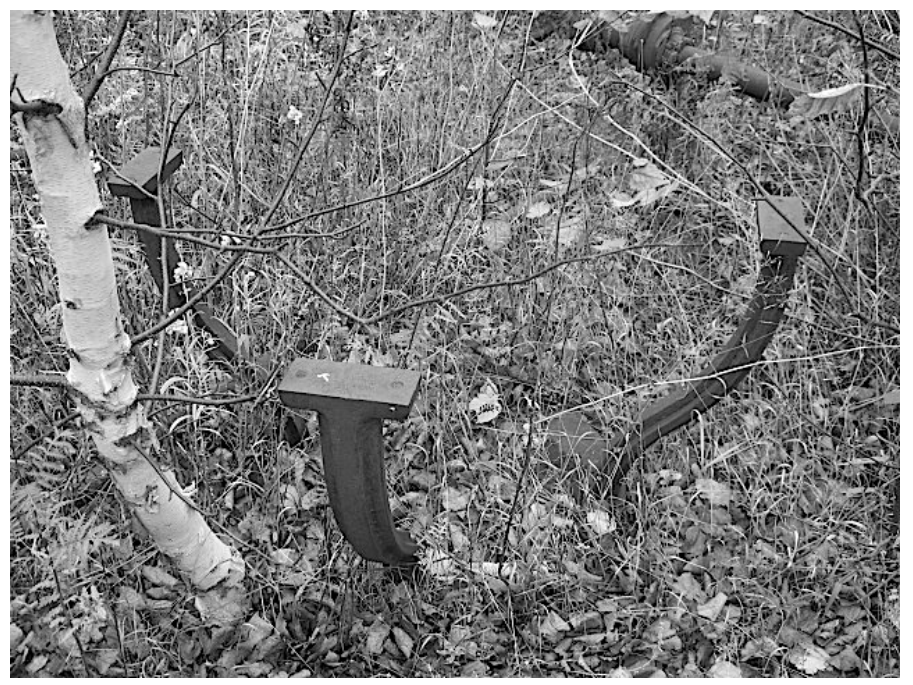

Figure 18. Overturned drill table. Quincy Mine Blacksmith Shop. October, 2011. Photograph by author. 


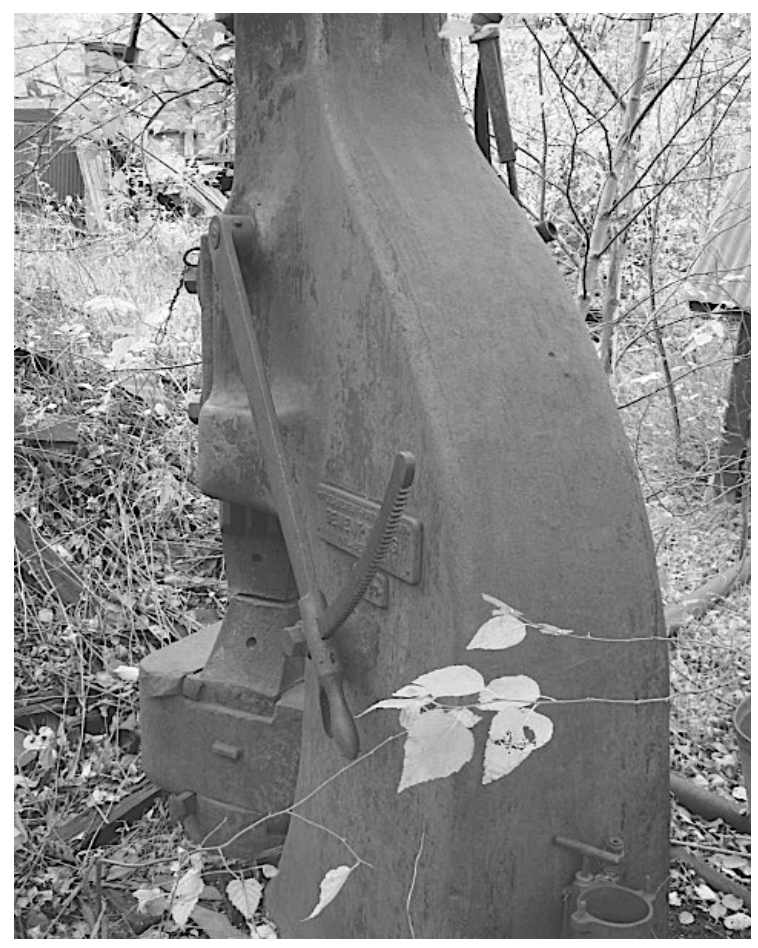

Figure 19. Steam hammer. Niles-Bement Pond Co., Philadelphia. Quincy Mine Blacksmith Shop. October, 2011. Photograph by author.

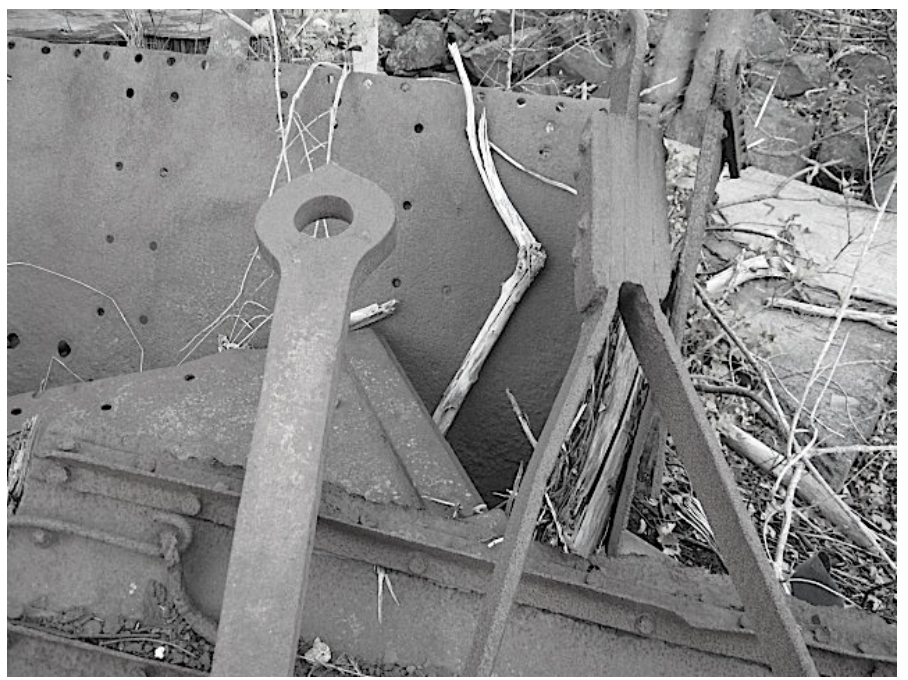

Figure 20. Skip parts and linkages. Quincy Mine Blacksmith Shop. October 2011. Photograph by author. 


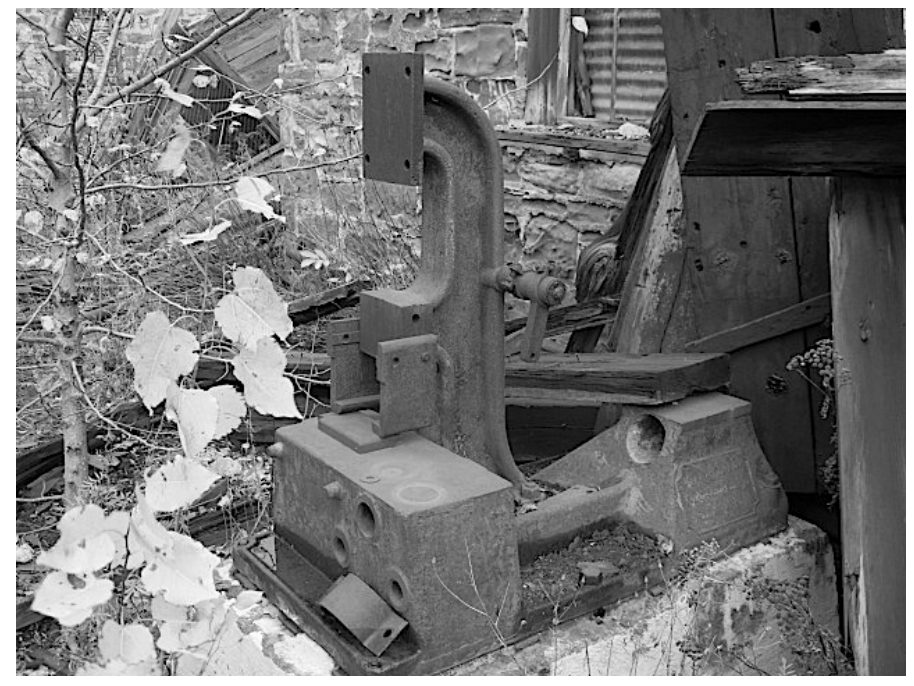

Figure 21. Cement base and mounting arm for hammers for Word Drill Sharpener. Quincy Mine Blacksmith Shop. October 2011. Photograph by author.

On the east side of the shop was (and still is) a No.2 Punching and Shearing machine, built by Hilles and Jones, Wilmington, Delaware (see Figure 16). A substantial device weighing several tons, this machine is also anchored into the earth, and was also powered by a drive belt connected to a drive shaft that was mounted to the trusses overhead. A patent from 1898, ascribed to John A. Nicholls of Pittsburg, Pennsylvannia describes the purpose of this invention: "to construct a machine which may be employed at the one side for punching beam-iron, T-iron, angle-iron, and all material of a like nature and at its opposite side be arranged for shearing like material, each mechanism operating independently of the other or 
coacting in unison if desired..." ${ }^{301}$ Large, thick, heavy pieces of steel bar and plate could be punched or cut with this device, and it may have been used to cut drill steel stock to desired lengths. An overhead chain hoist connected to the device itself held pieces aloft as they were guided into place. Both punching and shearing are cutting operations, so this device did not create the percussive sonifact of "metal on metal" impact, but it is difficult without seeing its operation just what kind of sound was produced.

Now lying on its side, not far from its original location, is an overhead drill press, fabricated by Prentice Bros. Company, Worchester, Massachusetts (see Fig. 17) A removable steel table that was located underneath it is now lying upside down (see Fig. 18). This device was also powered by the overhead belt drive, and was itself mounted to the trusses overhead to provide complete clearance beneath the chuck and cutting head. The purpose for this configuration is described in a patent:

The object of our invention is to produce a drill press capable of handling any ordinary run of work, and also capable of operating upon the middles of large articles the size of which is materially greater than the distance between the drill spindle and the support of the usual work table.

To this end we have produced a drill press which, instead of being supported upon the floor in the usual manner, is suspended rigidly from a ceiling, the construction being such that the drill spindle bracket may be readily adjusted in height from the floor and the work table may be readily removed. ${ }^{302}$

Positioned near the internal steel track within the shop, this drill press was used for drilling holes into large unwieldy forms, such as skips and compartment cars, as well

301 John A. Nicholls, "Combined Punching and Shearing Machine," Patent No. 613,072. October 25, 1898. United States Patent Office.

302 John Henry Birch and John Hays Birch, "Suspended Drill Press," Patent No. 857,020. June 18,1907, United States Patent Office. 
as smaller forms that could be mounted to the table below. Upon lifting it, the surface of the steel table showed many holes and depressions where the drill bit extended into its surface.

Another, extremely substantial belt driven device in the shop is the bolt forge. The purpose of the bolt-forging machine, as described in an early patent, was "to forge the head and shoulder of a carriage-bolt at a single operation, and with the sides of the square shoulder of the full size of the diameter of the round stem, and also to make the bolts, when forged, of practically uniform length from the under side of the head to the point of the stem..." ${ }^{303}$ The mass of this machine suggests that considerable force was applied to the bolt blanks as they were formed, leading one to believe that this may have been forged cold. A careful read of the initial patent issued to Burdict as well as a later patent issued to J. Wagner ${ }^{304}$ reveals no mention of heat being applied to the bolt blanks, although this is perhaps assumed.

In the north wing of the shop, occupying the entire section of space 50 by 124 feet, were two steam hammers, one produced by Niles-Bement Pond Company and another by William Sellers, both fabricated in Philadelphia. The Niles-Bement hammer is still in its 1914 location (see Fig. 19). These devices can be viewed as the host artifacts producing substantial and repeated sonifacts of metal on metal impact. Operating on compressed air with a pressure of 75-125 p.s.i., the Niles-Bement hammer incorporated an exhaust pipe for air release. ${ }^{305}$ Because of its mass and size,

303 Orrin C. Burdict, "Bolt Forging Machine," Patent No. 285,876. October 2, 1883. United States Patent Office.

304 J. Wagner, "Bolt Making and Forging Machine," Patent No. 666,167. January 15, 1901. United States Patent Office.

305 Niles Bement catalogue, 195. 
these tools were capable of drawing and forming heated metal of substantial dimensions, and were probably used for forming linkages such as the one pictured in Figure 20, as well as numerous other applications. The most obvious sonic forms resulting from the use of these hammers would have been repeated percussive and forceful impacts, which could be felt in the soles of the feet as well as heard. Both hammers had circular cranes above them which held the objects to be worked aloft, to be guided and shifted by a blacksmith separate from the operator of the hammer. The operation of these devices was notoriously awkward, and the sound of the hammer in full operation precluded verbal communication between the two blacksmiths:

Take, for example, the arrangement of the hand levers on most of the single-frame hammers in general use....To manipulate levers...the operator is placed not only in a cramped, awkward position, but so that he can only with difficulty see the work being done.... When working under a full head of steam, his left arm comes directly in front of his face, obscuring his view of the work. He must remain in this position until the operation on the work is completed; should he release his hold upon the throttle lever, the jar of the hammer would immediately bring that lever to the perpendicular position and shut off the steam. The operator's view of the work being obscured is also often responsible for his mistaking the signs which must necessarily be used while work is being done at a steam hammer on account of the noise. ${ }^{306}$

306 James Cran, Machine Blacksmithing, 32. 


\subsection{Drill Sharpening}

The most important function for the blacksmith shop of any mining company was the sharpening of drill steel (see Figure 21). An article from 1909 in The Engineering and Mining Journal estimated that the Calumet and Hecla Mining Company needed to sharpen 4000 bits per day in order to keep up with the drilling underground. ${ }^{307}$ Although a more modest operation than Calumet and Hecla, the Quincy Mine was in full gear during 1916, and the drill shop was probably operating three full shifts as was the rest of the mine. By August 14, 1914 the Quincy Mine was using "110 jackhammers, which shows the extent to which foot-wall exploration is being carried" ${ }^{1308}$ but by 1916 this number must have been significantly greater. Gleaned from several different sources, the process of sharpening a dulled drill steel in the Quincy Mining Company blacksmith shop during this time period is narrated below, with sources included within the text citation-style and then listed in footnotes at the end of the passage.

\section{Sequence of Operations for Sharpening of Drill Steel}

The drill steel is manually pushed into the shop on pushcars rolled off the flatcar from the loading dock of the Quincy and Torch Lake Railroad directly outside the blacksmith shop.

Dull drill steels are removed from the cart and placed in storage racks (Day 610), then they are placed on a drill steel table for straightening or straightened on an anvil

307 C.L. Fichtel, "Calumet and Hecla Drill-Sharpening Device," The Engineering and Mining Journal, 87 (22), May 29, 1909. 1073-1075.

308 "Wide Use of One-Man Drills in the Copper Country," Mining and Scientific Press, August 14, 1914. 266. 
(Gilman 592) with a sledge.

They are then placed in compartment car with a revolving top (Gilman 592).

If clogged, the holes in the bits are blown out with compressed air (Gilman 592).

The drill steel is heated in a forge, the gauging of drill steel temperature is done visually, by looking at the color of the heated steel. The blacksmiths "place (the steel) into the heating furnace, handling the steel in rotation by inserting a new piece when one is removed" (Gilman, 592). For this reason, drill sharpening is ideally done in a darkened area (Gillette, 52). This would correspond with the location of the Word Sharpeners under the loft structure.

"It has been determined by experiment that the time period of $4 \mathrm{~min}$. is desirable for heating the larger sizes of bits formed on the $1 \frac{1 / 4}{4}$ in. round hollow drill steel and in order to insure an output of one steel every $30 \mathrm{sec}$ " (Gilman 588).

When heated, the steels are then "pinned"..."for opening the hole in the hollow drill steel when it becomes closed during the sharpening operation or from other causes." (Day 609) "It has been found that by pinning the hole in the bit of the hollow drill steel before resharpening the bit, the hole will remain open after the bit has been resharpened..." (Day 612).

The drill steel is then placed into the sharpener, where it is formed "under light rapid percussive blows" (Gilman 590) by a "drill sharpening machine answering this requirement."

The basic process of sharpening a drill steel in a Word Sharpening Machine is described by William W. Word in his patent application. The heated drill steel is formed by two hammers "operated by any elastic fluid, preferably compressed air...connected by mechanical communications...with a foot-pedal...the movement of which in opposite directions starts or stops the hammers...alternatively one at a time, as governed by the range of movement of the pedal." One hammer (oriented vertically) forms the profile of the bit longitudinally along the shank, the other (oriented horizontally) forms the end of the cutting edge, the metal being "driven by redundancy" into its proper form by appropriate dies and dollies (Word, 2).

"After shaping, the bit is reheated for tempering and at the proper temperature is placed in the cooling bath...only the face of the bit is hardened" (Gillette 54) (Day 611) In some cases, the blacksmith will "dip the tip in the cyanide of potassium and then plunge the heated end in the oil vat," to cool, then place it in the compartment car face end down (Gilman 592).

The floor grinder is then used for "squaring off the ends and redressing drill shanks," 
and "for refacing dies and dollies and other general grinding" (Gilman 589).

Finally the bits are placed in sharpened steel rack (Day 613; Gilman 590).

For new drill steels, the shank end must be also formed also with the sharpener, this is the same process as sharpening a dull steel (Gilman 592). ${ }^{309} 310311312$

Since there are four drill sharpeners present on the layout of the shop in 1914, it is possible that the most of the operations detailed in the above sequence of operations happened four times simultaneously when the blacksmith shop was in full use, as well as the other numerous activities on site. The task of piecing together a plausible sonifactual assemblage seems close to impossible, but by looking closely at the blacksmith shop and its surroundings, we can certainly see that the sound environment was complex and layered, filled with multiple repetitive percussive strikes of metal on metal from four sharpeners, the hissing release of compressed air from the pistons of the hammers, the resonant ring of cold bits being straightened on anvils and steel tables, the deep roar of forges (the HAER drawing shows eighteen!), the thumping of earth underfoot from the steam hammers, the rumbling vibration of electric motor and belts in the trusses and roof structure, the exclamations of blacksmiths' communicating with each other. In attempting to truly capture this environment, one runs into the problem of the inadequacy of language, and perhaps a

309 R.J. Day, "Mine Blacksmith Shops," Engineering and Mining Journal. October 15, 1921. 609613.

310 George H. Gilman, "Ideal Shop for Sharpening Drill Steel," Engineering and Mining Journal. October 6, 1917. 585-593.

311 Halbert Powers Gillette, Handbook of Rock Excavation: Methods and Cost (New York: Clark Book Company, 1916).

312 William W. Word, "Process of Forging Rock Drills," Patent No. 732,727. June 23, 1903. United States Patent Office. 
new language needs to be invented to suit the purpose of describing individual sound-forms.

When writing about sonifacts, it is important to privilege the qualities of the sounds over their sources of origin, because it is the sounds themselves that are under consideration, not their host artifacts. While only a beginning, the following table presents an attempt, perhaps a guide for future attempts toward the recreation of a sonic assemblage. The ultimate goal is to move from sonifact (quality) towards host artifact (source object).

Table 5. Plausible reconstructed sonifactual assemblage in Quincy Mine Blacksmith Shop (production area), April 15, 1916.

\begin{tabular}{|c|c|c|c|c|c|}
\hline \multicolumn{2}{|c|}{ Sound-Form/Sonifact } & \multicolumn{2}{|c|}{$\begin{array}{c}\text { Source-process/Host } \\
\text { artifacts }\end{array}$} & \multirow{2}{*}{$\begin{array}{l}\text { Temporal information } \\
\mathrm{n} / \mathrm{a}\end{array}$} & \multirow{2}{*}{\begin{tabular}{l}
\multicolumn{1}{c}{$\begin{array}{c}\text { dB/Other } \\
\text { Properties }\end{array}$} \\
75-125 p.s.i./ $51 / 2-16^{1 / 2}$ \\
cubic feet $/$ min. $^{313}$ \\
116-132 dB
\end{tabular}} \\
\hline \multirow{2}{*}{\multicolumn{2}{|c|}{ Heavy Percussive }} & \multirow[t]{2}{*}{$\begin{array}{l}\text { Steam } \\
\text { Hammers }+ \\
\text { heated steel }\end{array}$} & $\begin{array}{l}\text { William } \\
\text { Sellers } 10^{\prime \prime} \mathrm{x} \\
18 "\end{array}$ & & \\
\hline & & & $\begin{array}{l}\text { Niles-Bement } \\
\text { Pond Co. }\end{array}$ & $\begin{array}{l}\text { Average } 3 \text { impacts per second } \\
\text { at full throttle } 314\end{array}$ & $116-132 \mathrm{~dB}^{315}$ \\
\hline \multirow{3}{*}{\multicolumn{2}{|c|}{ Light Percussive }} & \multicolumn{2}{|c|}{$\begin{array}{l}\text { Word drill sharpeners (5)+ } \\
\text { heated drill steel }\end{array}$} & $\begin{array}{l}24 \text { hrs- with pauses / 50-60 } \\
\text { steels/hr. capacity } 316 " L i g h t, \\
\text { rapid, percussive blows"1317 }\end{array}$ & $\begin{array}{l}90-100 \mathrm{~dB}^{318} \\
\text { (pneumatic } \\
\text { jackhammer/air chisel) }\end{array}$ \\
\hline & & \multicolumn{2}{|l|}{ Pinning ${ }^{319}$} & 24 hrs- Intermittent & \\
\hline & & \multicolumn{2}{|c|}{ Striking on anvils (2) } & 24 hrs- Intermittent & $100 \mathrm{~dB}^{320}$ \\
\hline Heavy & Pressurized & \multicolumn{2}{|c|}{$\begin{array}{l}\text { Steam hammers/ compressed } \\
\text { air exhaust }\end{array}$} & Intermittent, muffled. ${ }^{321}$ & \\
\hline
\end{tabular}

313 Niles Bement Pond Company, Machine Tools 1920 (Philadelphia: Niles Bement Pond Company, 1920) 193. (Company Catalogue).

314 http://www.youtube.com/watch?v=nARZj8SwVAE

$315 \mathrm{http} / / /$ www.epd.gov.hk/epd/english/environmentinhk/noise/guide_ref/files/tm_pp.pdf

316 Gillette, Handbook of Rock Excavation: Methods and Cost, 57.

317 Gilman, "Ideal Shop for Drill Sharpening," 509.

$318 \mathrm{http} / /$ www.engineeringtoolbox.com/sound-power-level-d_58.html

319 Day, "Mine Blacksmith Shops," 609.

320 http://www.engineeringtoolbox.com/sound-power-level-d_58.html

321 Niles Bement Pond Company, Machine Tools 1920 (Philadelphia: Niles Bement Pond Company, 1920) 193. (Company Catalogue). 


\begin{tabular}{|c|c|c|c|c|c|}
\hline \multirow[t]{3}{*}{ Aeolian } & & \multicolumn{2}{|c|}{$\begin{array}{l}\text { Steam exhaust: Quincy and } \\
\text { Torch Lake Railroad loading } \\
\text { dock }\end{array}$} & Intermittent. & $110 \mathrm{~dB}^{322}$ \\
\hline & & \multicolumn{2}{|c|}{ Sturtevant Blowers } & Constant, $24 \mathrm{hrs}$ & $\begin{array}{l}110 \mathrm{~dB} \text { ("Centrifugal } \\
\text { fan") }\end{array}$ \\
\hline & $\begin{array}{l}\text { Incendiary } \\
\text { (roar) }\end{array}$ & \multicolumn{2}{|c|}{$\begin{array}{l}\text { Bradley No. } 9 \text { Forges, } \\
\text { Bradley No. } 10 \text { Tempering } \\
\text { Forge }\end{array}$} & Constant, $24 \mathrm{hrs}$ & $94-102^{324}$ \\
\hline \multirow{3}{*}{\multicolumn{2}{|c|}{ Light Aeolian }} & \multicolumn{2}{|c|}{$\begin{array}{l}\text { Drill sharpeners/ compressed } \\
\text { air exhaust }\end{array}$} & $24 \mathrm{hrs}-$ Intermittent & \\
\hline & & \multicolumn{2}{|c|}{ Human breathing } & Constant, $24 \mathrm{hrs}$ & $10 \mathrm{~dB}^{325}$ \\
\hline & & \multicolumn{2}{|l|}{ Oil quench } & & \\
\hline \multirow{10}{*}{\multicolumn{2}{|c|}{$\begin{array}{l}\text { Tintinnabula (ringing) } \\
\text { Ferric resonant }\end{array}$}} & \multirow[t]{5}{*}{$\begin{array}{l}\text { Drill bits } \\
\text { striking: }\end{array}$} & $\begin{array}{l}\text { Compartment } \\
\text { car }\end{array}$ & $24 \mathrm{hrs}$ - Intermittent & \\
\hline & & & $\begin{array}{l}\text { Steel table } \\
\text { (straightening) }\end{array}$ & 24 hrs- Intermittent & $\begin{array}{l}100 \mathrm{~dB} \text { ("Banging of } \\
\text { steel plate) }{ }^{326}\end{array}$ \\
\hline & & & $\begin{array}{l}\text { Anvil } \\
\text { (straightening) }\end{array}$ & 24 hrs- Intermittent & $100 \mathrm{~dB}^{327}$ \\
\hline & & & $\begin{array}{l}\text { Furnace } \\
\text { support }\end{array}$ & 24 hrs-Intermittent & \\
\hline & & & $\begin{array}{l}\text { Storage } \\
\text { cabinet }\end{array}$ & 24 hrs- Intermittent & \\
\hline & & \multicolumn{2}{|c|}{ Chain hoists for steam stamps } & 24 hrs- Intermittent & \\
\hline & & \multicolumn{2}{|c|}{$\begin{array}{l}\text { Hand tools (hammers, dollies, } \\
\text { dies) }\end{array}$} & 24 hrs-Intermittent & \\
\hline & & \multicolumn{2}{|c|}{$\begin{array}{l}\text { Bell: Quincy and Torch Lake } \\
\text { Railroad loading dock }\end{array}$} & Periodic & $110 \mathrm{~dB}^{328}$ \\
\hline & & \multicolumn{2}{|c|}{$\begin{array}{l}\text { Bell: Pewabic Methodist } \\
\text { Episcopal church ( } 50 \text { yds.) }\end{array}$} & Periodic & \\
\hline & & \multicolumn{2}{|c|}{ Fastener sorting (loft structure) } & & \\
\hline \multirow[t]{2}{*}{ Vocal } & Sharp & \multicolumn{2}{|c|}{$\begin{array}{l}\text { Human warnings, alerts, } \\
\text { commands, exclamations }\end{array}$} & Intermittent & $60-70 \mathrm{~dB}^{329} 330$ \\
\hline & Melodic & \multicolumn{2}{|c|}{ Employees singing } & Periodic/ constant & $40-70 \mathrm{~dB}^{331}$ \\
\hline \multirow{3}{*}{$\begin{array}{l}\text { Structure- } \\
\text { borne/ } \\
\text { Steady } \\
\text { (hum, buzz, }\end{array}$} & \multirow{3}{*}{$\begin{array}{l}\text { Heavy (long } \\
\text { wavelength) }\end{array}$} & \multirow{3}{*}{$\begin{array}{l}\text { Belt drive } \\
\text { system } \\
\text { (connected to } \\
\text { trusses) }\end{array}$} & & & \\
\hline & & & $\begin{array}{l}\text { Blowers (loft } \\
\text { structure) }\end{array}$ & Constant 24 hrs. & \\
\hline & & & Bolt forge & Intermittent & \\
\hline
\end{tabular}

$322 \mathrm{http} / / /$ home.earthlink.net/ dnitzer/4HaasEaton/Decibel.html

$323 \mathrm{http}: / /$ www.engineeringtoolbox.com/sound-power-level-d_58.html

324 Bob Davis, "Reducing Noise from Forges and Foundries: The Handbook of the Black Country Forging and Foundry Project," (University of Southhampton/ISVR Consulting, 2002) http://www.isvr.co.uk/bcffp/forge.htm

$325 \mathrm{http}: / /$ www.engineeringtoolbox.com/sound-power-level-d_58.html

$326 \mathrm{http}: / /$ www.engineeringtoolbox.com/sound-power-level-d_58.html

327 Ibid.

$328 \mathrm{http} / / /$ home.earthlink.net/ dnitzer/4HaasEaton/Decibel.html

329 http://www.noisehelp.com/noise-level-chart.html

$330 \mathrm{http} / / / \mathrm{www}$. gcaudio.com/resources/howtos/loudness.html

331 Ibid. 


\begin{tabular}{|c|c|c|c|c|c|}
\hline \multirow[t]{4}{*}{ vibration) } & & & $\begin{array}{l}\text { Punch and } \\
\text { Shear }\end{array}$ & Intermittent & $110 \mathrm{~dB}^{332}$ \\
\hline & & & Drill Press & Intermittent & $100 \mathrm{~dB}^{333}$ \\
\hline & \multirow[t]{2}{*}{$\begin{array}{l}\text { Light (short } \\
\text { wavelength) }\end{array}$} & \multicolumn{2}{|c|}{$\begin{array}{l}\text { Electric motor for belts and } \\
\text { pulleys }\end{array}$} & Constant & \\
\hline & & \multicolumn{2}{|c|}{ Rainfall on slate roof } & Intermittent & \\
\hline \multirow[t]{7}{*}{ Ferric (other) } & & \multicolumn{2}{|c|}{ Steel rail/carts } & & \\
\hline & & \multicolumn{2}{|c|}{ Filing of drill steel } & & \\
\hline & & \multicolumn{2}{|c|}{ Floor grinder } & & $90 \mathrm{~dB}^{334}$ \\
\hline & & \multicolumn{2}{|c|}{ Forge hoods/cable and pulleys } & & \\
\hline & & \multicolumn{2}{|c|}{$\begin{array}{l}\text { Door hardware/ } \\
\text { hinges }\end{array}$} & & \\
\hline & & \multicolumn{2}{|c|}{$\begin{array}{l}\text { Manipulation of skips, } \\
\text { linkages, plate steel }\end{array}$} & & $100 \mathrm{~dB}^{335}$ \\
\hline & & \multicolumn{2}{|l|}{ Turntables } & & \\
\hline \multirow{3}{*}{$\begin{array}{l}\text { Deceased } \\
\text { arboreal } \\
\text { (wood) }\end{array}$} & & \multicolumn{2}{|l|}{ Doors (12) } & & \\
\hline & & \multicolumn{2}{|l|}{ Windows } & & \\
\hline & & \multicolumn{2}{|c|}{ Loft floors (with boots) } & & \\
\hline
\end{tabular}

\section{Conclusion and Recommendations}

The thing is...

You see what you want to see, And you hear what you want to hear.

- Harry Nilsson, The Point

For some, the study of sound is closely linked to media studies, and the contemporary uses and abuses of sonic power are tiresomely self-evident. I will only mention one example in order to place this thesis in a time frame as well as to illustrate the fundamental premise underlying most commercial uses of sound, namely: People don't listen.

$332 \mathrm{http}: / /$ home.earthlink.net/ dnitzer/4HaasEaton/Decibel.html

$333 \mathrm{http} / / /$ www.engineeringtoolbox.com/sound-power-level-d_58.html

$334 \mathrm{http}: / /$ www.engineeringtoolbox.com/sound-power-level-d_58.html

$335 \mathrm{http} / / / \mathrm{www}$.engineeringtoolbox.com/sound-power-level-d_58.html 
A bizarre advertising trend on television has swept the land, where pharmaceutical companies advertise their products with images of beautiful sunsets, dancing couples, soft, soothing music, puppies and flowers and pies and kite-flying; but overlaid on top of these images and muzak are announced the adverse side effects, spoken in a stern and serious voice, words and phrases such as "Death may result from the use of this product," or "Blindness, permanent disfigurement, and loss of use of fingers and toes may occur," etc. The incongruity of images of happy people living free and joyful lives juxtaposed with the terrifying words of possible death or disability is disturbing and at times comical. The success of these advertisements points to a society that relies heavily upon ocularcentric cues and values. Blesser and Ruth-Salter have noted that "sensory practice changes the brain" ${ }^{336}$ and although I cannot say what exactly has changed in my brain over the course of the last several months that I have spent researching and writing this thesis, I can definitely attest to a heightened awareness to sound, sometimes much to my dismay. A stated goal of this project is to work towards a demystification of sound, but a knowledge and understanding of sound's material and enduring nature can do little to remove its inherent qualities of surprise and shock.

Archaeoacousticians such as Reznikoff, Devereux and others who concern themselves with the material remains of sound-producing spaces and tools work with an underlying assumption (and rightfully so) that the sound of a reconstructed neolithic bone flute played today is very similar to the sound that it produced when it

336 Barry Blesser and Linda Ruth-Salter, Spaces Speak, Are You Listening? Experiencing Aural Architecure., 45. 
was made and played. In this thesis I have tried to address the goals of acoustic archaeology by accepting the enduring nature of sound as a given (We say: "I've heard that before" for a reason!) and moving forward to establish sound as artifact in and of itself. While an attempt to place an analytical distance between sound-forms and their host artifacts is difficult and challenging, it is not the first time this has been posited, as mentioned in an earlier discussion of the work of Pierre Schaeffer.

Archaeologists are privileged with an intellectual stance of taking the material world seriously, and this includes sound. In his article "Vision, Media, Noise and the Percolation of Time," archaeologist Christopher L. Witmore states the matter quite succinctly: "We hear the past." I am in full agreement with this, and also with his observation that "sound is not solely temporal so long as the things remain." ${ }^{337}$ In this thesis, I have tried to place sound, as sonifact, fully on par with things: conceptualized as host artifacts.

The ramifications of sound as artifact are manifold, but perhaps the most pressing need is the development of a new descriptive language of sound. Given the repeatability and predictability of sonifacts, there is no reason we cannot name them as easily as colors or shapes. I have deemed this to be a project outside the scope of this thesis, however I do feel that terminology relying upon the source of origin or onomotopeia is a step backwards. Sound-forms need to be described first for their qualities, as things in and of themselves; again, a difficult task since we are predisposed to attach meaning to them.

337 Christopher L. Witmore, "Vision, Media, Noise and the Percolation of Time," in Journal of Material Culture, Vol. 11(3): 276 
However, a less difficult task facing archaeologists is to simply take a sonic awareness into the field. Last summer I attended an archaeological field school at the Cliff Mine site in Clifton, Michigan. Early in the term we read an autobiography of a young nineteenth-century schoolteacher, Henry Hobart, and many of his observations helped to bring the history of the site alive. One of the excavation sites was a stamp mill at the base of an almost sheer cliff of stone (hence the name). Because of the periodic motion of the stamp mill, we know that its sound was rhythmic, and because of the weight of the stamps and the mass of the anvils we know that it was percussive also. Located at the base of a hill comprised of a somewhat reflective surface such as stone, the sound of this stamp mill was probably heard all across the town which was situated directly opposite the creek. One can easily imagine Henry Hobart gaining inspiration from this rhythmic sound as he wrote down the words to the song "Ben Bolt" in his diary, as mentioned earlier. Hobart's selection of this poem is moving and prophetic, as it seems to describe the scenario now at the Cliff Mine site:

Oh don't you remember the wood, "Ben Bolt,"

Near the green sunny slope of the hill Where oft we have sung 'neath the wide spreading shade, And kept time with the click of the Mill The Mill has gone to decay, "Ben Bolt" And silence now reigns all around; See the old rustic porch with its roses so sweet, Lies scattered and fallen to the ground. Oh! don't you remember the school, "Ben Bolt," And the master so kind and true, And the little nook by the clear running brook Where we gathered the flowers as they grew. ${ }^{338}$

Questions and observations pertaining to sound can be easily included in field notes,

338 Hobart, Copper Country Journal, 90. 
and unexpected insights may emerge. As excavations proceed, it would serve archaeologists well to be cognizant that the lives of past peoples carried a significant sonic component. While archaeoacoustics currently exists as its own subdiscipline, all investigations and excavations could easily gain from taking sonic considerations into the field. For example, could a group of uncovered artifacts have a sound producing purpose? Two metal spoons perhaps? A carpenter's saw as a musical instrument? In handling this door hardware or this bottle am I recreating a sonifact that has not been heard in over a hundred years? As my voice echoes (or doesn't echo) in this space am I creating a hybrid sonifact through the interaction of my voice with the host artifact of the space itself? What is the overall sonic quality of the space? Do spatial partitions and orientations of structures have particular acoustic purposes/effects? What are the sounds we now are hearing over the course of a day? How does this compare with yesterday? While listening to the site, do we detect other species presence? How has the acoustic presence of our investigation changed or disturbed the sonifactual assemblage on site? I would argue for the inclusion of sound as a quality to be noted in field notes along with soil texture and color: the sounds of host artifacts as well as the overall sound environment of the excavation. All excavation sites, especially sites within standing structures, can be considered sonic middens, and from time to time a moment of silence can be observed to listen to the existing sonifactual assemblage on site. Archaeologists are privileged with the task of sensory dependent investigation: listening and hearing is one of the senses that we take into the field as we approach sites. All artifacts and ecofacts are 
sonically related, the question is what significance we attach to this.

Table 6. Field Notes: Daily Sonic Checklist

\begin{tabular}{|c|c|c|}
\hline Observer: & Date/Time: & Location: \\
\hline \multirow{3}{*}{$\begin{array}{l}\text { Describe the overall sonic } \\
\text { environment of the site. }\end{array}$} & Morning & \\
\hline & Afternoon & \\
\hline & Evening & \\
\hline \multicolumn{2}{|c|}{$\begin{array}{l}\text { Are there any acoustic phenomena on site that may have } \\
\text { endured over time? In other words, is there an existing } \\
\text { sonifactual assemblage that should be noted and preserved? If } \\
\text { so, please elaborate. (Does the site have unique properties of } \\
\text { echo or reverberation? }\end{array}$} & \\
\hline \multicolumn{2}{|c|}{$\begin{array}{l}\text { Does the space, structure under investigation have any } \\
\text { significance pertaining to historic sound? Include any historical } \\
\text { research regarding the sonic past. }\end{array}$} & \\
\hline \multicolumn{2}{|c|}{$\begin{array}{l}\text { Do any uncovered artifacts have possible acoustic or noise } \\
\text { making purposes? (i.e., Are there any host artifacts?) }\end{array}$} & \\
\hline \multicolumn{2}{|c|}{$\begin{array}{l}\text { Do structures or artifacts seem intended for the purpose of } \\
\text { reduction or escape from sound or noise? For instance, could } \\
\text { the site itself be considered a sonic refuge? }\end{array}$} & \\
\hline \multicolumn{2}{|c|}{$\begin{array}{l}\text { In excavation, have any possible sonifacts been created? (i.e. } \\
\text { uncovering a wood floor that hasn't vibrated with human } \\
\text { footsteps for over } 100 \text { years or so) }\end{array}$} & \\
\hline \multirow{3}{*}{$\begin{array}{l}\text { Dedicate five minutes per day, } \\
\text { the same time each day, to } \\
\text { listen and count the occurence } \\
\text { of the following sound-forms. } \\
\text { Ask all on site to remain silent } \\
\text { in order to remove the sounds } \\
\text { of the observers from the } \\
\text { sonifactual asssemblage } \\
\text { recorded. }\end{array}$} & $\begin{array}{l}\text { Geophony (wind, rain, } \\
\text { thunder, waves) }\end{array}$ & \\
\hline & Biophony (other life forms) & \\
\hline & $\begin{array}{l}\text { Anthrophony (all sounds } \\
\text { created by human activity) }\end{array}$ & \\
\hline
\end{tabular}

A predictable summary statement for many articles, essays and even books regarding historic sound is something along the lines of "More needs be done..." and 
as much as I was trying to avoid contributing my own voice to this chorus, I am afraid that I must write the same. It would have been ideal-- time, weather and health permitting-- to have spent more time studying the particular acoustic qualities of the blacksmith shop proper, to really delve into the particulars of the site and all of the various detailed aspects of the activities that were going on there. One of the main tenets that I have taken from my studies is that as an archaeologist, if one is contemplating doing any kind of intervention that would alter or affect the archaeological record, the first and foremost goal is to do no harm. The Quincy Mine blacksmith shop remains as I found it. As one may surmise, an archaeoacoustic investigation of the shop's past sound environment doubles the task: in order to arrive at a sonifact one must first re-create the host artifact. Perhaps this is a project for a $\mathrm{PhD}$ level investigation.

However, while internally auralizing a sonic environment may be difficult, there is no reason to conclude that an archaeoacoustic investigation must result in an actual sonic recreation any more than one would insist upon a visual representation. The compiled data of the Quincy Mine Blacksmith Shop and its environment speaks for itself, with an accomodating and willing listener. The site incorporated a layered and complex sonic assemblage, a few whispers of which still exist on site. While a more resonant structure filled with a greater number of host-artifacts on site may have proven to provide greater data, I stayed with the Quincy Mine Blacksmith Shop as a subject because its existence resonates with certain themes pertaining to industrial sound and music, and as work progressed, historical research continued to reveal 
interesting stories about its past.

The practical application of an archaeoacoustic investigation such as this one upon the future of a structure could be of great interest to the field of heritage studies. For example, since we have determined that the dirt floor of the blacksmith shop was acoustically advantageous for the blacksmiths working there, it would never be advisable to install a wood floor or pour a concrete floor in the space. It is hoped that in adaptive reuse efforts, sonic integrity becomes a value to be cherished, rather than dismissed.

While attempts have been made to incorporate sound into museum exhibits, the results are frequently unsatisfactory. Because of sound's intrusive quality, a listener needs to be guided through a sonic tour gently, in ways that do not create alarm. A musical and listening tradition that has been passed down from Pythagoras to the present day is the discipline of 'acousmatic' listening, where listeners or audience members gather in a darkened room, and the source of sound (Pythagoras as teacher in antiquity, or musicians in the present day) is concealed behind a screen or otherwise obscured in order to allow the listeners to focus on the words or sounds themselves. The discipline of acousmatic listening has great promise for the development and appreciation of sonic heritage. Ideally, this would lead to the creation of a physical Museum of Sound, where listeners would sit in a dark room and be able to focus upon the individual sound-forms as they emerge and recede, with an interpretive narrative to introduce and explain each sound.

Industrial sound elicited immediate responses from those exposed to it, and as 
demonstrated by the work of Luigi Russolo and Dziga Vertov, there was no delay in acknowledging that a profound change was occuring in the anthrophonic sonic environment, in both intensity and diversity. The Quincy Mining Company blacksmith shop and its nearby environment is a microcosm of a sonic shift that was taking place all across the industrializing world. The 'sonic significance' of this blacksmith shop is not due to any superlative quality regarding the particular sounds it produced or contained, but rather from its existence as a representative example of a sonic change that occured rather quickly across the landscape. In the spring of 2012, I brought a group of students from a sound design class to the site, and we brainstormed over ways in which the sounds produced within the shop could be recreated, or brought back to life. Once the class was over in the spring, this project ceased, but there was a discussion about the possibility of different computer auralization programs available. In an interesting article about this process, Murphy and Brereton demonstrate that it is possible to auralize spaces that are only partially standing, by generating a computer model of the space and then introducing virtual sounds into the virtual space. In particular, the authors discuss an attempt to piece together the sounds within St. Michael's Cathedral in Coventry: "what the building would have sounded like at the height of its importance around 1500," even though "only the original walls and spire" remain. The authors concede that it is very difficult to ascertain the accuracy of the results of this effort. ${ }^{339}$

339 Damian Murphy and Jude Brereton, "Virtual Acoustics for Heritage Spaces." Institute for the Public Understanding of the Past. http://www.york.ac.uk/ipup/projects/york/stories/papers/murphy.html. Accessed on March 21, 2012. 
The silence that now fills abandoned industrial spaces is instructive in its own right, and introducing "piped-in" sounds into the blacksmith shop would probably be ineffective, but the use of personal listening devices, an "audio tour" of the space as it may have sounded in the past might serve to enhance the contrast between the past and present soundscapes. Presenting sound as a primary heritage value may assist in its attaining the status of a primary mode of perception, but the former will never be fully achieved without the latter. A 'schizophonic' situation could arise when one is forced to move back and forth between environmental sound digital recordings, since authority is almost always granted to electronic capture over airborne sound. Even so, if executed with care, a narrated and guided sonic tour of the blacksmith shop could have magical results, and the listener would be able to momentarily perceive a nuanced yet dramatic sonic change, but only if the volume is kept low. Many of the operations within the shop produced sounds close to the pain threshold, and if the goal is accurate representation, it would be inaccurate to present these sounds with reduced volume, and this may lead to a romanticization.

In the hours of poring over medical records from the Quincy Mine, it was the absence of accounts or discussion regarding hearing loss that was the most striking, and yet we all know from first hand experience that industrial workers attain significant hearing loss. Although becoming less frequent as manufacturing jobs disappear, my experience as a young boy was filled with older men and women who spoke far too loudly, in order to hear themselves. Any interpretive strategy that attempts to discuss industrial sound without addressing hearing loss is problematic. 
Industrial sound is a complex phenomenon. For some, it has musicality- for others, it is a source of torment. For some it is a source of reassurement and calm, for others it is a reason to leave the city and seek another home. For some, it is a projection of power, for others a projection of futility or a reminder of powerlessness. For some it is communication, connection and belonging, to others it is just "noise."

As is the case with most museum exhibitions, the allowance for artistic expression may well serve a project of sonic heritage interpretation. We have ruled out the possibility of "accuracy," since it would simply deafen the listeners, but perhaps the significance of the 'event' of industrial sound can be conveyed in other ways. As mentioned before, I would envision a Museum of Sound as a haven for acousmatic listening, where visual images are presented on a screen gradually but only as faded remnants of the past, and the sonifacts that correspond with the host-artifacts represented are also introduced in a gentle way that does not interrupt contemplation or reflection. If such a museum were to be specifically constructed for the blacksmith shop, it should be a separate structure, where visitors could move from the shop itself into a space dedicated for the presentation of a reconstructed sonifactual assemblage. The previous section "Narrative: A Plausible Subjective Experience of Historic Sound" could serve as a blueprint, or "script" for such an effort.

In general, the soundscape of the close environment of the Quincy Mine blacksmith shop was polyrhythmic, formed of repetitive impact sound of metal on metal, some resonant and "ringing," others muted and sharp, and this also holds true for the percussive sounds of the wider environment, the repetitive ringing of bells, pounding 
of pilings, explosions of dynamite, gunshots, wood-chopping, the stamping and crushing of ore, etc... This stands in stark contrast to what one might hear at any given moment standing next to the blacksmith shop in 2013.

One final observation. The implications of affording sound status as artifact are provocative for many reasons. Not the least of which is that it suggests a fusion of the disciplines of archaeoacoustics with both linguistics and musicology.

\section{Dedication}

My contemplation of sound had its origins in several calm, quiet conversations that took place during the summer of 2009 in the dark living room of a friend and sound artist, Maryanne Amacher, who lived in Kingston, NY, while I was also living and working there. Maryanne was allowing the forces of nature to reclaim her house as she continued to live in it, and my task as a carpenter was to improve the facade for aesthetic purposes, but she specifically told me not to fix the leaks. These leaks were significant, and during a heavy rainfall the water would pour into certain areas of the house like a river. While many might consider this behavior as "crazy," I have too much respect for her as an artist and scientist to be so dismissive. I think she was creating a sonic environment that pleased, and as a researcher of sound, I think she was working on something. The first paper I prepared for a conference was entitled "The Acoustics of Abandonment and Reintegration," ${ }^{340}$ and I think this title originates from this experience. Before she died, Maryanne handed me a book, The

340 Jeffrey L. Benjamin, "The Acoustics of Abandonment and Reintegration," (Paper presented at The Heritage of Mines and Mining. University of Innsbruck, Austria. April 16, 2011). 
Last and First Men, by Olaf Stapledon. It was our intention to read and discuss this

book, but we never had the chance:

Their lives were brief, their love of music intense. It seemed to them a tragic flaw in the nature of existence that the melody of the individual life must either fade into dreary senility or be cut short, never to be repeated. Now music had a special significance for this race. So intense was their experience of it, that they were ready to regard it as in some manner the underlying reality of all things. In leisure hours, snatched from a toilful and often tragic life, groups of peasants would seek to conjure about them by song or pipe or viol a universe more beautiful, more real, than that of daily labour. Concentrating their sensitive hearing upon the inexhaustible diversity of tone and rhythm, they would seem to themselves to be possessed by the living presence of music, and to be transported thereby into a lovelier world. No wonder they believed that every melody was a spirit, leading a life of its own within the universe of music. No wonder they imagined that a symphony or chorus was itself a single spirit inhering in all its members. No wonder it seemed to them that when men and women listened to great music, the barriers of their individuality were broken down, so that they became one soul.... ${ }^{341}$

341 Olaf Stapledon, Last and First Men (New York: Dover, 1968), 148. 


\section{References}

Adolphson, Rudolph. Medical record. Quincy Copper Mining Company Collection, Box 002, File 552. MTU Archives and CCHC, MTU, Michigan.

Alexander, Eleanor A. East Hancock Revisited. History of a Neighborhood, Circa 1880-1920. Hancock, MI: Self Published. 1984.

Alfrey, Judith and Tim Putnam. The Industrial Heritage: Managing Resources and Uses. London: Routledge. 1992.

American Bell and Foundry Company: Manufacturers of Church, Chapel, School, Court House, Fire Alarm and Farm Bells. Company catalogue. Northville, Michigan. 1903.

Associated Press, (Jan. 15, 1915). "Holiday Cheer in the Trenches: German and British Soldiers Participate in Christmas Festivities." Evening Copper Journal. Page 1., Microfilm Collection, MTU Archives and Copper Country Historical Collections, Michigan Technological University, Michigan.

Augoyard, Jean-Francois and Henry Torgue, eds. Sonic Experience: A Guide to Everyday Sounds (Montreal: McGill-Queen's University Press, 2005).

Bakeless, John. The Eyes of Discovery: The Pageant of North America as Seen by the First Explorers. New York: Dover, 1961.

Benjamin, Jeffrey L. "The Acoustics of Abandonment and Reintegration." Paper presented at The Heritage of Mines and Mining. Innsbruck, Austria, April 16, 2011.

Benjamin, Jeffrey L. "Lessons from the Kinetic Past: Repetition and Trance in Industrial Social Formation. " Paper presented at The Cultural Memory of Sound and Space: The $17^{\text {th }}$ Finnish Music Researchers' Symposium. Turku, Finland, March 13-15, 2013.

Benjamin, Jeffrey L. "Listening to Industrial Silence: Sound as Artifact." Paper presented at XII Nordic Tag, the meeting of Nordic Theoretical Archaeology Group, University of Oulu; Oulu, Finland, April 25-28, 2012.

Bijsterveld, Karin. "The Diabolical Symphony of the Mechanical Age: Technology and Symbolism of Sound in European and North American Noise Abatement Campaigns, 1900-40." Social Studies of Science 31:1 (2001): 37-70.

Birch, John Henry and John Hays Birch, "Suspended Drill Press," Patent No. 857,020. June 18,1907, United States Patent Office. 
Birdsall, Carolyn. "Earwitnessing: sound Memories of the Nazi Period," in Sound Souvenirs: Audio Technologies, Memory and Cultural Practices, edited by Karin Bijsterveld and Jose van Dijck, 169-181. Amsterdam: Amsterdam University Press, 2009.

Bonner, Mary Graham. (May 20, 1916)."Robins' Spring Concert," in "Daddy's Evening Fairy Tale." Evening Copper Journal, Page 6. Microfilm Collection, MTU Archives and CCHC, MTU, Michigan.

Blesser, Barry and Linda-Ruth Salter. Spaces Speak, Are You Listening? Experiencing Aural Architecture. Cambridge: MIT Press, 2007.

Bradley, Betsy Hunter. The Works: The Industrial Architecture of the United States. New York: Oxford University Press, 1999.

Bradley, Betsy Hunter. The Works: The Industrial Architecture of the United States. New York: Oxford University Press, 1999.

Brooks, Herbert. "A November Outing in the Forests of Clover-Land," in CloverLand, December, 1916, p. 13. Microfilm Collection, MTU Archives and Copper Country Historical Collections, Michigan Technological University, Michigan.

Buckley, Ann. "Organized Sound and Tonal Art in Long Term Perspective." In Hearing the Past: Essays in Historical Ethnomusicology and the Archaeology of Sound, edited by Ann Buckley. Liege: Etudes et Recherches Archeologiques de l'Universite de Liege, 1998.

Burdict, Orrin C.. "Bolt Forging Machine." Patent No. 285,876. October 2, 1883. United States Patent Office.

Cage, John. Silence. Middletown, CT: Wesleyan University Press, 1961.

Church, Bill. "Stories of the Northwoods (Win Awenen Nisitotung)." The Daily Mining Gazette. CCVF: Native Americans. MTU Archives and CCHC.

Coates, Peter A. "The Strange Stillness of the Past: Toward an Environmental History of Sound and Noise." Environmental History 10: 4 (2005): 636-665.

Coleman, Satis N. Bells: Their History, Legends, Making and Uses. Chicago: Rand McNally and Co., 1928.

Corbin, Alain. Village Bells: Sound and Meaning in the 19 $9^{\text {th }}$-Century French Countryside. New York: Columbia University Press, 1998. 
Corbin, Alain. "Identity, Bells, and the Nineteenth-Century French Village," in Hearing History, A Reader, edited by Mark M. Smith, 184-204. Athens: University of Georgia Press, 2004.

Cran, James. Machine Blacksmithing. New York: The Industrial Press, 1910.

Davis, Bob. "Reducing Noise from Forges and Foundries: The Handbook of the Black Country Forging and Foundry Project." Southhampton: ISVR University of Southhampton, 2002.

Day, R.J. "Mine Blacksmith Shops," in Engineering and Mining Journal, October 15, 1921: 609-613.

"Deafness Cannot Be Cured," Advertisement (December 5, 1914), Daily Mining Gazette, Page 8. Microfilm Collection, MTU Archives and CCHC, MTU, Michigan.

Deetz, James. Invitation to Archaeology. Garden City, New York: The Natural History Press, 1967.

Devereux, Paul. Stone Age Soundtracks: The Acoustic Archaeology of Ancient Sites. London: Vega, 2001.

Dodge, Don. Transcription of recorded interview with Jo Urion, Historian. Calumet: Keweenaw National Historic Park, February 24, 2005.

Ebert, Wolfgang. Kathedralen der Arbeit (Cathedrals of Work). Translated by Ingrid Taylor. Berlin: Ernst Wasmuth Verlag, 1996.

Edensor, Tim. Industrial Ruins: Spaces, Aesthetics and Materiality. Oxford: Berg, 2005.

Fichtel, C.L.. "Calumet and Hecla Drill-Sharpening Device." The Engineering and Mining Journal. 87 (22), May 29, 1909. 1073-1075.

Fitch, James Marston. American Building 2: The Environmental Forces That Shape It. New York: Schocken Books, 1972.

Fitzjohn, Matthew. "The Use of GIS in Landscape Heritage and Attitudes to Place." I n Heritage Studies: Methods and Approaches, edited by Marie Louise Stig Sorensen and John Carmen. London: Routledge, 2009: 237-252.

Forster, Hon. John Harris, Early Settlement of the Copper Regions of Lake Superior," in Pioneer Collections. Report of the Pioneer Society of the State of Michigan. Together with Reports of County, Town, and District Pioneer. 
Societies.Vol. VII. Lansing: Thorp and Godfrey, State Printers and Binders, 1886. 189-190. Accessed October 1, 2012. http://books.google.com/

Fowler, Chris. The Archaeology of Personhood: An Anthropological Approach. London: Routledge, 2004.

Frimodig, Mac. The Copper Harbor Stare. The Fort Wilkins Natural History Association and Michigan Department of Natural Resources. No date.

Friz, Anna. "Vacant City Radio." In In the Place of Sound: Architecture/Music/Acoustics, edited by Colin Ripley, Marco Polo and Arthur Wrigglesworth. Newcastle, UK: Cambridge Scholars Publishing, 2007.

Froberg, Hazel ed. Trestles and Tracks: A Study of Keweenaw Bay and Arnheim. L'Anse, Michigan: Keweenaw Bay and Arnheim Extension Study Group, 1983.

Fulkerson, Mrs. Clarke, "1916 Diary: Notes by Mrs. Clarke Fulkerson," in Chris Chabot ed., Tales of White Pine: An Illustrated Oral History of White Pine, Michigan and Environs (Ontonogan, Michigan: Ontonogan Herald Company, 1979.

Fuller, R. Buckminster. Untitled Epic Poem on the History of Industrialization. New York: Simon and Schuster, 1962.

Garrett, Bradley L. "Assaying history: creating temporal junctions through urban exploration." Environment and Planning D: Society and Space 29 (2011): 10481067.

Given, Michael. The Archaeology of the Colonized. London: Routledge. 2004.

Gillespie, Charles C., ed. A Diderot Pictorial Encyclopedia of Trades and Industry. New York: Dover Publications Inc., 1959.

Gillette, Halbert Powers. Handbook of Rock Excavation: Methods and Cost. New York: Clark Book Company, 1916.

Gilman, George H. "Ideal Shop for Sharpening Drill Steel," Engineering and Mining Journal. October6, 1917. 585-593.

Given, Michael. The Archaeology of the Colonized. London: Routledge 2004.

Goodman, Leslee. "Quiet, Please: Gordon Hempton On the Search for Silence in a Noisy World." The Sun. September 2010, Issue 417.

Gordon, Robert B. and Patrick M. Malone, The Texture of Industry: An 
Archaeological View of the Industrialization of North America. New York: Oxford University Press, 1994.

Graff, George P. The People of Michigan. Second Edition, revised. Bicentennial Publication. Lansing: Michigan Department of Education. State Library Services, 1974.

Grueneisen, Peter. Soundspace: Architecture for Sound and Vision. Basel: Birkhauser, 2003.

Hester, Thomas R. et al., Field Methods in Archaeology: Seventh Edition. Mountain View, California: Mayfield Publishing Company, 1997.

Hobart, Henry. Copper Country Journal: The Diary of Schoolmaster Henry Hobart, 1863-1864, edited by Philip P. Mason. Detroit: Wayne State University Press, 1991.

Homo-Lechner, Catherine. "False. Authentic. False Authenticity. Contributions and Failures of Experimental Archaeology as Applied to Music Instruments," in Hearing the Past: Essays in Historical Ethnomusicology and the Archaeology of Sound, edited by Ann Buckley, 29-63. Liege: Etudes et Recherches Archeologiques de l'Universite de Liege, 1998.

Historic American Engineering Record. A Look at the Architecture and Communities of the Quincy Mining Company. Hancock, MI: Quincy Mine Hoist Association, no date.

"History of Methodism in the Upper Peninsula of Michigan," (Published by The Historical Society of The Detroit Annual Conference, 1955) 55. CCVF: Churches. MTU Archives and CCHC.

Hyde, Charles K. Copper for America: The United States Copper Industry from Colonial Times to the 1990's. Phoenix: The University of Arizona Press, 1998.

Jamison, James K. This Ontonogan Country: The Story of an American Frontier. Ontonogan, MI: Ontonogan Herald Company, 1939.

Kahn, Douglas. "Ether Ore: Mining Vibrations in American Modernist Music." In Hearing Cultures: Essays on Sound, Listening and Modernity, edited by Veit Erlmann, 107-130. New York: Berg, 2005.

Kekke, Bertha Ruutila. "Recollection of Early School Days," in Pioneers of Green: A Collection of Contributed Historical Data. Ontonogan: Ontonogan Herald Co., 1976. 
Keweenaw County Historical Society. Central Mine: On the 100 Year Anniversayr of the Closing of the Central Mine. 1898-1998. Keweenaw County Historical Society, 1998.

Keweenaw National Historical Park, "Quincy Cultural Landscape Report," accessed May 15, 2012, http://www.nps.gov/kewe/parkmgmt/quincy-clr.htm.

Kettner, Magnus. (July 6, 1916). "The West Is Calling." Evening Copper Journal. Page 1. Microfilm Collection, MTU Archives and Copper Country Historical Collections, Michigan Technological University, Michigan.

Krause, Bernie L., PhD. "The Niche Hypothesis: How Animals Taught Us to Dance and Sing." a c cessed May 5, 2012 at http://users.auth.gr/paki/files/soundscape/referances/niche.pdf

Lanier, Gabriel M. and Bernard L. Herman, Everyday Architecture of the MidAtlantic. Baltimore: Johns Hopkins University Press, 1997.

Lankton, Larry. Hollowed Ground: Copper Mining and Community Building on Lake Superior, 1840's-1990's. Detroit: Wayne State University Press, 2010.

Lankton, Larry D. and Charles K. Hyde. Old Reliable: An Illustrated History of the Quincy Mining Company. Hancock, MI: The Quincy Mine Hoist Association, Inc., 1998.

Lucretius. The Nature of the Universe. Translated by R.E. Latham. Baltimore: Penguin Classics. 1960.

Lund, Casja S. "What is Wrong with Music Archaeology? A Critical Essay from a Scandinavian Perspective Including a Report About a New Find of a Bullroarer." In Hearing the Past: Essays in Historical Ethnomusicology and the Archaeology of Sound. Edited by Ann Buckley. Liege: Etudes et Recherches Archeologiques de l'Universite de Liege, 1998.

The M. Van Orden Company, (April 21, 1916). Advertisement. The Calumet News, Page 4. Microfilm Collection, MTU Archives and Copper Country Historical Collections, Michigan Technological University, Michigan.

Maki, Wilbert B. Hancock: A Mosaic of Memories. Calumet, Michigan: Greenlee Printing Company, 1984.

Maki, Swante. Medical record. Quincy Copper Mining Company Collection., Box 001, File 300. MTU Archives and CCHC, MTU, Michigan. 
Mason, Thomas F. Letter to Captain Harris. July 31, 1895. Quincy Copper Mining Company Collection., Box 366, Folder 008. MTU Archives and CCHC, MTU, Michigan.

Melioli, Matteo. "Inhabiting Soundscape: Architecture of the Unseen World." In In the Place of sound: Architecture/Music/Acoustics, edited by Colin Ripley, Marco Polo and Arthur Wrigglesworth, 44-75. Newcastle, UK: Cambridge Scholars Publishing, 2007.

Merleau-Ponty, Maurice. Phenomenology of Perception. Translated by Colin Smith. London: Routledge, 2008.

Mills, Steve. Applying Auditory Archaeology to Historic Landscape Characterization: A pilot project in the former mining landscape of Geevor and Levant Mines, West Penwith, Cornwall. Cardiff: Cardiff School of History and Archaeology, 2005.

Monette, Clarence J. Hancock, Michigan Remembered. Lake Linden, Michigan: Self-published, 1982.

Monette, Clarence J. Early South Range, Volume One. Lake Linden, Michigan: Selfpublished, 1995.

Monette, Clarence J. Early Red Jacket and Calumet in Pictures. Lake Linden, Michigan: Self published, 1988.

Monette, Clarence J. Laurium, Michigan's Early Days. Laurium, Michigan: Selfpublished, 1986.

Monette, Clarence J. Trimountain and Its Copper Mines. Lake Linden: Self published, 1991.

Mumford, Lewis. Technics and Civilization. New York: Harcourt, Brace and Company, 1934.

Muntersbjorn, Madeleine. E-mail message to author. February 20, 2011.

Murdoch, Angus. Boom Copper: The Story of the First U.S. Mining Boom. Calumet: Roy W. Drier and Louis G. Koepel, 1964.

Murphy, Damien and Jude Brereton. "Virtual Acoustics for Heritage Spaces." Institute for the Public Understanding of the Past. http://www.york.ac.uk/ipup/projects/york/stories/papers/murphy.html. Accessed on March 21, 2012. 
The New York Times (no author), "Chile Mining Accident (2010)," The New York Times, October 12, 2012. Accessed January 4, 2012 , http://topics.nytimes.com/top/reference/timestopics/subjects/c/chile_mining_acciden t 2010/index.html?s $=$ oldest\&

Nicholls, John A. "Combined Punching and Shearing Machine." Patent No. 613,072. October 25, 1898. United States Patent Office.

Niles Bement Pond Company, Machine Tools 1920. Philadelphia: Niles Bement Pond Company, 1920.

No author (July 5, 1916). "Fourth Was a Very Quiet One in Hancock." Evening Copper Journal. Microfilm Collection, MTU Archives and Copper Country Historical Collections, Michigan Technological University, Michigan. (note 181).

No author (July 1, 1916). "Doing Away with Noise." Evening Copper Journal, Page 3. Microfilm Collection, MTU Archives and Copper Country Historical Collections, Michigan Technological University, Michigan. (note 182).

No author, Editorial Statement, Clover-Land Magazine, Menominee, Michigan. April, 1916, p. 16. Vol.1, No.3. Reel \# ( ). Microfilm Collection, MTU Archives and Copper Country Historical Collections, Michigan Technological University, Michigan. (note 184).

No author (April 24, 1916). "Makes Complaint for Street Car Disturbance." Evening Copper Journal. Page 11. Microfilm Collection, MTU Archives and Copper Country Historical Collections, Michigan Technological University, Michigan. (note 210).

No author (Dec. 6, 1914). "Army Sings Hymns on March." Daily Mining Gazette. Page 5. Microfilm Collection, MTU Archives and Copper Country Historical Collections, Michigan Technological University, Michigan. (note 214).

No author (July 13, 1916). "Cannonade at Ypres Heard in London." Evening Copper Journal. Page 1. Microfilm Collection, MTU Archives and Copper Country Historical Collections, Michigan Technological University, Michigan. (note 216).

No author (July 11, 1916). "Roar of Guns Heard 340 Miles." Evening Copper Journal, Page 1. Microfilm Collection, MTU Archives and Copper Country Historical Collections, Michigan Technological University, Michigan. (note 217).

No author (December 2, 1914). "Carol Singers Will Organize Choruses." Daily Mining Gazette, Page 7. Microfilm Collection, MTU Archives and CCHC, MTU, Michigan. (note 219). 
No author (July 16, 1916). "Portage Lake Assured a Rare Musical Treat." Sunday Mining Gazette, Page 8. Microfilm Collection, MTU Archives and CCHC, MTU, Michigan. (note 222).

No author (December 19, 1914). "Children and Elders Join in Christmas Song." Daily Mining Gazette, Page 10. Microfilm Collection, MTU Archives and CCHC, MTU, Michigan. (note 224).

No author (April 24, 1916). Advertisement. Evening Copper Journal, Page 1. Microfilm Collection, MTU Archives and CCHC, MTU, Michigan.

Ontonogan Herald Company. Pioneers of Green: A Collection of Contributed Historical Data. Ontonogan: Ontonogan Herald Company, 1976. (note 228).

No author, "The Calumet Earthquake of 1905," Copper Country Vertical File: Earthquakes. MTU Archives and Copper Country Historical Collections, Michigan Technological University, Michigan. (note 231).

No author, (May 16, 1916), "Air Blast Shocks Calumet District." Evening Copper Journal, Page 5. Microfilm Collection, MTU Archives and CCHC, MTU, Michigan. (note 232).

No author, (December 5, 1914). "Use of Dynamite Gets Highway Man to Court." Daily Mining Gazette, Page 6. Microfilm Collection, MTU Archives and CCHC, MTU, Michigan. (note 237).

No author, "Pewabic Church Anniversary," Page 3. Daily Mining Gazette, Microfilm Collection, MTU Archives and CCHC, MTU, Michigan. (note 257).

Olson, Bjornar. In Defense of Things: Archaeology an the Ontology of Objects. Walnut Creek, CA: Altamira Press, 2010.

Ontonogan Herald Company. Pioneers of Green: A Collection of Contributed Historical Data. Ontonogan: Ontonogan Herald Company, 1976.

Oomen, Anne-Marie. Pulling Down the Barn: Memories of a Rural Childhood. Detroit: Wayne State University Press, 2004.

Palmer, Marilyn and Peter Neaverson. Industrial Archaeology: Principles and Practice. London: Routledge, 1998.

Pijanowski, Bryan C., Luis J. Villanueva-Rivera, Sarah L. Dumyahn, Almo Farina, Bernie L. Krause, Brian M. Napoletano, Stuart H. Gage, and Nadia Pieretti. 
"Soundscape Ecology: The Science of Sound in the Landscape." BioScience 613 (2011): 203-216.

Rath, Richard Cullen. "Hearing American History." The Journal of American History 2 (2008): 417-431.

Rath, Richard Cullen. How Early America Sounded. Ithaca: Cornell University Press, 2003.

Reznikoff, Iegor. "The Evidence of the Use of Sound Resonance from Palaeolithic to Medieval Times." In Archaeoacoustics. Edited by Scarre, Chris and Graeme Lawson. Cambridge: McDonald Institute for Archaeological Research, 2006. 77-84.

Reznikoff, Iegor. "On the sound related to painted caves and rocks." Paper presented at XII Nordic Tag, the meeting of Nordic Theoretical Archaeology Group, University of Oulu; Oulu, Finland, April 25-28, 2012.

Rickard, T.A. Rickard. The Copper Mines of Lake Superior (New York: Engineering and Mining Journal, 1905.

Rindel, Jens Holger. "Preserving the Acoustical Heritage of Historical Buildings." Abstract for a paper presented the European Congress on Acoustics, Budapest, Hungary, August 29-September 2, 2005.

Ripley, Colin. "Introduction: In the Place of sound." In In the Place of Sound: Architecture/Music/Acoustics. Newcastle UK: Cambridge Scholars Publishing, 2007.

Riedweg, Christopher. Pythagoras: His Life, Teaching, and Influence. Ithaca: Cornell University Press, 2005.

Russolo, Luigi. The Art of Noise: Futurist Manifesto, 1913. New York: Something Else Press, 1967.

Schafer, R. Murray. The Tuning of the World. Toronto: McClelland and Stewart, 1977.

Schaeffer, Pierre. In Search of a Concrete Music. Translated by Christine North and John Dack. Berkeley: University of California Press, 2012.

Smilor, Raymond Wesley. "Confronting the Industrial Environment: The Noise Problem in America,1893-1932." PhD diss., University of Texas at Austin, 1978.

Smith, Mark M., "The Garden in the Machine: Listening to Early American 
Industrialization." In The Oxford Handbook of Sound Studies, edited by Trevor Pinch and Karin Bijsterveld, 40-57. New York: Oxford University Press, 2012.

Snow, C.P.. The Two Cultures and the Scientific Revolution. New York: Cambridge University Press, 1961.

The Status of Sound: Writing Histories of Sonic Art, Graduate Center, City University of New York, Friday, November 30, 2012. Martin E. Segal Theater, 365 Fifth Avenue, NYC.

Sturgeon Valley Historical Society, Inc., Pioneering in Pelkie. Pelkie, Michigan: Sturgeon Valley Historical Society, 1985.

Sturtevant, B.F.. "Design for a Blower-Case." Design No. 3,399. March 2, 1869. United States Patent Office.

Sturtevant, B.F.. "Improvement in Pressure-Blowers." Patent No. 92,489. July 13, 1869. United States Patent Office.

Todd, William Rogers. Letter to Charles L. Lawton. Quincy Copper Mining Company Collection., Box 336, Folder 008. MTU Archives and CCHC, MTU, Michigan.

Thompson, Clive. "On How Man-Made Noise May Be Altering Earth's Ecology." Wired Magazine 16.06 (2008). Accessed January 23, 2012, http://www.wired.com/science/planetearth/magazine/16-06/st thompson

Thompson, Emily. The Soundscape of Modernity. Cambridge: MIT Press, 2002.

Thurner, Arthur W. Calumet Copper and People: History of a Michigan Mining Community. 1864-1970. Hancock, Michigan: Self published, 1974.

Thurner, Arthur W. Strangers and Sojourners: A History of Michigan's Keweenaw Peninsula. Detroit: Wayne State University Press, 1994.

Trigger, Bruce G. A History of Archaeological Thought. Cambridge: Cambridge University Press, 2009.

Trower, Shelley. Senses of Vibration: A History of the Pleasure and Pain of Sound. New York: Continuum International Publishing Group, 2012.

Truax, Barry. ed., The World Soundscape Project's Handbook for Acoustic Ecology. Vancouver: ARC Publications, 1978. 
Van Bueren, Thad M. and Kimberly Wooten. "Making the Most of Uncertainties at the Sanderson Farm." Historical Archaeology 43(2) (2009): 108-134.

Vitruvius. The Ten Books of Architecture. Translated by Morris Hicky Morgan. New York: Dover, 1960. 139.

Wagner, J. "Bolt Making and Forging Machine." Patent No. 666,167. January 15, 1901. United States Patent Office.

Waller, Steven J. "Intentionality of Rock-art Placement Deduced from Acoustical Measurements and Echo Myths," in Archaeoacoustics, ed. Chris Scarre and Graeme Lawson (Cambridge: McDonald Institute for Archaeological Research, 2006), 34.

Wellington, A.M. ed., Piles and Pile Driving: being a reprint of some of the articles which have appeared in Engineering News on pile driving and the safe load of piles and of the pamphlet on "Bearing piles" by Rudolph Hering. New York: Engineering News Publishing Co., 1893.

Westerkamp, Hildegard. "Linking Soundscape Composition and Acoustic Ecology." Organized Sound: An International Journal of Music and Technology: 7,1 (2002). Accessed September 30, 2011 , http://www.sfu.ca/ westerka/writings \%20page/articles\%20pages/linking.html

Westerkamp, Hildegard. "Soundwalking," Accessed September 30, 2011, http://www.sfu.ca/ westerka/writings\%20page/articles\%20pages/soundwalking.html First published in Sound Heritage, Volume 3, No. 4, Victoria B.C., 1974

Weston, Eustace. Rock Drills: Design, Construction, and Use. London: McGrawHill Book Company, 1910.

Wills, Hedley. Medical record. Quincy Copper Mining Company Collection, Box 351, Folder 017. MTU Archives and CCHC, MTU, Michigan.

Witmore, Christopher L. "Vision, Media, Noise and the Percolation of Time." Journal of Material Culture, 11(3) 2006: 267-292.

Word, William W. "Process of Forging Rock Drills." Patent No. 732,727. June 23, 1903. United States Patent Office.

1908 Annual Report. Quincy Mining Company Collection, Box 358, File 034. MTU Archives and Copper Country Historical Collections, Michigan Technological University, Michigan.

1915 Annual Report. Quincy Mining Company Collection, Box 358, File 034. MTU 
Archives and Copper Country Historical Collections, Michigan Technological University, Michigan. 


\title{
Appendix: Letters of Permission to Reproduce Images
}

The following letter is provided as documentation of permission to reproduce the following images: Fig. 6, page 126 (Image\#MS015-MI-2-74); Fig. 7, page 127 (Image\#MS015-MI-2-93); Fig. 8, page 128 (Image\#30F14A-QD2723); Fig. 9, page 129 (Image\#30F14A-QD2225); Fig. 10, page 130 (Image\#30F14A-QD2722); Fig. 10, page 131 (Image\#30F14A-QD2501).

\author{
MICHIGAN TECHNOLOGICAL UNIVERSITY ARCHIVES

$$
\text { AND }
$$

COPPER COUNTRY HISTORICAL COLLECTIONS

PHOTOGRAPHIC AGREEMENT

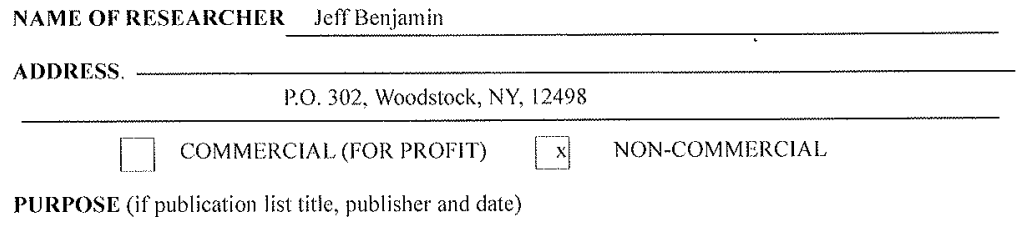

For inclusion in my thesis "Sound As Artifact." This thesis is part of my work towards a masters degree in Industrial Archacology.

1 hereby request permission to have the materials fisted below photographically reproduced. I agree to abide by the policies of the Michigan 'Technological University Archives and Copper Country Historical Collections and any additional restrictions pertaining to particular collections.

The Michigan Technological University Archives and Copper Country Historical Collections makes these photographic reproductions available for one time use only. If published, the credit line must read:

Michigan Technological University Archives and Copper Country Historical Collections - or --

Michigan Tech Archives

and should inciude any additional information crediting the donor or collection as detailed below.

All rights, including those of further duplication, are reserved in full by the MTU Archives and Copper Country Historical Collections. Photographic inages may only be digitally scanned or digitally enhanced with the express written permission of the Aretives. Digital copies must either be destroyed or returned to the Archives upon completion of the one-tine use described in dis agrement. The user assumes full responsibility for misuse of prints or violation of copyright.

No copies may be placed in other institutions. The master copies of these inages will remain with the MTU Archives and Copper Country Historical Collections. This institution reserves the right to request return of copies when the researcher is finished with them.

Signature of staff nember

Signature of researcher

DESCRIPTION OF MATERIAL (filled out by staff member)

Image \#: No Neg 2009-03-08-01

lmage\#:MS015-MI-2-74

Image \#:MS015-MI-2-93

Map \# 30F14A-QD2723

Map\# 30F14A-QD2225

Map\# 30F14A-QD2722

Map\# 30F14A-QD2501

DATE $12 J_{\text {aly } 2013}$ 
The following letter is provided as documentation for permission to reproduce the following image: Figure 4, page 118.

Memorandum

July 9, 2013

To: $\quad$ File

From: $\quad$ Archivist, Keweenaw NHP

Subject: Authorization to Publish photograph from the Koepel collection

This statement authorizes Jeff Benjamin of Michigan Technological University to publish an historic photo of the Quincy ME Church provided to him from the Koepel collection on May 4, 2012, with the understanding that all legal obligations regarding copyright, copyright status, fair use, and privacy still apply, and remain the responsibility of Jeff Benjamin. Granting permission to Jeff Benjamin to publish this image does not constitute an acceptance of any legal or other liability on the part of Keweenaw National Historical Park should the image provided to Jeff Benjamin be misused in any way. (Please refer to the Researcher Duplication, Registration, and Copyright and Privacy Restriction Forms on file.)

Signed: Date: 7.9 .13

Jeremiah Mason, Archivist, Keweenaw NHP

Signed: Date: $7-12-13$

Jeff Benjamin, Michigan Technological University 